\author{
UNIVERSIDADE DE SÃO PAULO \\ CENTRO DE ENERGIA NUCLEAR NA AGRICULTURA
}

PAULO ROGÉRIO MASSONI

\begin{abstract}
DETERMINAÇÃO DA CONCENTRAÇÃO DE ELEMENTOS QUÍMICOS POTENCIALMENTE TÓXICOS EM AEROSSÓIS PRESENTES NO INTERIOR DE UMA PEQUENA INDÚSTRIA DE FUNDIÇÃO DE METAIS, UTILIZANDO AMOSTRADOR TEMPORAL E A TÉCNICA DE FLUORESCÊNCIA DE RAIOS X
\end{abstract}




\section{DETERMINAÇÃO DA CONCENTRAÇÃO DE ELEMENTOS QUÍMICOS POTENCIALMENTE TÓXICOS EM AEROSSÓIS \\ PRESENTES NO INTERIOR DE UMA PEQUENA INDÚSTRIA DE FUNDIÇÃO DE METAIS, UTILIZANDO AMOSTRADOR TEMPORAL E A TÉCNICA DE FLUORESCÊNCIA DE RAIOS X}

Tese apesentada ao Centro de Energia Nuclear na Agricultura da Universidade de São Paulo para obtenção do título de Doutor em Ciências.

Área de concentração: Energia Nuclear na Agricultura e no Ambiente

Orientador: Prof. Dr. Virgilio Franco do Nascimento Filho 
AUTORIZO A DIVULGAÇÃO TOTAL OU PARCIAL DESTE TRABALHO, POR QUALQUER MEIO CONVENCIONAL OU ELETRÔNICO, PARA FINS DE ESTUDO E PESQUISA, DESDE QUE CITADA A FONTE.

Dados Internacionais de Catalogação na Publicação (CIP)

Seção Técnica de Biblioteca - CENAVUSP

Massoni, Paulo Rogério

Determinação da concentração de elementos químicos potencialmente tóxicos em aerossóis presentes no interior de uma pequena indústria de fundição de metais, utilizando amostrador temporal e a técnica de fluorescência de raios X / Paulo Rogério Massoni; orientador Virgílio Franco do Nascimento Filho. - - Piracicaba, 2009.

95 p.: fig.

Tese (Doutorado - Programa de Pós-Graduação em Ciências. Área de Concentração: Energia Nuclear na Agricultura e no Ambiente) - Centro de Energia Nuclear na Agricultura da Universidade de São Paulo. 
MASSONI, P. R. Determinação da concentração de elementos químicos potencialmente tóxicos em aerossóis presentes no interior de uma pequena indústria de fundição de metais, utilizando amostrador temporal e a técnica de fluorescência de raios X. 2009. 95 f. Tese (Doutorado) - Centro de Energia Nuclear na Agricultura, Universidade de São Paulo, São Paulo, 2009.

\section{ERRATA}

FOLHA 48, $2^{\circ}$ parágrafo:

Onde está escrito: "...tensão de $30 \mathrm{kV}$ e corrente $30 \mathrm{~mA}$. ."

Acrescentar: "...tensão de $30 \mathrm{kV}$ e corrente $30 \mathrm{~mA}$, durante 300 s por amostra."

FOLHA 51, legenda da figura 4.8 (gráfico dos espectros):

Incluir (a) e (b) para os gráficos da esquerda e da direita respectivamente e alterar a legenda: (a) grosso-MP $\mathbf{1 0 - 2 , 5}_{\text {e (b) fino-MP }}$ (2,5.

FOLHA 59, equação na figura 5.9:

Onde está: $S=0,0006288 Z^{3}-0,2249 Z^{2}+3,884$

Incluir: $+2,254 Z$, ficando $S=0,0006288 Z^{3}-0,2249 Z^{2}+2,254 Z+3,884$

FOLHA 60, equação na figura 5.11:

Trocar y por $\mathbf{S}$ e $\mathbf{x}$ por $\mathbf{Z}$, ficando:

$S=-0,00089 Z^{3}+0,19088 Z^{2}-6,24083 Z+56,29662$

Folha Linha

109

$15 \quad 16$

$17 \quad 10$

$35 \quad 6$

$59 \quad 9$

$79 \quad 10$

$81 \quad 8$

\section{Onde se lê}

...concentração material...

...serão coletadas...

Dos materiais...

...detector de raios $X$ apropriados...

...também são alterados...

...durante o prcesso...

...registros riscos...
Leia-se

...concentração de material...

...foram coletadas...

Nos materiais...

...detector de raios $\mathrm{X}$ apropriado...

...também foram alterados...

...durante o processo...

...registros de riscos... 
Dedico ao meu amado filho Gabriel Ramos Massoni 


\section{AGRADECIMENTOS}

Ao Prof. Dr. Virgílio Franco do Nascimento Filho, um ser humano exemplar, pela sua orientação indispensável para a elaboração e execução deste trabalho, pela sua dedicação, atenção e, em especial, pela amizade.

Ao amigo Eduardo de Almeida, técnico do Laboratório de Instrumentação Nuclear do CENA/USP, pela sua disposição e importante colaboração em várias etapas da execução deste trabalho.

Ao amigo Sérgio Luis de Jesus, responsável pelo Núcleo de Pesquisas em Geoquímica e Geofísica da Litosfera da ESALQ/USP, pela sua importante contribuição na realização da análise morfológica do particulado atmosférico estudado neste trabalho.

Ao Centro de Energia Nuclear na Agricultura por colocar à disposição os laboratórios, pelas facilidades de utilização do campus e pela oportunidade da realização do curso de pós-graduação em nível de Doutorado. 
"A mente que se abre a uma nova idéia jamais voltará ao seu tamanho original"

Albert Einstein 


\section{RESUMO}

MASSONI, P. R. Determinação da concentração de elementos químicos potencialmente tóxicos em aerossóis presentes no interior de uma pequena indústria de fundição de metais, utilizando amostrador temporal e a técnica de fluorescência de raios X. 2009. 95 f. Tese (Doutorado) - Centro de Energia Nuclear na Agricultura, Universidade de São Paulo, São Paulo, 2009.

Este trabalho foi desenvolvido objetivando a determinação e a avaliação dos perfis temporais da concentração de alguns elementos químicos potencialmente tóxicos presentes no material particulado em suspensão (MPS) no interior de uma pequena indústria de fundição de metais - bronze, ferro e alumínio - que, em concentrações elevadas, podem acarretar sérios riscos à saúde do trabalhador. Para isso foi utilizado um amostrador temporal de MPS, que coleta amostras de aerossóis em intervalo de tempo pré-programados, separando-os por tamanho: (a) fração fina ou respirável (partículas com diâmetro aerodinâmico menor que 2,5 $\mu \mathrm{m}, \mathrm{MP}_{2,5}$ ) e (b) fração grossa ou inalável (entre 2,5 a $10 \mu \mathrm{m}, \mathrm{MP}_{10-2,5}$ ), durante todo o período do processo de fundição (da fusão à moldagem). As amostras coletadas, na forma de faixas (strips) sobre um filtro (fração fina) e sobre um impactador (fração grossa), foram analisadas pela técnica de fluorescência de raios $X$ por dispersão de energia (EDXRF), utilizando na excitação um tubo de raios $X$ com alvo de $M o$ e e na detecção dos raios $X$ característicos um detector semicondutor de $\mathrm{Si}(\mathrm{Li})$ acoplado a um analisador de pulsos multicanal, interpretando-se posteriormente os espectros de raios $X$ obtidos pelo aplicativo AXIL. Para algumas amostras também foi feita uma análise com microscópio eletrônico de varredura (SEM/EDS) para se conhecer a morfologia dos particulados. Deste modo foi possível determinar a concentração de elementos químicos potencialmente tóxicos presentes em um ambiente de uma pequena indústria de fundição de metais, mostrando que o momento mais crítico dessa atividade foi o da moldagem e também determinar a forma do MPS. Na fundição do bronze e ferro, as concentrações dos elementos $\mathrm{Cr}$, Mn, $\mathrm{Ni}$ e $\mathrm{Pb}$, principalmente na fração fina no momento de moldagem, mostraram-se muito superior aos limites recomendados pelas agências brasileira e norte-americana. Apesar de não haver limites recomendados para o elemento $\mathrm{Zn}$, foi verificada uma alta concentração principalmente na concentração na fração fina, o mesmo sucedendo para o $\mathrm{Cu}$. Com respeito a fundição de alumínio, foi observado altas concentrações principalmente de $\mathrm{Zn}$ e $\mathrm{Cu}$, somente na fração fina, não ocorrendo na fração grossa. Pelos resultados obtidos pode-se concluir que os trabalhadores estão sujeitos a condições insalubres de trabalho nesse tipo de ambiente, aconselhando-se o uso permanente de equipamentos adequados de proteção visando de preferência a fração fina, assim como um monitoramento constante desses elementos químicos durante todas as etapas do processo de fundição, principalmente na de moldagem.

Palavras-chave: Fundição de Metais. Poluição ambiental. Material particulado em suspensão. Amostrador rotativo. Fluorescência de raios $X$ por dispersão de energia. EDXRF. Saúde do trabalhador. 


\begin{abstract}
MASSONI, P. R. Toxic inorganic elements content in suspended particulate matter inside a small foundry plant by streaker sampler and energy dispersive $X$ ray fluorescence technique. 2009. $95 \mathrm{f}$. Thesis (Doctoral) - Centro de Energia Nuclear na Agricultura, Universidade de São Paulo, São Paulo, 2009.
\end{abstract}

The aim of this work was to evaluate the chemical concentration of some potentially toxic inorganic chemical elements and the time profiles in fine $\left(\mathrm{PM}_{2.5}\right.$, particles up to 2.5 $\mu \mathrm{m})$ and coarse $\left(\mathrm{PM}_{2.5-10}\right.$, particles from 2.5 to $\left.10 \mu \mathrm{m}\right)$ suspended particulate matter (SPM) inside a small foundry plant - bronze, iron and aluminium -, in which at high concentrations turns a healthy concern. For these purpose, a rotating streaker airparticulate sampler for sampling during all day foundry activity was utilized. Fine SPM was collected on a filter and coarse SPM in turn by an impactor. The collected samples were analyzed by energy dispersive X-ray fluorescence (EDXRF) technique employing a Mo target tube in the excitation, and the detection was carried out through $\mathrm{Si}(\mathrm{Li})$ semiconductor detector coupled to multichannel analyser, deconvolutting the X-ray spectra with AXIL software help. It was also carried out particulated morphological analysis by scanning electron microscopy with energy dispersive X-ray spectrometer coupled (SEM/EDS). In this manner, the inorganic chemicals content were determined in the small foundry allowing concluding that the moulding step is the critical one taking into account the amount of pollutant released. During bronze and iron melting, the $\mathrm{Cr}$, $\mathrm{Mn}, \mathrm{Ni}$ and $\mathrm{Pb}$ contents in SPM were higher than allowed values by Brazilian and United States legislations. It was also verified a high $\mathrm{Zn}$ and $\mathrm{Cu}$ content, mainly in the fine suspended particulate matter, although these elements are not contemplated by national nor international laws. Thus, due to this unhealthy environmental working conditions inside the small foundry plant, a proper individual protection equipment is mandatory mainly for fine suspended particulate matter, and a constant air pollutant monitoring in foundry plants is demanded, mainly during the moulding step.

Keywords: Metals foundry. Environmental pollution. Suspended particulate matter. Streaker sampler. Energy dispersive X-ray fluorescence. EDXRF. Worker health. 


\section{SUMÁRIO}

$\begin{array}{lr}\text { 1- INTRODUÇÃO } & 10\end{array}$

$\begin{array}{ll}\text { 2- REVISÃO DA LITERATURA } & 17\end{array}$

2.1- Material particulado em suspensão atmosférica (MPS) 17

2.2- Inalação e respiração de material particulado e saúde 20

2.3- Legislação ambiental e material particulado na atmosfera 23

2.4- Amostradores: impactadores inerciais e filtros 26

2.5- Caracterização química 28

2.6- Aplicações da espectrometria de raios X para análise de MPS 29

3- FUNDAMENTAÇÃO TEÓRICA 35

3.1- Equação Fundamental $\quad 37$

3.2- Sensibilidade analítica elementar $\quad 39$

3.3- Limite de detecção $\quad 40$

4- MATERIAIS E MÉTODOS 42

4.1- Local de amostragem 42

4.2- Composição da matéria prima 43

4.3- Amostrador rotativo de particulado atmosférico 43

4.4- Excitação das amostras por meio de EDXRF com fenda $\begin{array}{ll}\text { colimadora } & 47\end{array}$

4.5- Interpretação dos espectros de raios X 51

4.6- Caracterização do sistema excitação-detecção 51

4.7- Microscopia eletrônica 52

5- RESULTADOS E DISCUSSÃO 53 
5.1.1- Particulado fino

5.1.2- Particulado grosso

5.2- Sensibilidade analítica elementar e limite de detecção

5.3- Amostras-padrão certificadas

5.4- Concentração dos elementos no MPS e momento crítico da fundição

5.5- Concentração dos elementos durante a fundição comparados aos níveis de concentração estabelecidos por agências ambientais

6- CONCLUSÕES 


\section{DETERMINAÇÃO DA CONCENTRAÇÃO DE ELEMENTOS \\ QUÍMICOS POTENCIALMENTE TÓXICOS EM AEROSSÓIS \\ PRESENTES NO INTERIOR DE UMA PEQUENA INDÚSTRIA DE \\ FUNDIÇÃO DE METAIS, UTILIZANDO AMOSTRADOR \\ TEMPORAL E A TÉCNICA DE FLUORESCÊNCIA DE RAIOS X}

\section{INTRODUÇÃO}

A crescente urbanização e industrialização têm originado em todo o mundo um aumento da emissão de partículas e substâncias poluentes na atmosfera, bem como sua deposição no solo, nos vegetais, obras de arte, etc. Esse aumento das concentrações de material particulado e de poluentes na atmosfera é responsável por danos à saúde, pela redução da produção agrícola, por danos em florestas e, de modo geral, origina desequilíbrios nos ecossistemas, principalmente naqueles localizados em áreas de intensa urbanização.

Mesmo em alguns países nos quais a concentração material particulado atmosférico, os quais podem conter metais pesados, vem reduzindo 
(GRIEKEN, 2008), no interior de pequenas indústrias de fundição encontramos problemas sérios de poluentes atmosféricos e de presença de material particulado contendo metais pesados.

Nas pequenas indústrias de fundição de metais, os trabalhadores permanecem a maior parte do tempo de sua jornada diária de trabalho, próximos aos locais de fusão da matéria prima (Figura 1.1) e da moldagem (Figura 1.2), sem a utilização de equipamentos adequados de proteção respiratória e sem fiscalização e monitoramento sobre a quantidade e

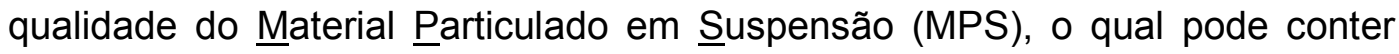
elementos químicos potencialmente tóxicos (WINBERRY JUNIOR et al., 1999).

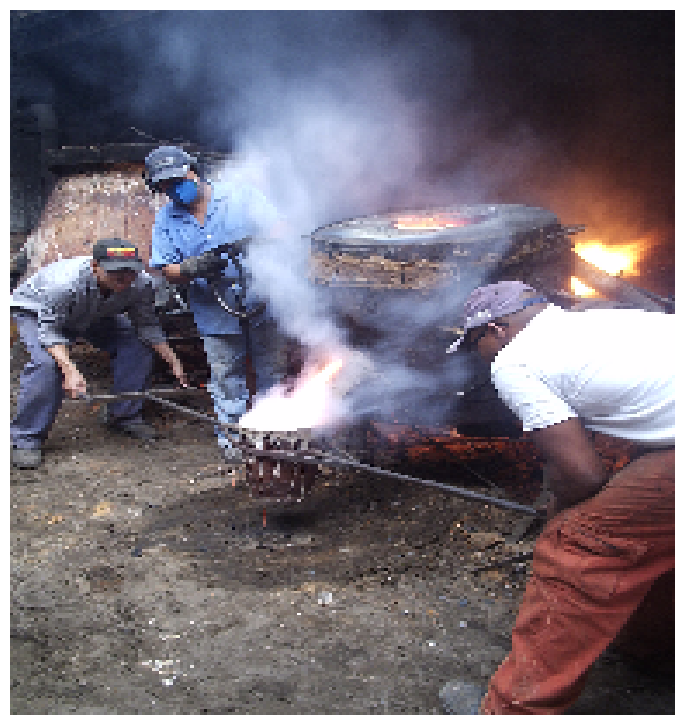

Figura 1.1: Trabalhadores em uma pequena indústria de fundição recolhendo do forno o material fundido (bronze) para a moldagem, onde a alta concentração de elementos provavelmente tóxicos é evidente, podendo-se visualizar dois deles sem protetores nasais e manuais. 


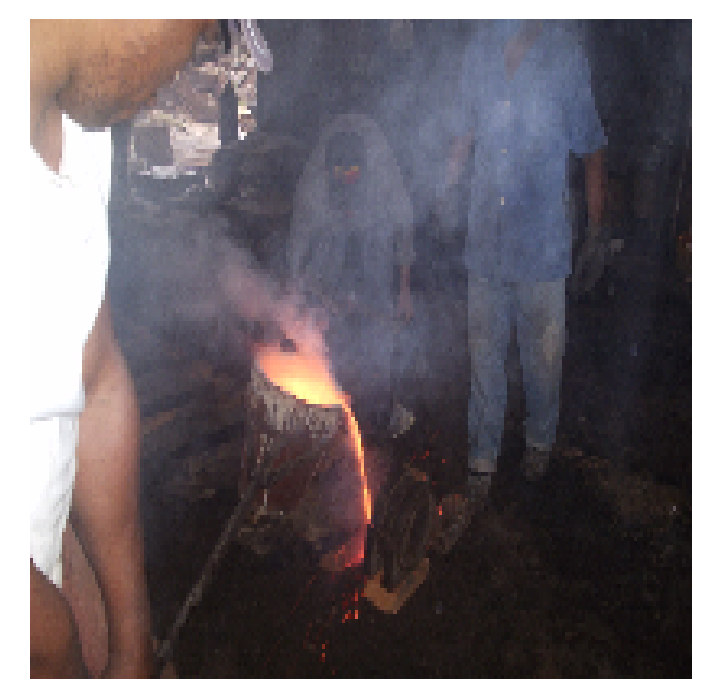

Figura 1.2: Trabalhadores preenchendo os moldes com material fundido (moldagem), sem protetor nasal ou manual.

Desse modo, esses trabalhadores estão sujeitos à inalação de partículas grossas (diâmetros aerodinâmicos entre 2,5 e $10 \mu \mathrm{m}$ ) e à respiração de partículas finas (diâmetros aerodinâmicos menores que 2,5 $\mu \mathrm{m}$ ), que podem afetar as regiões traqueobronquial e alveolar, respectivamente. Sendo assim, elementos como o cromo, níquel e chumbo, ao estarem presentes em grandes concentrações no MPS do interior de indústrias de fundição de metais, podem causar mal ao sistema neurológico, imunológico e também representar grande perigo à saúde devido às propriedades cancerígenas que apresentam alguns destes elementos (AZEVEDO e CHASIN, 2003).

A classificação do particulado em suspensão atmosférica é determinada segundo sua dimensão (diâmetro aerodinâmico) (CETESB, 2008), 
dotando assim de simbologia para o MPS de diâmetro aerodinâmico menor que $10 \mu \mathrm{m}$ e suas frações fina e grossa:

- $\mathrm{MP}_{10}$ - particulado com diâmetros aerodinâmicos menores que 10 m.

- $\mathrm{MP}_{2,5}$ - particulado com diâmetros aerodinâmicos inferiores a 2,5 $\mu \mathrm{m}$, referente à fração fina do particulado $\mathrm{MP}_{10}$.

- $\mathrm{MP}_{10-2,5}$ - particulado com diâmetros aerodinâmicos entre 2,5 $\mu \mathrm{m}$ e menores que $10 \mu \mathrm{m}$ (equivalente a $\mathrm{MP}_{10}-\mathrm{MP}_{2,5}$ ), referente à fração grossa do particulado $\mathrm{MP}_{10}$ (qualquer MPS menor que $10 \mu \mathrm{m}$ ).

A fração fina do particulado em suspensão é particularmente importante, pois pode alcançar os alvéolos pulmonares e causar sérios danos irreversíveis à saúde, dependendo de sua composição química e concentração (DERÍSIO, 1992). Desse modo, referindo-se ao MPS, a determinação da qualidade (elementos químicos presentes) e quantidade (concentração desses elementos) torna-se necessária para a identificação dos momentos críticos nessa atividade industrial, sendo indispensável a monitoração da presença de elementos químicos potencialmente tóxicos nos aerossóis contidos nos ambientes de fundição (MASSONI et al., 2006).

Para estudos deste tipo, nos quais são envolvidas matrizes sólidas, a técnica analítica de fluorescência de raios X (XRF, abreviação de $\underline{X}$ Ray Fluorescence) tem um grande potencial de aplicação por ser uma técnica analítica multielementar e não destrutiva, usada para obter informações qualitativas e quantitativas da composição elementar das amostras. Esta técnica é baseada na produção e detecção de raios $\mathrm{X}$ característicos emitidos pelos elementos constituintes da amostra quando convenientemente irradiada 
com partículas aceleradas (elétrons, prótons) ou radiações eletromagnéticas (raios X, raios gama) (NASCIMENTO, 1993).

Além das variantes clássicas da fluorescência de raios $\mathrm{X}$, denominadas de fluorescência de raios X por dispersão comprimento de onda (WDXRF, Wavelength Dispersive $\underline{X}-\underline{R} a y$ Fluorescence) e fluorescência de raios X por dispersão de energia (EDXRF, Energy Dispersive $\underline{X}$ - $\underline{\text { Ray }}$ Fluorescence), há outras de grande interesse tem sido desenvolvidas, como a fluorescência de

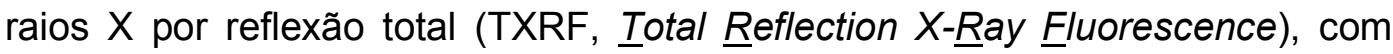
baixos limites de detecção devido a baixa intensidade da radiação de fundo espalhada (também denominada de continuum ou background), a fluorescência de raios $X$ com microssonda ( $\mu$-EDXRF), também conhecida como microfluorescência de raios X (AIGINGER e WOBRAUSCHEK, 1974), a fluorescência de raios $X$ acoplado à microscopia eletrônica de varredura (SEM/EDS, ㅁcanning Electron Microscopy/ennergy Dispersive X-Ray Spectrometry) e a emissão de raios $\mathrm{X}$ induzida por partícula (PIXE, Particle Induced $\underline{X}$-Ray Emission), todas variantes da EDXRF (IAEA, 1996).

As técnicas de $\mu$-EDXRF, SEM/EDS e PIXE podem analisar áreas microscópicas das amostras, fornecendo informações sobre a distribuição superficial de elementos (mapping; PÉREZ e SÁNCHES, 1996). A variante SEM/EDS tem sido empregada por vários grupos de pesquisa, ligados às universidades brasileiras (GERAB, 1996), assim como a variante PIXE aplicada em centros de pesquisas nacionais (TAVARES, 1990).

As micro-análises têm demonstrado ser muito eficientes para localizar e determinar distribuição espacial de elementos em diversos tipos de 
amostras. Encontram atualmente em vias de desenvolvimento dispositivos ópticos capazes de focalizar um feixe de raios $\mathrm{X}$ em pequenas regiões do espaço. Estes dispositivos baseados no fenômeno de reflexão total consistem em finos tubos capilares dentro dos quais os feixes de raios $\mathrm{X}$ se propagam, refletindo-se totalmente sobre as paredes internas, sem sofrer atenuação ou dispersão. Estas são as microssondas de raios $X$ que permitem análises de alta resolução espacial, da ordem de $\mu \mathrm{m}$ (FIORI et al., 1976; KUCZUMOW et al., 1996).

O método $\mu$-EDXRF é uma variante importante ainda pouco desenvolvida no Brasil. Ela fornece a distribuição química superficial dos elementos nas amostras, com resolução micrométrica (pixel) da ordem de 300 $\mu \mathrm{m}$ (HOLYNSKA et al., 1997; BERNASCONI et al. 1994), mas necessita de um capilar de quartzo, o qual é relativamente caro.

No caso do presente trabalho, serão coletadas e analisadas amostras de aerossóis no interior de uma pequena indústria de fundição de metais, a qual terá seu nome e local preservados. A mesma produz peças de ferro, bronze e alumínio.

Para a caracterização morfológica tanto do particulado fino como do grosso, utilizou-se o sistema SEM/EDS (CUNHA e SILVA, 2002, LOPES, 2003), cujo equipamento fica instalado no Núcleo de Pesquisas em Geoquímica e Geofísica da Litosfera da Universidade de São Paulo (NUPEGEL- Campus Luiz de Queiróz - ESALQ/USP, Piracicaba-SP). 
Dessa forma é objetivo deste trabalho determinar, não somente as formas e tamanhos com que se apresentam as partículas na atmosfera no interior da indústria de fundição, mas também a concentração temporal dos elementos presentes nos aerossóis em determinado instante e os momentos mais críticos do processo de fundição. 


\section{2- REVISÃO DA LITERATURA}

\section{1- Material particulado em suspensão atmosférica (MPS)}

O material particulado em suspensão atmosférica, que é toda partícula sólida presente no aerossol (mistura de sólidos e líquidos suspensos no ar), pode ter origem natural ou antropogênica (causada por atividades humanas). Sua classificação é feita sob dois aspectos: (a) orgânico, que identifica as partículas oriundas de combustão, esfoliação de materiais poliméricos e biológicos, transformações químicas em diferentes processos que envolvem compostos orgânicos e (b) inorgânico, referente às partículas formadas pela combustão de minerais fósseis ou não (podendo conter metais), por processos de esfoliação, pelos diversos tipos de atividades industriais e por fontes naturais. Dos materiais particulados inorgânicos resultantes de atividades humanas, pode-se destacar os elementos $\mathrm{Ca}, \mathrm{Ti}, \mathrm{V}, \mathrm{Cr}, \mathrm{Mn}, \mathrm{Fe}, \mathrm{Co}$, $\mathrm{Ni}, \mathrm{Cu}, \mathrm{Zn}, \mathrm{Br}$ e $\mathrm{Pb}$, dos quais, por exemplo, $\mathrm{Cr}$ e Ni possuem propriedades carcinogênicas (MANAHAN, 1994; AZEVEDO e CHASIN, 2003). 
Com referência ao tamanho do particulado atmosférico, a Agência Americana de Proteção Ambiental (USEPA - United States Environmental Protection Agency) fez, no início da década de 70, um primeiro padrão de qualidade do ar referente ao MPS: partículas totais em suspensão (PTS) com uma faixa de tamanho menor que $100 \mu \mathrm{m}$, que inclui particulado sólido ou líquido suspenso no ar, em forma de poeira, neblina, aerossol, fumaça, fuligem, etc.

A partir do final da década de 80 até recentemente, uma nova padronização referente à qualidade do ar, tem sido feita pela USEPA relacionando o diâmetro aerodinâmico do particulado com a sua entrada no trato respiratório humano: o particulado inalável, cujo diâmetro aerodinâmico deve ser menor que $10 \mu \mathrm{m}$, denominado $\mathrm{MP}_{10}$, e o particulado respirável, de diâmetro aerodinâmico menor que 2,5 $\mu \mathrm{m}$ (que representa uma parcela do particulado $\mathrm{MP}_{10}$ ), denominado $\mathrm{MP}_{2,5}$.

Sendo assim, as frações do particulado atmosférico passaram a ser chamadas de fração grossa do particulado inalável $\left(\mathrm{MP}_{10-2,5}\right.$ - partículas entre 2,5 e $10 \mu \mathrm{m}$ ) e fração fina, o próprio $\mathrm{MP}_{2,5}$, sendo esta última fração de atenção especial, pois ela é mais potencialmente tóxica por entrar nos alvéolos pulmonares, podendo causar, além das doenças respiratórias, outras como neurológicas, causada pelo chumbo, ou carcinogênicas, causadas pelo cromo, (USEPA, 1999).

Um dos primeiros trabalhos realizado no Brasil sobre a composição de aerossóis foi feito na cidade de São Paulo, especificamente dentro do Instituto de Energia Atômica, atualmente Instituto de Pesquisas 
Energéticas e Nucleares, Cidade Universitária (MIYAMARU, 1972; SAIKI e LIMA, 1973). Utilizou filtros de éster de celulose (da marca Millipore, tipo AA, com $47 \mathrm{~mm}$ de diâmetro e 0,8 $\mu \mathrm{m}$ de diâmetro de poros) na coleta e posterior análise por ativação neutrônica (nêutrons térmicos) com separação radioquímica na determinação quantitativa de $\mathrm{As}, \mathrm{Br}, \mathrm{Hg}$, $\mathrm{Sb}$ e Se. Estes elementos foram separados por destilação do restante da amostra previamente irradiada com nêutrons térmicos através da sua transformação em brometos voláteis e bromo elementar. $\mathrm{O} \mathrm{Br}$ foi retido em uma solução de $\mathrm{NaOH}$ e os demais elementos em resinas trocadoras de íons, e as atividades induzidas dos radionuclídeos foram determinadas utilizando-se analisador multicanal acoplado a detector cintilador sólido de $\mathrm{Nal}(\mathrm{Tl})$. Em algumas amostras encontrou-se também urânio, cuja presença também foi comprovada pela técnica de irradiação com nêutrons epitérmicos. O resíduo da destilação foi também analisado por espectrometria de alta resolução empregando-se um detector semicondutor de $\mathrm{Ge}(\mathrm{Li})$, determinando-se qualitativamente os elementos $\mathrm{Cu}, \mathrm{Fe}, \mathrm{K}, \mathrm{La}, \mathrm{Na}, \mathrm{Sc}, \mathrm{Sm}, \mathrm{W}$ e Zn.

A Organização Mundial da Saúde reconhece o chumbo como um dos elementos químicos mais perigosos para a saúde humana. Mesmo com a proibição da adição do chumbo tetraetila na gasolina em alguns países, a concentração do $\mathrm{Pb}$ no particulado atmosféricos da zona urbana diminuiu, porém não acabou com o problema da poluição por esse metal, devido a outras fontes decorrentes de atividades industriais e urbanas, que também são responsáveis pela poluição atmosférica por chumbo particulado, colocando em risco a saúde das populações (COCHRAN et al., 1998). 
Vanz et al. (2003), analisaram a concentração de chumbo no MPS da cidade de Rio Grande-RS, cuja região apresenta um longo histórico de problemas referentes ao impacto ambiental atmosférico por poeira e metais particulados, causado por atividades portuárias e industriais, especialmente do setor de fertilizantes, refino de petróleo e industria de alimentos. Esse estudo mostrou que existe um processo de contaminação atmosférica por chumbo em Rio Grande e na região estuarina da Lagoa dos Patos. Em algumas regiões do interior do Rio Grande do Sul, os níveis de chumbo no MPS muitas vezes superam os limites legais estabelecidos pelas agências ambientais internacionais. Em muitos países, o chumbo é o único metal cuja presença na atmosfera é controlada por legislação (STERN, 1977), mas no Brasil, no entanto, não existem normas específicas para o seu controle na atmosfera.

\section{2- Inalação e respiração de material particulado e saúde}

Segundo o relatório da Companhia de Tecnologia e Saneamento Ambiental (CETESB, 2008), quanto menor o tamanho do particulado atmosférico, maiores os efeitos maléficos à saúde, os quais podem ser significativos, principalmente em pessoas com doença pulmonar, asma e respiratória, podendo inclusive ocorrer mortes prematuras.

Durante o trabalho do aparelho respiratório humano (inspiração), as partículas atmosféricas com diâmetros aerodinâmicos maiores que $10 \mu \mathrm{m}$ até $100 \mu \mathrm{m}$ (consideradas insolúveis), ficam retidas entre as narinas e a traquéia, enquanto que as menores que $10 \mu \mathrm{m}$ (solúveis), alcançam o 
pulmão, podendo sofrer sedimentação na região traqueobronquial e nos alvéolos pulmonares (no caso das partículas de diâmetros iguais ou inferiores à 2,5 $\mu \mathrm{m})$. As partículas insolúveis são removidas muito lentamente do organismo pelas células de defesa (da ordem de meses), já as solúveis, são removidas dos alvéolos para a corrente sanguínea, podendo representar sérios riscos à saúde. Desta forma classifica-se as partículas atmosféricas em 3 categorias: (1) inaláveis (tamanhos menores $100 \mu \mathrm{m}$ ) que afetam o sistema respiratório de um modo geral, (2) torácicas (tamanhos entre 2,5 $\mu \mathrm{m}$ e menores que $10 \mu \mathrm{m}$ ) que afetam a região traqueobronquial e alveolar e (3) respiráveis (tamanhos menores que 3,5 $\mu \mathrm{m}$ ) que afetam intensamente a região alveolar, seguindo para a corrente sanguínea (INNOCENTINI,1993).

Sendo assim, os vários efeitos do MPS no trato respiratório humano, estão associados à remoção das partículas atmosféricas pelo aparelho respiratório, à presença de substâncias nestas partículas (que em grandes concentrações apresentam propriedades tóxicas e carcinogênicas) e à capacidade destas amplificar os efeitos fisiológicos dos gases presentes no ar, tornando-os mais nocivos, podendo provocar doenças agudas, doenças crônicas, diminuição da longevidade, dano ao crescimento, irritação sensorial e podendo levar até a morte (DERÍSIO, 1992).

O homem tem necessidade diária de aproximadamente $15 \mathrm{~kg}$ de ar, $1,5 \mathrm{~kg}$ de alimento sólido e 2 litros de água. Dentro destas necessidades vê-se que o consumo de ar deve ser contínuo, pois é essencial para a visão, olfato e audição. Essa quantidade de ar inspirado, entra em contato com $70 \mathrm{~m}^{2}$ de superfície alveolar nos pulmões. Estima-se que uma pessoa pode viver 5 
semanas sem alimento, 5 dias sem água, mas não mais que 5 minutos sem ar (MARQUES, 2000).

Com o objetivo de investigar a estrutura de defasagem entre exposição à poluição do ar e internações hospitalares por doenças cardiovasculares em idosos, Martins et al. (2006) coletaram dados a respeito da saúde de pessoas com mais de 64 anos de idade entre os anos de 1996 e 2001, na cidade de São Paulo-SP. Também analisaram os níveis diários de poluentes atmosféricos $\left(\mathrm{CO}, \mathrm{MP}_{10}, \mathrm{O}_{3}, \mathrm{NO}_{2}, \mathrm{NO}_{2}\right)$, bem como os dados referentes à temperatura mínima e a umidade relativa do ar. No desenvolvimento deste trabalho, foram utilizados modelos restritos de distribuição polinomial em modelos aditivos generalizados de regressão de Poisson para estimar os efeitos dos poluentes no dia em que os indivíduos foram expostos e até 20 dias após a essa exposição, controlando-se para sazonalidades de longa e curta duração, feriados e fatores meteorológicos. Os resultados mostraram que as doenças cardiovasculares em São Paulo são fortemente afetadas pela poluição do ar e os efeitos foram mais intensos no gênero feminino. Variações de $\mathrm{PM}_{10}\left(26,21 \mu \mathrm{g} / \mathrm{m}^{3}\right)$ e $\mathrm{SO}_{2}\left(10,73 \mu \mathrm{g} / \mathrm{m}^{3}\right)$ foram associados com aumentos de $3,17 \%$ nas admissões por insuficiência cardíaca congestiva e de $0,89 \%$ para admissões por todas as doenças cardiovasculares no dia da exposição, respectivamente. 


\section{3- Legislação ambiental e material particulado na atmosfera}

De acordo com a CETESB (2008), o monitoramento da qualidade do ar tem como metas: (1) fornecer dados para ativar ações de emergência durante períodos de estagnação atmosférica, quando os níveis de poluentes na atmosfera podem representar risco à saúde das pessoas; (2) avaliar a qualidade do ar seguindo os limites estabelecidos para proteger a saúde e o bem estar dos indivíduos; (3) acompanhar as tendências e as mudanças na qualidade do ar, em razão das alterações nas emissões dos poluentes.

Para cumprir esses objetivos, é necessário estabelecer limites para cada um dos poluentes monitorados, os quais são denominados padrões de qualidade do ar, que são dois: o primário e o secundário. O padrão primário de qualidade do ar indica concentrações de poluentes na atmosfera que, ultrapassadas, poderão afetar a saúde das pessoas. Entende-se também como padrão primário, níveis máximos toleráveis de concentração de poluentes atmosféricos em curto e médio prazo. No caso dos padrões secundários de qualidade de ar, as concentrações de poluentes atmosféricos abaixo das quais se prevê o mínimo dano ao meio ambiente em geral. Esses níveis de padrões secundários não se aplicam às áreas urbanas e mais desenvolvidas. Na verdade eles foram estabelecidos com a intenção de estabelecer uma política de prevenção da degradação da qualidade do ar, devendo ser aplicados às áreas de preservação e de proteção ambiental, entre outros.

A Resolução CONAMA (Conselho Nacional do Meio Ambiente) $n^{\circ}$ 03/90, estabeleceu os padrões nacionais de qualidade do ar e os 
respectivos métodos de referência. Os padrões nacionais de qualidade do ar fixados nesta resolução, para material particulado, estão apresentados na Tabela 2.1. Esses padrões de qualidade do ar são fixados pelas agências regulamentadoras de cada país. A Tabela 2.2 apresenta valores limites de concentração de partículas inaláveis adotados pela agência americana USEPA (CETESB, 2008):

Tabela 2.1: Padrões nacionais de qualidade do ar - Resolução CONAMA n 03 de 28/junho/90 (fonte: CETESB, 2008).

\begin{tabular}{|c|c|c|c|l|}
\hline POLUENTE & $\begin{array}{c}\text { TEMPO DE } \\
\text { AMOSTRAGEM }\end{array}$ & $\begin{array}{c}\text { PADRÃO } \\
\text { PRIMÁRIO } \\
\left(\mu \mathrm{g} / \mathrm{m}^{3}\right)\end{array}$ & $\begin{array}{c}\text { PADRÃO } \\
\text { SECUNDÁRIO } \\
\left(\mu \mathrm{g} / \mathrm{m}^{3}\right)\end{array}$ & $\begin{array}{c}\text { MÉTODO DE } \\
\text { MEDIÇÃO }\end{array}$ \\
\hline Partículas & MGA $^{*}$ & 80 & 60 & Amostrador de \\
Suspensão & $24 \mathrm{~h}^{* * *}$ & 240 & 150 & grandes \\
volumes
\end{tabular}

${ }^{*}$ MGA = Média Geométrica Anual.

${ }^{* *}$ MAA $=$ Média Aritmética Anual.

${ }^{* * *}$ não deve ser excedido mais de uma vez ao ano.

**** Neste caso, considera-se partículas inaláveis $=\mathrm{MP}_{10}$ 
Tabela 2.2: Padrões de qualidade do ar adotados pela Agência de Proteção Ambiental dos Estados Unidos - USEPA (fonte: CETESB, 2008).

\begin{tabular}{|c|c|c|c|}
\hline POLUENTE & $\begin{array}{c}\text { TEMPO DE } \\
\text { AMOSTRAGEM }\end{array}$ & $\begin{array}{c}\text { PADRÃO } \\
\text { PRIMÁRIO } \\
\left(\boldsymbol{\mu g} / \mathbf{m}^{3}\right)\end{array}$ & $\begin{array}{c}\text { MÉTODO DE } \\
\text { MEDIÇÃO }\end{array}$ \\
\hline$M_{10}$ & MAA $^{* *}$ & 50 & Separação \\
inercial filtro \\
\end{tabular}

* MGA = Média Geométrica Anual.

${ }^{* *}$ MAA = Média Aritmética Anual.

${ }^{* \star *}$ não deve ser excedido mais de uma vez ao ano.

O monitoramento da concentração de partículas na atmosfera é feito pela amostragem de aerossóis, os quais contêm material particulado que, por sua vez, contém elementos que, em grandes concentrações podem apresentar alta toxicidade. A amostragem é feita conforme o objetivo da análise: determinação da concentração do MPS e confronto com o conteúdo da legislação local, entendimento das propriedades físico-químicas da poluição atmosférica e verificação dos compostos ou elementos químicos presentes no material particulado, e identificação das possíveis fontes emissoras (HINDS, 1999).

As amostragens podem ser: (1) por gravimetria, além de ser método prático e econômico, é a principal técnica para avaliação da quantidade 
de material particulado suspenso na atmosfera, que consiste na filtração do ar e posterior cálculo da razão entre massa e volume de ar coletado e (2) dicotômetros de diâmetro, que durante o processo de sucção do ar, o particulado é separado por faixas de diâmetro, as quais são inicialmente impactadas e as de menor diâmetro seguem no fluxo de ar até os filtros (WILLEKE e BARON, 1993).

\section{4- Amostradores: impactadores inerciais e filtros}

Os impactadores inerciais são muito utilizados para estudos da determinação da massa de aerossol por faixa de diâmetro, apresentando várias versões, desenvolvidas para fins específicos. Neste amostrador, as partículas de diâmetro aerodinâmico maior do que o de corte ficam retidas no impactador durante a sucção de ar, enquanto que as de menor seguem o fluxo no interior do amostrador até serem retidas em um filtro. Alguns dos mais comuns amostradores de particulado atmosférico são mostrados na Figura 2.1 (WILLEKE e BARON, 1993): 


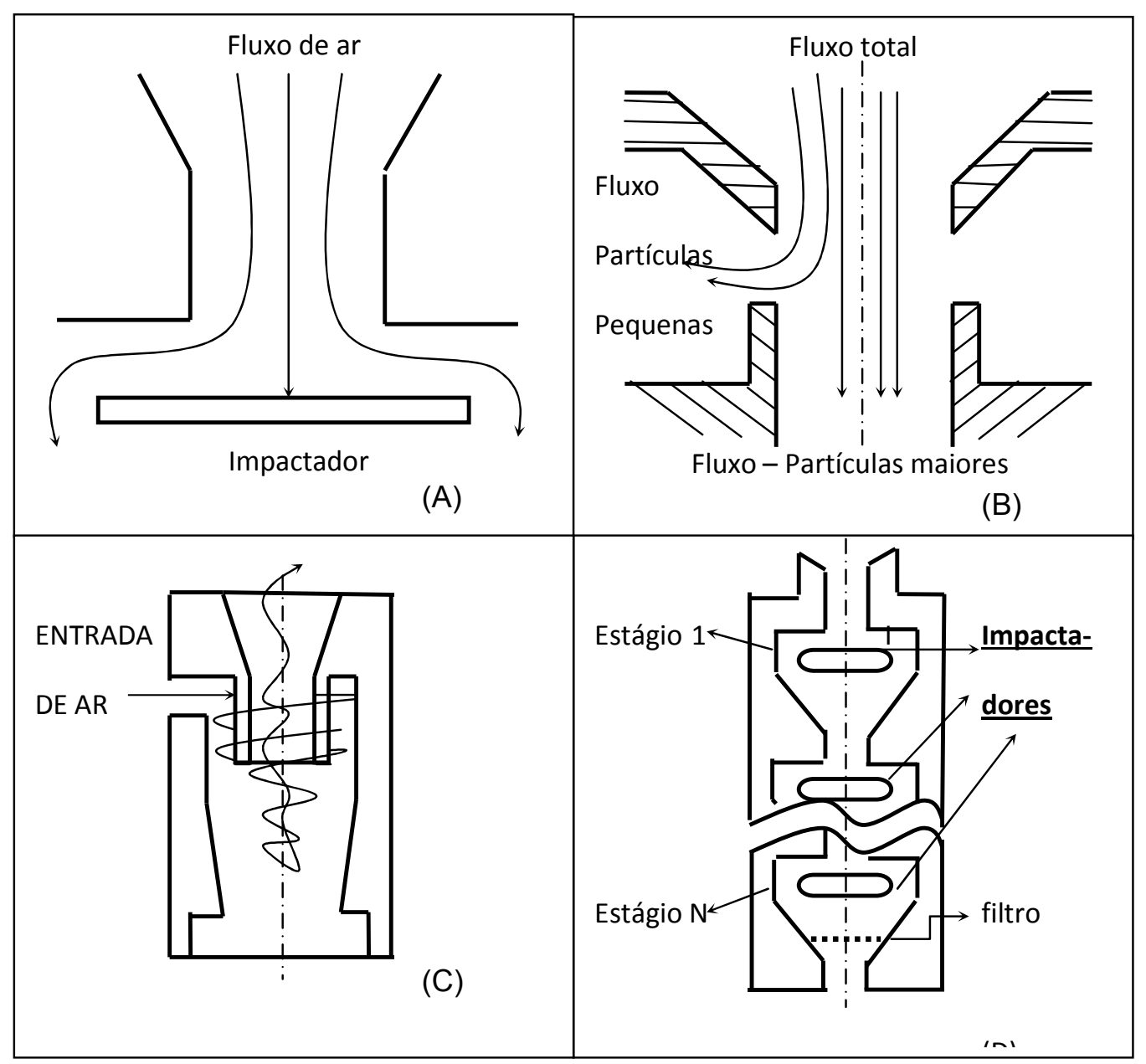

Figura 2.1: Esquema de amostradores: (A) impactador inercial convencional, (B) impactador virtual; (C) ciclone; (D) impactador de cascata de estágios.

Segundo Willeke e Baron (1993), a escolha dos filtros e impactadores utilizados nos amostradores está relacionada ao objetivo do estudo. As principais características dos filtros são resistência mecânica, estabilidade química, eficiência da coleta, capacidade de carga, compatibilidade com os métodos analíticos do material coletado e ser 
homogêneo de modo que valores referentes ao branco, determinados em análise do filtro sem amostra, sejam bem definidos.

Os filtros mais utilizados são de fibras de celulose, de vidro, plásticas e mistas. No caso dos filtros de fibra de vidro, que proporcionam uma eficiência de filtração de $99 \%$ para partículas de tamanho superior à $0,3 \mu \mathrm{m}$, são mais empregados em amostradores de grandes volumes. Já no caso do uso de membranas de éster de celulose (meio filtrante higroscópico), possuem uma microestrutura uniforme e muito complexa e, devido à elevada perda de carga que este tipo de membrana propicia, não se recomenda para coletas em amostradores de grandes volumes (AGV). Sendo assim, essas membranas são utilizadas para amostrador de médio (vazão até 100 litros/min) e de pequeno volume (APV - vazão até 20 litros/min) e são indicadas para análises químicas não destrutivas como no caso da EDXRF.

\section{5- Caracterização química}

A caracterização química de MPS em filtros utilizados em amostradores, como os citados anteriormente, além de ser adequada ao filtro utilizado, deve ser de acordo com o objetivo da análise. As técnicas mais utilizadas atualmente são: fluorescência de raios $X$ - XRF (NASCIMENTO et al., 2005, HE e ESPEN, 1991), microscopia eletrônica de varredura (SEM/EDS) e emissão de raios $X$ induzida por partícula (PIXE) (ARTAXO, 1995). Estas técnicas são largamente utilizadas, pois permitem uma avaliação tanto qualitativa como quantitativa da concentração dos elementos presentes na 
amostra, de modo simultâneo e não destrutivo, com alta sensibilidade e sem a necessidade de preparação das amostras (NASCIMENTO, 1999; MARQUES, 2000).

\section{6- Aplicações de espectrometria de raios X para análise de MPS}

Espen e Adams (1974) fizeram coleta de MPS utilizando filtro de celulose de $63 \mathrm{~cm}^{2}$ realizando uma amostragem por um período de 24 h fazendo o uso de uma bomba de vácuo que permitia uma vazão de $20 \mathrm{~m}^{3} / \mathrm{h}$. $A$ análise foi por EDXRF, utilizando um tubo de raios $X$ com alvo de $W$ e alvo secundário de Mo numa tensão/corrente $40 \mathrm{kV} / 40 \mathrm{~mA}$, irradiando as amostras por $2000 \mathrm{~s}$, e detectando os raios X característicos num detector de $\mathrm{Si}(\mathrm{Li})$. Neste experimento, utilizando filtro de celulose para $9 \mathrm{mg} / \mathrm{cm}^{2}$, a menor concentração detectada foi de $20 \mathrm{ng} / \mathrm{cm}^{2}(\mathrm{Zn})$. Se utilizasse filtros mais finos, a sensibilidade do espectrômetro poderia ser maior, e assim o limite de detecção para determinados elementos seria melhor, devido a diminuição do continuum.

Pushkin et al. (1987) descreve que, nos últimos anos, o uso das técnicas analíticas modernas de alta sensibilidade, têm aumentado significativamente, nos estudos da composição química elementar do MPS em aerossóis. Isto se deve principalmente à crescente poluição ambiental e à influência dos aerossóis no organismo humano.

No trabalho feito por Piórek (1980) relatou alguns problemas de poluição atmosférica em áreas de parques nacionais em Cracóvia, Polônia, utilizando a técnica de fluorescência de raios $\mathrm{X}$ por dispersão de energia para 
analisar as amostras em filtros de papel Whatman 41, que foi utilizado em amostrador AGV. O objetivo deste estudo foi a determinação do nível de poluição da atmosfera local pelos elementos $\mathrm{Fe}, \mathrm{Zn}, \mathrm{Pb}$ e Se, cujas fontes eram provavelmente das indústrias da região.

Raoof e Al-Sahhaf (1992) fizeram campanha de amostragem de MPS durante duas semanas em vários locais da cidade de Riad, Arábia Saudita. Para coleta dos aerossóis, utilizaram bombas de vácuo e filtros de papel Whatman 41 num amostrador colocado a 1,6 $\mathrm{m}$ acima do solo, de modo a evitar que poeira, areia, etc, se misturassem às amostras de MPS no filtro. A análise foi feita empregando-se a técnica de EDXRF, utilizando detector de $\mathrm{Si}(\mathrm{Li})$ e um analisador multicanal (1024 canais). Foram detectados $\mathrm{Fe}, \mathrm{Ni}, \mathrm{Cu}$, Zn e $\mathrm{Pb}$, que sofriam variação de concentração na atmosfera dependendo da região. Naquela de maior atividade antropogênica, como trânsito intenso, atividades industriais, as concentrações desses elementos citados se apresentavam maiores, principalmente no caso do $\mathrm{Pb}$, que apresentou, numa determinada região, uma concentração maior que $4 \mu \mathrm{g} / \mathrm{m}^{3}$, cujo valor é considerado muito acima dos padrões estabelecidos pelas agências de controle ambiental.

Gatebe et al. (1996) iniciou em dezembro de 1993 uma amostragem de particulado atmosférico fino e grosso em Nairobi, Quênia, numa área residencial de subúrbio a uma altitude aproximada de $1800 \mathrm{~m}$. Fezse duas séries de coleta de amostras por semana, nas quais o amostrador coletava $1 \mathrm{~m}^{3} / \mathrm{h}$ durante $24 \mathrm{~h}$. A técnica utilizada para a caracterização das amostras foi a de EDXRF, irradiando as amostras por $1000 \mathrm{~s}$ com limites de 
detecção variando entre $1 \mathrm{ng} / \mathrm{m}^{3}$ a $4.150 \mathrm{ng} / \mathrm{m}^{3}$. Identificou-se no particulado $\mathrm{Fe}, \mathrm{Ca}, \mathrm{Mn}$ e Zn com origem provável da crosta terrestre (solo) e de atividades antropogênicas o $\mathrm{Cu}, \mathrm{Br}$ e $\mathrm{Pb}$. Apesar de $\mathrm{Pb}$ mostrar-se em níveis inferiores ao estabelecido pela Organização Mundial de Saúde, sua fonte principal, assim como a do $\mathrm{Br}$, é devido à emissão de gases dos veículos, pois a gasolina utilizada tinha estes elementos como parte da sua composição química.

Com a intenção de investigar diferentes tipos de filtros para análise de elementos-traços na atmosfera, Ali e Bacso (1996) realizou a coleta de MPS em aerossol. As partículas foram coletadas em três tipos de filtros e as amostras foram analisadas pelas técnicas EDXRF, PIXE e SEM/EDS. Concluiu-se com isso que as membranas da Nuclepore são mais adequadas para este tipo de análise de elementos-traços devido a seus valores de "branco" serem menores do que os que se encontra em filtros de fibra de vidro e filtros ash free.

Ellis et al. (1997) afirma que a análise por EDXRF de elementos químicos presente em amostras de material particulado em suspensão atmosférica impregnados em filtros finos (membranas) apresentam resultados compatíveis com outras técnicas, como PIXE e ativação neutrônica, e ainda se apresenta com aplicação mais prática.

Matsumoto (2001) obteve informações referentes ao nível de poluição ambiental em Campinas-SP, analisando amostras de particulado atmosférico e de águas superficiais (chuva e rio), utilizando-se as técnicas de EDXRF com tubo de raios $X$ para análise de água de rio e TXRF com radiação síncrotron para análise de água de chuva e de particulado atmosférico (com 
pré-digestão via úmida). O estudo mostrou que o nível de concentração de particulados na atmosfera é satisfatório, que as águas pluviais, apesar de se ter na região fontes de emissão industrial, de cloretos e de ressuspensão do solo, não apresentaram contaminação, porém os rios apresentaram indícios de contaminação de alguns elementos, como $\mathrm{Fe}, \mathrm{Co}, \mathrm{Ni}$ e $\mathrm{Cu}$, que se mostraram em níveis maiores que os estabelecidos pelo CONAMA (Conselho Nacional do Meio Ambiente).

Kebin et al. (2001) analisaram num período pouco maior que 1 ano (jul/1999 a set/2000) a concentração e a composição do material particulado atmosférico fino $\left(\mathrm{MP}_{2,5}\right)$ em dois locais da cidade de Beijing, China, onde encontraram variações da concentração do particulado entre 37 e 357 $\mu \mathrm{g} / \mathrm{m}^{3}$, neste período, com poucas diferenças entre as localidades. Para a coleta do MPS utilizou-se do amostrador de pequeno volume com membrana de Teflon, seguindo de análise por EDXRF, determinando a concentração de mais de 40 elementos.

Com as facilidades existentes no LIN/CENA, Lopes (2003) realizou uma avaliação da composição química do material particulado em suspensão na atmosfera em Londrina-PR e Piracicaba-SP. A amostragem foi realizada nas estações de verão e inverno, utilizando-se um amostrador tipo fixo (stacker), permitindo a coleta simultânea de particulado fino (partículas com diâmetro aerodinâmico menor que $2,5 \mu \mathrm{m}$ ) e grosso (entre 2,5 e $10 \mu \mathrm{m}$ ), utilizando filtros com $47 \mathrm{~mm}$ de diâmetro e diâmetros de poros de 0,4 e $8 \mu \mathrm{m}$, respectivamente. A análise das amostras foi realizada através da técnica de EDXRF. Foi também utilizado um microscópio eletrônico de varredura acoplado 
a um sistema de fluorescência de raios $X$ por dispersão em energia (SEM/EDS) para a caracterização química e morfológica dos principais grupos de partículas existentes no material particulado. A metodologia de análise de agrupamento foi usada para identificar as possíveis fontes de emissão ou de formação do material particulado (APPOLONI et al., 2005).

Ho et al. (2003) fez coleta de MPS fino e grosso, em rodovias de Hong Kong, China, em local com intenso fluxo de veículos automotores. A análise das amostras que foi feita pela técnica de EDXRF, mostrou que o particulado grosso apresentou-se em maior quantidade que o fino, e os elementos Al e Si apresentaram as maiores concentrações tanto no particulado fino como no grosso. Constatou-se também que os elementos encontrados $\mathrm{K}$, $\mathrm{Ca}$, Ti e Fe são oriundos principalmente do solo e $\mathrm{Zn}$ e $\mathrm{Pb}$ do combustível utilizados pelos veículos automotores que circulam pelas rodovias.

Bruno et al. (2004), fizeram um levantamento sistemático da quantidade de material particulado $\left(\mathrm{MP}_{10}\right.$ e $\left.\mathrm{MP}_{2,5}\right)$, presentes na atmosfera da cidade de São Carlos, SP, bem como estimativa de fontes via o modelo matemático Balanço Químico de Massas (BQM). A amostragem foi realizada em um aparelho dicotômetro, com filtros Nuclepore, em um amostrador de grandes volumes (Hi-vol) e filtro de fibra de vidro. Os resultados mostram que existe uma relação estreita entre a concentração de $\mathrm{MP}_{10}$ e $\mathrm{MP}_{2,5}$ em cada amostragem, independente do dia de coleta, no período estudado. As simulações sugerem que as fontes de material particulado variam significativamente de acordo com a época do ano. 
Num período de junho de 2005 a maio de 2006, Ochsenkühn et al. (2008) coletaram material particulado grosso $\left(\mathrm{MP}_{10-2,5}\right)$ e fino $\left(\mathrm{MP}_{2,5}\right)$ numa área industrial em Aspropyrgos-Attica, Grécia, que foram analisados por EDXRF, reflectometria, espectrometria de absorção atômica (AAS - Atomic absorption spectroscopy) e de emissão atômica com plasma indutivamente acoplado (ICP-AES - inductively coupled plasma-atomic emission spectrometry). No verão, a concentração média encontrada no particulado $\mathrm{MP}_{10}$ no verão foi de $64,95 \mu \mathrm{g} / \mathrm{m}^{3}$, enquanto que no particulado $\mathrm{MP}_{2,5}$ foi de $31,7 \mu \mathrm{g} / \mathrm{m}^{3}$, No inverno a concentração média obtida de $\mathrm{MP}_{10}$ foi de $68,2 \mu \mathrm{g} / \mathrm{m}^{3}$ e de $\mathrm{MP}_{2,5}$ foi de $28,8 \mu \mathrm{g} / \mathrm{m}^{3}$. A média entre verão e inverno foi de $66 \mu \mathrm{g} / \mathrm{m}^{3}$, o que excedeu o limite anual de $40 \mu \mathrm{g} / \mathrm{m}^{3}$ (Conselho Diretivo 83/399/ECC).

Para fazer a caracterização física e química, do $\mathrm{Na}$ ao $\mathrm{Pb}$ em material particulado, Vecchi et al. (2008), fizeram em Milão, Itália, amostragem de $\mathrm{PM}_{10}$ durante 2 semanas no verão e 2 semanas no inverno de 2006 . Foi analisada tanto da fração fina $\left(\mathrm{MP}_{2,5}\right)$ quanto a fração grossa $\left(\mathrm{MP}_{10-2,5}\right)$ do $\mathrm{PM}_{10}$. Encontrou-se no particulado $34 \%$ de material orgânico no verão e $33 \%$ no inverno, enquanto que material inorgânico foi de $16 \%$ no verão e $24 \%$ no inverno. Este experimento mostrou que nessa região ocorreu grande variação da composição do material particulado $\mathrm{MP}_{10}$. 


\section{3- FUNDAMENTAÇÃO TEÓRICA}

$A$ análise de amostras por fluorescência de raios $X(X R F)$, tem como base a medida das intensidades dos raios $X$ característicos emitidos pelos elementos presentes nas amostras, após uma excitação em geometria adequada (CARNEIRO e NASCIMENTO FILHO, 1996; SIMABUCO e NASCIMENTO FILHO, 1994). A medida das intensidades é possível de ser realizada por meio do uso de detector de raios $X$ apropriados $e$, posteriormente, equações fundamentais para quantificar os elementos contidos nas amostras.

Existem duas variantes clássicas na metodologia de fluorescência de raios X: (1) a WDXRF (Wavelength Dispersive $\underline{X}$ - $\underline{\text { Ray }}$ Fluorescence), a qual utiliza a lei de Bragg na separação e medida das intensidades dos raios $X$ característicos $e$, portanto, necessita de um movimento sincronizado e preciso entre o cristal difrator e o detector, encarecendo o sistema, e (2) a EDXRF (Energy Dispersive $\underline{X}$ - $\underline{\text { Ray }}$ Fluorescence) também conhecida como fluorescência de raios $\mathrm{X}$ dispersiva em energia, com instrumentação menos dispendiosa e emprego mais prático 
(NASCIMENTO FILHO, 1993), utilizando-se de detector de alta resolução, capaz de discriminar as diferentes energias dos raios $\mathrm{X}$.

Cada elemento, ao ser excitado na amostra, ejeta elétron do nível de energia mais interno, provocando vacância a qual deverá ser preenchida pelo elétron da camada posterior. Esse elétron, que realizou salto quântico para preencher a vacância, sofre perda de energia na forma de um fóton de raios $\mathrm{X}$, de energia característica, específica para cada elemento.

Em resumo, as etapas da análise por fluorescência de raios $X$ por dispersão de energia constam em: (a) excitação dos elementos da amostra os quais sofrem a fluorescência, (b) detecção e medida da intensidade dos raios $X$ característicos e (c) determinação da concentração dos elementos na amostra por meio das intensidades dos raios $\mathrm{X}$, fazendo uso de equações apropriadas, conforme pode ser visualizado na Figura 3.1.

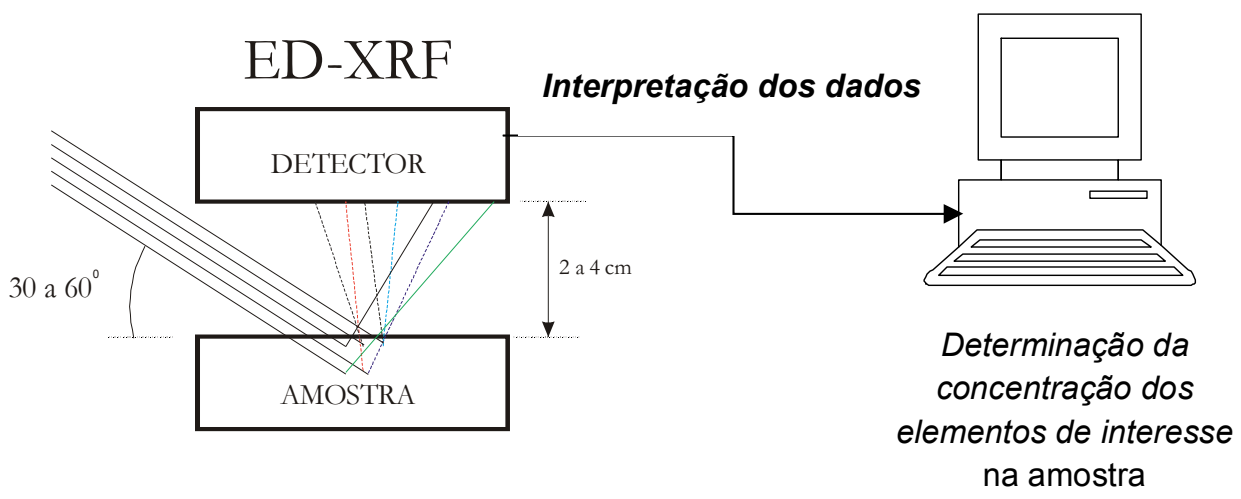

Figura 3.1: Geometria de excitação-detecção da EDXRF, com linhas contínuas representando os raios $X$ incidentes e as espalhadas coloridas, os raios $X$ característicos. Após a detecção dos raios $X$ característicos, determina-se a concentração dos elementos de interesse por meio de software. 


\section{1- Equação fundamental}

Quando a excitação é monoenergética, utiliza-se de uma expressão matemática (equação 1) que relaciona a intensidade dos raios $X$ característicos com a concentração de um determinado elemento na amostra (GRIEKEN e MARKOWICS, 2002):

$$
\mathbf{I}=\mathbf{S} \cdot \mathbf{C} \cdot \mathbf{f}
$$

onde I é a intensidade dos raios $\mathrm{X}$ característicos detectados (cps), $\mathbf{S}$ a sensibilidade analítica do espectrômetro de raios $X$ para o elemento de interesse $\left(\mathrm{cps} . \mu \mathrm{g}^{-1} \cdot \mathrm{cm}^{2}\right)$, c a concentração do elemento de interesse na amostra $\left(\mu \mathrm{g} / \mathrm{cm}^{2}\right)$ e $\mathbf{f}$ o fator de absorção (adimensional) para os raios $X$ do elemento de interesse na amostra. A equação 2 descreve a dependência do fator de absorção pela espessura $\mathbf{D}$, da densidade $\boldsymbol{\rho}_{0}$ da amostra e do coeficiente de absorção mássico total $\chi$ (depende fundamentalmente da energia de radiação incidente e emergente para os elementos da amostra), ambas as grandezas referentes à amostra:

$$
f=\frac{1-e^{-\chi \cdot \rho_{0} \cdot D}}{\chi \cdot \rho_{0} \cdot D}
$$

Pela equação 2, para amostras consideradas finas, isto é com D tendendo a zero (D muito pequeno), obtém-se a condição na qual o fator de absorção assume valor 1 , isto é, $\mathbf{f}=1$, como no caso de material particulado atmosférico depositado em filtro. 
A sensibilidade analítica elementar "S" do espectrômetro, variável extremamente importante nos estudos de fluorescência de raios $\mathrm{X}$, depende de outras variáveis, como da geometria excitação-detecção, da eficiência do detector e do número de raios $\mathrm{X}$ produzidos de cada elemento presente na amostra, os quais dependem da energia de excitação. Essas grandezas físicas são apresentadas na equação 3:

$$
\mathbf{S}=\mathbf{G} . \boldsymbol{\varepsilon} \cdot \mathbf{K}
$$

onde $\mathbf{G}$ é o fator de geometria excitação-detecção, $\boldsymbol{\varepsilon}$ é a eficiência do detector para os raios $\mathrm{X}$ característicos e $\mathbf{K}$ representa o número de raios $\mathrm{X}-\mathrm{Ka}$ (devido às vacâncias preenchidas na camada $K$ por elétrons oriundos da camada $L$ ) emitidos dos elementos da amostra, dependente da energia dos fótons da radiação incidente (excitação das amostras). Em particular, K é chamado de constante de parâmetros fundamentais pois, devido à sua dependência de energia de excitação, envolve outras grandezas físicas as quais são representadas na equação 4:

$$
\mathbf{K}=\tau \cdot \mathbf{w} \cdot\left(\mathbf{1}-\frac{\mathbf{1}}{\mathbf{j}}\right) \cdot \mathbf{x}
$$

sendo $\tau$ o coeficiente de absorção mássico para o efeito fotoelétrico do elemento de interesse na energia de excitação, w é o rendimento da fluorescência na camada $K$, j é a razão de salto quântico do elétron (camada $L$ para a K) e $\mathbf{x}$ é a fração de fótons $\mathrm{Ka}$ característicos emitidos em relação à todos os fótons emitidos da camada $\mathrm{K}$. 
Uma vez determinada a sensibilidade elementar S (equação 1) para o elemento de interesse, com o uso de amostras-padrão, é então possível determinar a concentração dos c elementos presentes na amostra (considerada fina) em unidades de massa do elemento de interesse por unidade de área da amostra. Determinada essa concentração, conhecendo a vazão de ar num tempo determinado de coleta de amostra (ar sofre sucção pela bomba de vácuo para o particulado atmosférico ser depositado no filtro) e a área de deposição de amostra, pode-se obter a concentração do elemento de interesse na amostra em unidades de massa do elemento de interesse por unidade de volume de ar succionado, fazendo uso da equação 5:

$$
C=c \cdot A /\left(Q_{\mathrm{ar}} \cdot \mathbf{t}\right)
$$

onde C é a concentração de particulado atmosférico no ar em unidades de massa do elemento de interesse por unidade de volume de $\operatorname{ar}\left(\mu \mathrm{g}_{\mathrm{e}} / \mathrm{m}_{\mathrm{ar}}{ }^{3}\right), \mathbf{A}$ é a área de deposição do material particulado no filtro $\left(\mathrm{cm}^{2}\right), \mathbf{Q}_{\mathrm{ar}}$ é a vazão de ar succionado ( $\mathrm{m}^{3} /$ hora), e $\mathbf{t}$ o tempo de sucção de ar (h) ou de coleta de aerossol para aquela amostra.

\section{2- Sensibilidade analítica elementar}

Para a caracterização do sistema excitação-detecção, é necessário determinar a sensibilidade do espectrômetro para cada elemento com a utilização da equação 1. Para isso, faz-se uso de amostras finas certificadas (de concentrações c conhecidas), as quais são irradiadas, na mesma geometria utilizada na irradiação das amostras, para a determinação da 
intensidade dos raios $\mathrm{X}$ característicos $\mathbf{I}$ elementares, possibilitando a estimativa de uma equação de correlações entre a sensibilidade analítica $\mathbf{S}$ e o número atômico $\mathbf{Z}$ e assim, com a equação obtida pela curva do gráfico, determinar a sensibilidade para elementos contidos e não contidos nas amostras-padrão certificadas.

\section{3- Limite de detecção}

Durante a análise dos espectros de pulsos de raios $X$, visualiza-se sob os picos uma linha aproximadamente contínua que delimita uma área que é devida em parte à intensidade dos raios $\mathrm{X}$ característicos (denominada intensidade líquida) de um determinado elemento de interesse i e em parte ao continuum ou background $\mathbf{B G}$ na região desse elemento $\mathbf{i}$.

O limite de detecção LD para cada elemento tem proporção direta à intensidade do BG sob o pico desse elemento e inversa à sensibilidade elementar analítica $\mathbf{S}$ de acordo com a equação proposta por Grieken e Markowics, 2002. Esta equação, associada à razão entre a área da amostra $\mathbf{A}$ e o volume $\mathbf{V}$ succionado de ar para esta amostra, fornece o limite de detecção em $\mu \mathrm{g} / \mathrm{m}^{3}$ (equação 6):

$$
L D=\frac{3}{S} \frac{\sqrt{B G}}{t} \frac{A}{V}
$$

onde t é o tempo de excitação-detecção da amostra. 
Uma observação muito importante a respeito do limite de detecção é que para os elementos de número atômico abaixo de 13 (Al), ele afetado num caso de baixo rendimento de fluorescência. Existem também outras ocorrências bem conhecidas que interferem no limite de detecção em energia dispersiva, como baixo valor para o efeito fotoelétrico e a absorção dos raios $\mathrm{X}$ característicos pela janela de berílio e pelo ar entre a amostra e o detector. 


\section{4- MATERIAIS E MÉTODOS}

As amostras de aerossóis foram coletadas, utilizando um amostrador rotativo, durante todo o processo de fundição de metais (bronze, ferro e alumínio) no mesmo local onde essa atividade ocorre. Em seguida essas amostras são levadas para análise por EDXRF utilizando de uma fenda para colimar os feixes de raios $\mathrm{X}$, devido a pequena área das amostras de aerossóis.

\section{1- Local de amostragem}

A coleta das amostras foi realizada no interior de uma pequena indústria de fundição de bronze, ferro e alumínio situada na cidade de Piracicaba-SP. Os processos de fundição são realizados nessa indústria em dias e/ou períodos diferentes para cada metal, isto é, não se faz processos de fundição simultâneos de dois ou mais metais, mas sim de um metal por vez.

A cidade de Piracicaba está situada em uma das regiões mais industrializadas e produtivas do Estado de São Paulo e possui mais de 5 mil indústrias, tendo grande potencial metalúrgico e mecânico, bem como em 
outras áreas de produção industrial como o setor petroquímico, têxtil, alimentício, etc. (http://www.ciagri.usp.br/piracica/econ p.htm, acessado em 03/dez/2008).

\section{2- Composição da matéria prima}

A matéria-prima utilizada na fundição de bronze, de acordo com o fornecedor, tem a seguinte composição: 84 a $86 \%$ de Cu, 4,3 a 6,0\% de Sn, 4 a $6 \%$ de $\mathrm{Pb}, 4$ a $6 \%$ de $\mathrm{Zn}, 0,25 \%$ no máximo de $\mathrm{Fe}, 0,80 \%$ no máximo de $\mathrm{Ni}$, 0,05\% de Al e traços de Mn.

No caso da fundição de ferro, os lingotes, utilizados como matéria-prima contém, segundo o fabricante, $2,16 \%$ de $\mathrm{Si}, 0,078 \%$ de $\mathrm{Mn}$, $0,07 \%$ de $\mathrm{P}, \quad 0,014 \%$ de S e $4,06 \%$ de $\mathrm{C}$, sendo Fe o restante.

Já, na fundição de alumínio, a composição é bastante variada, pois são fundidas de uma só vez, peças de alumínio de diferentes origens. São peças (sucatas) de médio e grande porte que empresas solicitantes do serviço fornecem para a indústria executar a fundição e finalizar o produto.

\section{3- Amostrador rotativo de particulado atmosférico}

O coletor de aerossóis, tipo amostrador rotativo, adquirido pelo LIN do CENA/USP juntamente com filtros de membrana de éster de celulose, medidor de vazão de ar, foi colocado na referida localidade durante o período de 8 horas, 5 horas, e 4 horas, referentes aos processos de fundição (fusão e moldagem da matéria-prima) de bronze, ferro e alumínio, respectivamente. Essa diferença de tempo de coleta deve-se ao fato do processo de fundição ser 
feito em diferentes tempos para cada metal e também devido à quantidade de material a fundir.

O amostrador rotativo de aerossóis foi instalado no local de fundição a 15 metros do local da fusão da matéria prima e moldagem e a uma altura de $3 \mathrm{~m}$ do solo, necessária para que não haja riscos de obstrução do canal por onde entra o ar no amostrador como poeira, areia, que podem ser pulverizadas enquanto os funcionários trabalham no local. Foi associado à uma bomba de vácuo, medidor de vazão e medidor de volume (Figura 4.1) e programado para rotacionar o filtro e o impactador a cada 20 minutos Deste modo pôde ser feita a coleta de amostras de aerossóis durante todo o período de exposição dos trabalhadores às atividades durante os processos de fusão e moldagem de ferro, bronze e alumínio. Este procedimento foi repetido por duas vezes em cada tipo de fundição.

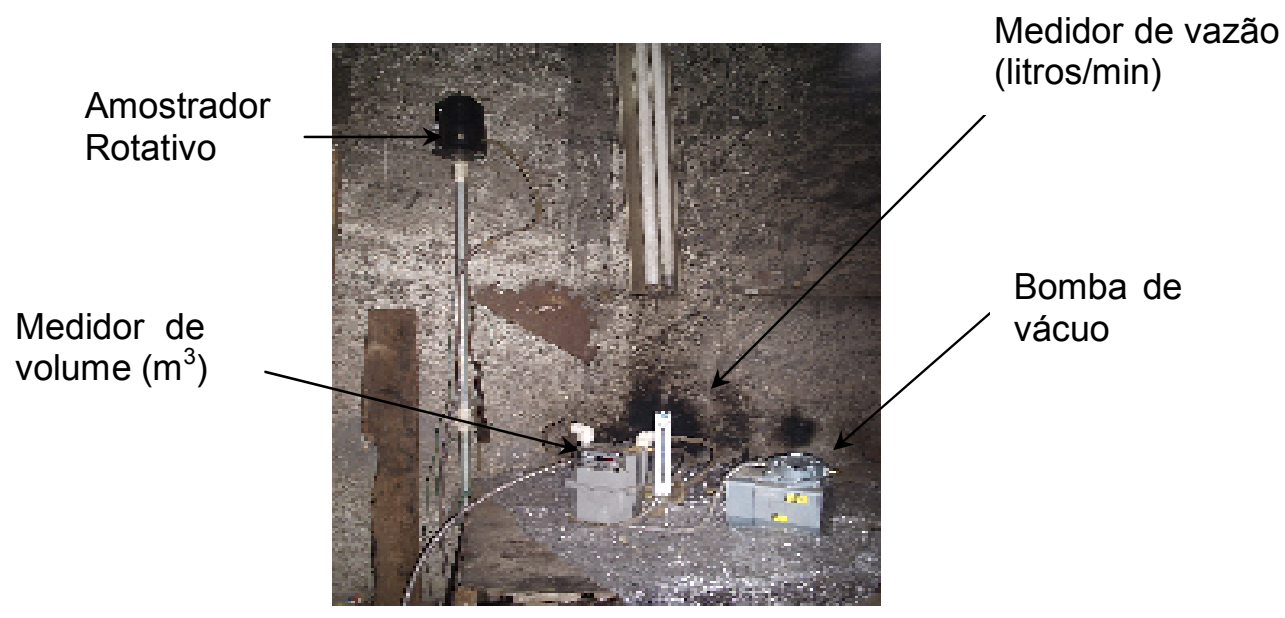

Figura 4.1: Amostrador rotativo de aerossóis (streaker air-particulate sampler) com o medidor de volume, medidor de vazão e a bomba de vácuo succionando o ar, possibilitando o depósito do particulado grosso e fino no impactador e no filtro, respectivamente, ambos sofrendo rotação devido ao motor de passo do amostrador. 
Este amostrador, fabricado pela PIXE International Corporation (streaker air-particulate sampler, modelo S2P no valor aproximadamente de US\$ 5,000.00), é capaz de coletar de modo automatizado o material particulado atmosférico em intervalos de tempo pré-definidos de 1 segundo a 99 horas, separando as partículas por tamanho (fina: $\mathrm{MP}_{2,5}$ e grossa: $\mathrm{MP}_{10-2,5}$ ). No presente trabalho utilizou-se um tempo de 20 minutos para cada coleta.

$$
\text { O impactador (Figura 4.2-a) e o filtro (Figura 4.2-b) de }
$$
aerossóis utilizados no amostrador rotativo têm diâmetros iguais a $82 \mathrm{~mm}$, e suas especificações são SF-1N4 (U\$35.00) - suporte de amostra com filtro de 0,4 $\mu \mathrm{m}$ de diâmetro de poro (Nuclepore - PCTE) para coleta de particulado fino e para a coleta de particulado grosso, SF-1K (U\$35.00) - suporte de amostra coberto com uma fina camada de um fluido adesivo, respectivamente. $O$ particulado grosso fica depositado por impacto no impactador que contém o fluido adesivo, enquanto que o particulado fino segue pelo orifício central do impactador chegando no filtro para particulado fino, onde é finalmente retido (Figura 4.3). 


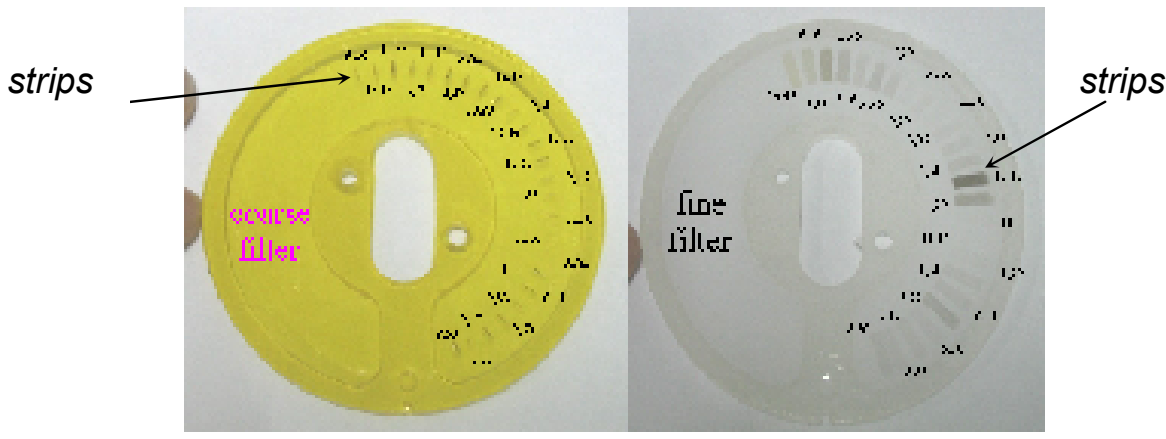

(a)

(b)

Figura 4.2: (a) Impactador para coleta de particulado grosso (SF-1K); (b) filtro para coleta de particulado fino (SF-1N4) utilizados no amostrador rotativo.

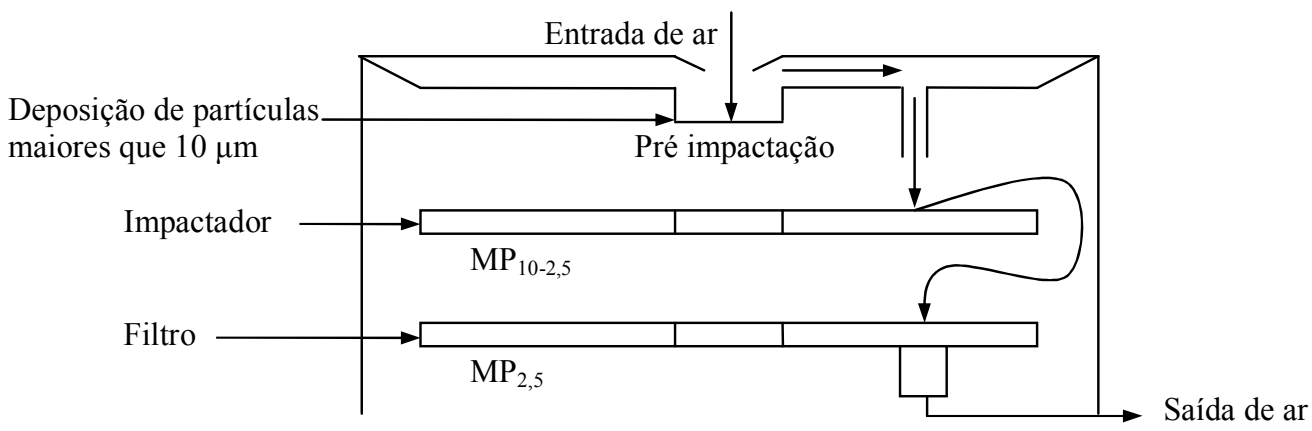

Figura 4.3: Esquema do impactador e filtro quando recebem o particulado atmosférico grosso $\left(\mathrm{MP}_{10-2,5}\right)$ e fino $\left(\mathrm{MP}_{2,5}\right)$, respectivamente.

No momento da sucção de ar, o particulado com diâmetro maior que $10 \mu \mathrm{m}$ sofre uma pré-impactação ficando retido na entrada do amostrador, possibilitando a separação das partículas em fração grossa $\left(\mathrm{MP}_{10-2,5}\right)$ retida no impactador, e fração fina $\left(\mathrm{MP}_{2,5}\right)$ que continuará em fluxo até ficar retida no filtro. Tanto impactador como o filtro são rotacionados no interior do amostrador. A principal vantagem que esse tipo de amostrador apresenta é a possibilidade de uma análise temporal, podendo-se fazer uma programação de cada coleta por um tempo conveniente, utilizando-se o mesmo 
filtro e impactador para várias amostras. A Figura 4.4 ilustra as dimensões das faixas das amostras (strips) dos particulados fino no filtro e grosso no impactador.

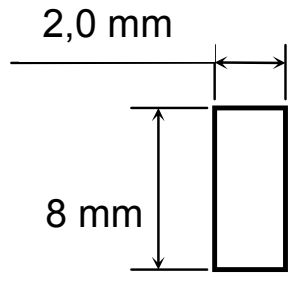

(a)

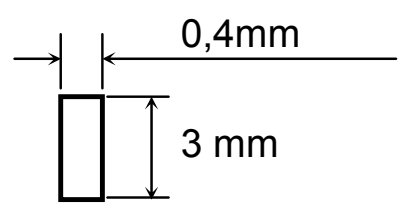

(b)

Figura 4.4: Ilustração das faixas (strips) de amostras de particulado (a) fino e (b) grosso com suas respectivas dimensões.

\section{4- Excitação das amostras por meio de EDXRF com fenda colimadora}

No Laboratório de Instrumentação Nuclear (LIN) do Centro de Energia Nuclear na Agricultura (CENA) da Universidade de São Paulo (USP) foi desenvolvido um colimador de feixe de raios $X$, que consta de um corpo de bronze com uma fenda retangular de $5 \mathrm{~mm}$ de comprimento por 0,5 $\mathrm{mm}$ de largura, tornando possível a irradiação das faixas (strips) de MPS no filtro e no impactador, pois a área das amostras de particulado depositado em ambos é muito pequena, da ordem de $10 \mathrm{~mm}^{2}$ e com formato retangular. Colocada a fenda (direção vertical) na saída do feixe de raios $X$ do tubo, e posicionando o filtro numa geometria conveniente, foi possível irradiar as amostras de MPS contidas nesse filtro, as quais foram coletadas por um amostrador rotativo (streaker air-particulate sampler - modelo S2P) (D'ALESSANDRO et al., 2004; PRATI et al., 1998; HOLYNSKA, 1995; PIXE Int. Co., 2008). Este amostrador rotaciona os filtros em intervalos definidos de tempo para a amostragem, isto é, 
programa-se a periodicidade de passo (step) do filtro durante a sucção de ar para a coleta de aerossol.

A parte analítica do trabalho foi desenvolvida no Laboratório de Instrumentação Nuclear (LIN) do CENA/USP, onde se tem disponível toda a instrumentação necessária para a excitação das amostras e produção dos raios $\mathrm{X}$ característicos utilizando EDXRF com fenda colimadora.

A excitação dos elementos químicos contidos nas amostras foi feita com a utilização de um tubo de raios $X$ (marca Philips, modelo PW 2215/20) com alvo de Mo utilizando filtro $\mathrm{Zr}$, acoplado a um gerador de alta tensão (marca Philips, modelo PW 1830), operando com tensão de $30 \mathrm{kV}$ e corrente $30 \mathrm{~mA}$. Na detecção dos raios $X$ característicos foi utilizado um detector semicondutor de $\mathrm{Si}(\mathrm{Li})$ de alta resolução para raios $\mathrm{X}$ (marca ORTEC, modelo SLP 06165-P), com janela de Be, área ativa $30 \mathrm{~mm}^{2}$ e $165 \mathrm{eV}$ de resolução, acoplado a módulos eletrônicos de polarização, amplificadores, placa analisadora multicanal e computador, ambos da marca ORTEC.

Como a área de deposição do particulado nos filtros é pequena, necessitou-se da utilização desse colimador metálico de feixes de raios $X$ que, apesar de ter provocado uma redução na intensidade do feixe incidente, tem a grande vantagem do custo desprezível $(R \$ 100,00)$ em relação aos capilares de quartzo (US\$10,000.00 - 25,000.00). O colimador de bronze (revestido com prata metálica) para o feixe de raios $\mathrm{X}$ vindos do tubo, tem as seguintes dimensões: $72 \mathrm{~mm}$ de comprimento, $10 \mathrm{~mm}$ de diâmetro de entrada e fenda retangular de $5 \times 0,5 \mathrm{~mm}$ na saída (Figura 4.5). 


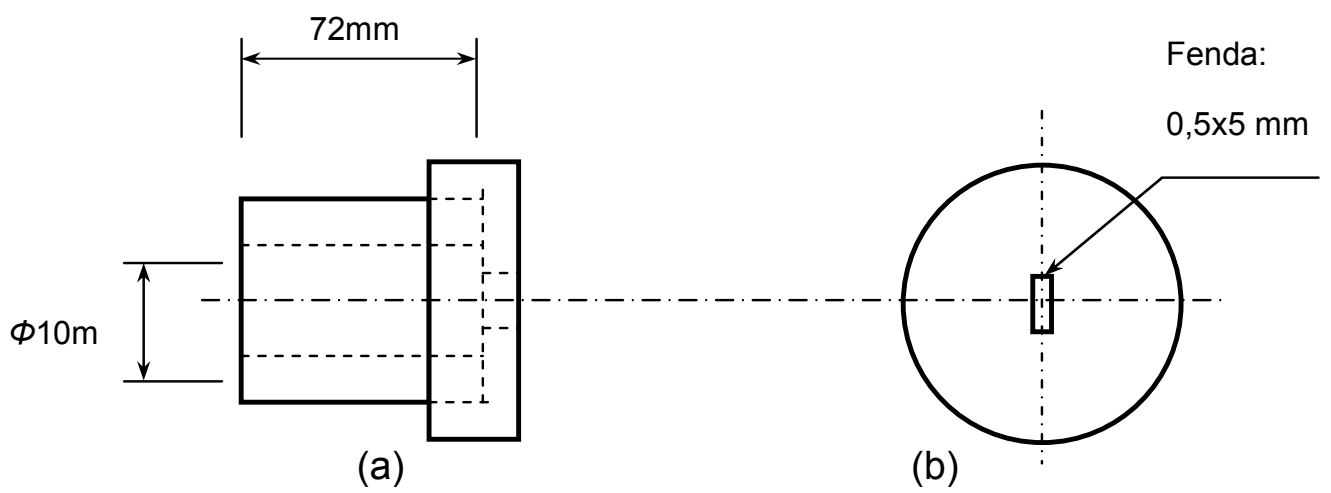

Figura 4.5: Esquema da fenda colimadora de raios $X$ em duas vistas: (a) vista lateral (detalhes internos em tracejado) e (b) vista frontal.

Os raios $X$ que saem do tubo passam pela fenda onde são colimados e em seguida atingem a amostra, a qual será excitada e, em conseqüência disto, os elementos nela presentes emitirão raios $X$ característicos que serão detectados num detector semicondutor de $\mathrm{Si}(\mathrm{Li})$ (Figura 4.6).

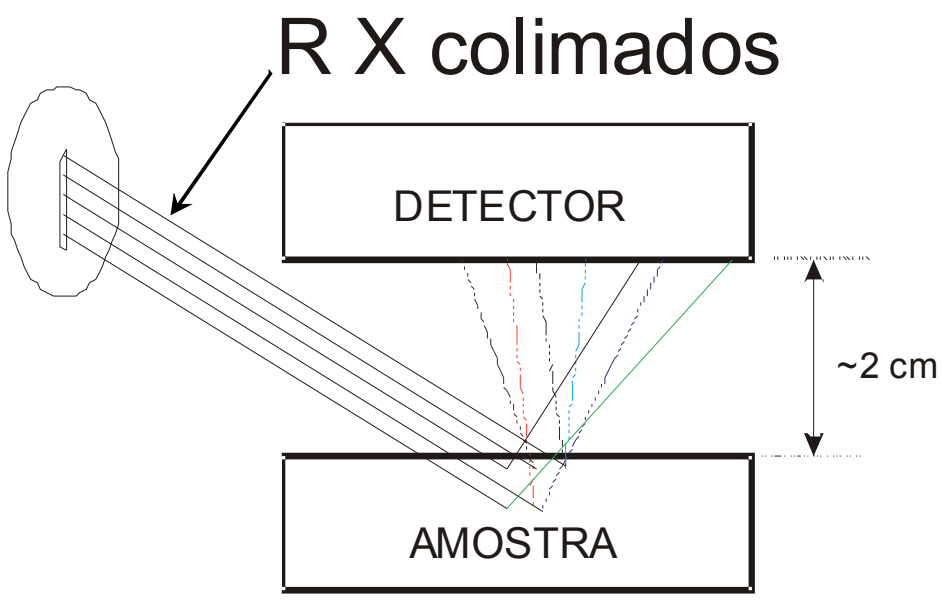

Figura 4.6: Geometria da excitação-detecção: os raios X produzidos no tubo são colimados na fenda $e$ incidem na amostra; os raios $X$ característicos dos elementos presentes são detectados no detector. 
Após a coleta do particulado atmosférico do referido local com o amostrador, desacoplou-se o filtro e o impactador (Figura 4.7-a) de seu interior colocando-os em seguida no suporte de acrílico já acoplado no detector (Figura 4.7-b). Estando pronta a geometria excitação-detecção, pôde-se então irradiar as amostras do filtro e do impactador, girando-os no suporte após cada medida. Isso possibilitou a medida da intensidade dos raios $\mathrm{X}$ característicos para posterior determinação da concentração dos elementos presentes na atmosfera da fundição em cada intervalo de tempo.

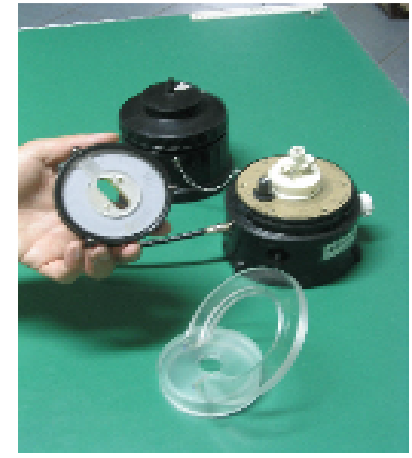

(a)

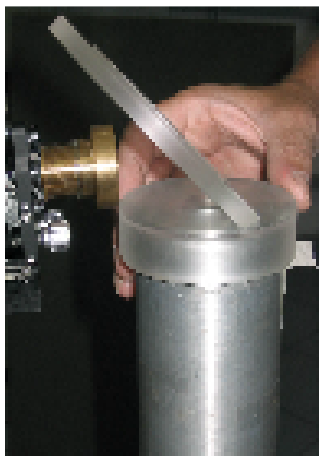

(b)

Figura 4.7: a) Amostrador rotativo desmontado após a coleta de aerossóis, ao lado o suporte de acrílico para o filtro utilizado durante a análise da amostra por EDXRF; b) Filtro no suporte contendo amostra a ser analisada por fluorescência de raios $X$ colimados pela fenda de bronze.

A excitação/detecção foi feita ao ar e, sendo assim, foi possível quantificar do elemento $\mathrm{K}$ em diante. As amostras foram guardadas para serem posteriormente analisadas sob vácuo, de modo que se possa quantificar do elemento $\mathrm{Al}$ ao $\mathrm{Ca}$ com tensão de $10 \mathrm{kV}$ e filtro de Fe. 


\section{5- Interpretação dos espectros de raios $X$}

A interpretação dos espectros de raios $X$ foi feita com a utilização do programa aplicativo AXIL (ESPEN et al., 1977), desenvolvido na Universidade de Antuérpia, Bélgica. Este software possibilita a determinação das intensidades dos raios $\mathrm{X}$ característicos $\mathbf{I}$ emitidos dos elementos da amostra após ter sido irradiada convenientemente.

Como ilustração, a Figura 4.7 mostra os espectros com picos de concentração de elementos presentes em MPS fino e grosso.
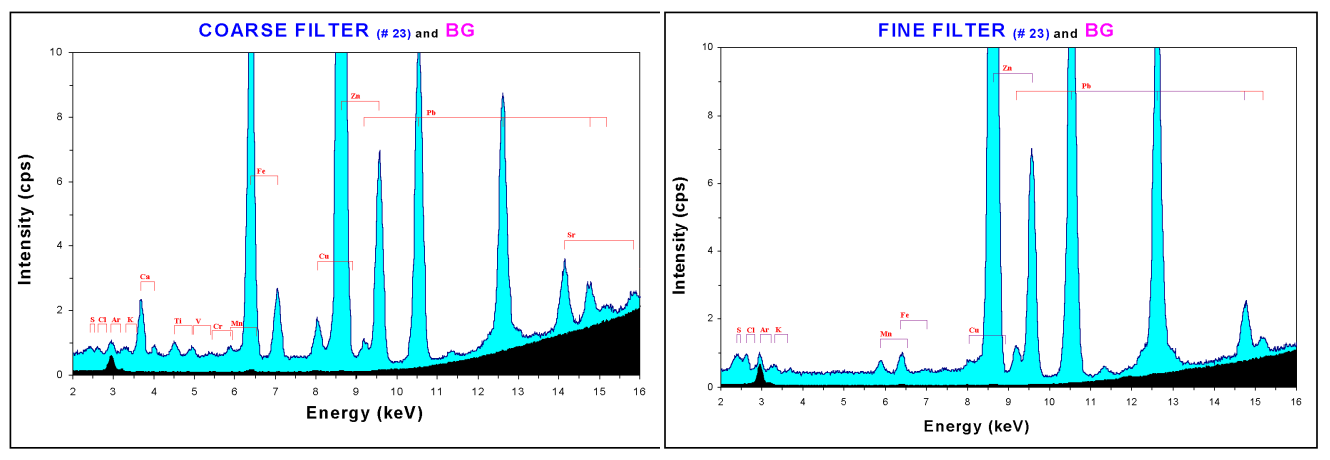

Figura 4.8: Ilustração dos espectros de raios $X$ - picos de concentração de elementos presentes no particulado atmosférico (a) fino- $\mathrm{MP}_{2,5} \mathrm{e}$ (b) grosso-MP $10-2,5$.

\section{6- Caracterização do sistema excitação-detecção}

A caracterização do sistema excitação-detecção foi feita por meio da análise de amostras-padrão certificados (de concentração conhecida) produzidos pela MicroMatter/USA, possibilitando a determinação, das sensibilidades analíticas e dos limites de detecção elementares. 
Com a medida das intensidades dos raios $\mathrm{X}$ das amostraspadrão e concentrações elementares, calculou-se a sensibilidade analítica $\mathbf{S}$ do espectrômetro para cada elemento utilizando a equação 1. Em seqüência, estimou-se a correlação da sensibilidade analítica em função do número atômico, e com ela possível determinar a sensibilidade analítica para elementos dos quais não se tem padrões certificados. Após a determinação da sensibilidade analítica elementar e das áreas sob os picos característicos de uma amostra testemunha (continuum), os limites de detecção do equipamento para os elementos de interesse foram calculados.

Assim, encontrados os parâmetros para análise das amostras de aerossóis, determinou-se a concentração temporal dos elementos nos particulados fino e grosso da atmosfera local durante as fundições de bronze, ferro e alumínio, bem como o momento mais crítico destas atividades.

\section{7- Microscopia eletrônica}

Com a intenção de analisar a morfologia do particulado atmosférico, cuja informação é de grande interesse e importância neste trabalho, fez-se a caracterização morfológica das partículas (particulado grosso e fino) contidas no impactador e no filtro utilizando de um microscópio eletrônico de varredura (JEOL, modelo JSN 5600LV) acoplado a um sistema de micro-análise por raios $\mathrm{X}$ por espectroscopia de energia dispersiva (NORAN, modelo Voyager). Este equipamento está instalado no Núcleo de Pesquisas em Geoquímica e Geofísica da Litosfera da Universidade de São Paulo (NUPEGEL/USP - campus Luiz de Queiroz, Piracicaba-SP). 


\section{5 - RESULTADOS E DISCUSSÃO}

\section{1- Morfologia do MPS}

As informações obtidas a respeito da morfologia do particulado atmosférico coletado durante o processo de fundição, tanto do particulado fino como do grosso foram obtidas por meio da utilização do microscópio eletrônico de varredura acoplado a um sistema de análises por fluorescência de raios X (SEM/EDS) para análise. O impactador e o filtro, com as amostras de particulado fino e grosso, foram recortados em dimensões adequadas para poder acomodá-las no equipamento de microscopia.

\subsection{1- Particulado fino}

A Figura 5.1, com escala de $10 \mu \mathrm{m}$, foi obtida a partir da amostra do filtro de particulado fino onde procura se destacar a distribuição do particulado mais ao fundo em contraste a algumas partículas maiores retidas na superfície. Na Figura 5.2, com maior aumento (escala $1 \mu \mathrm{m}$ ), observa-se o estado de aglomeração do particulado em região da figura 
anterior. Atenta-se ao fato de que o nível de compactação é tal que até mesmo os orifícios do filtro não podem mais ser observados

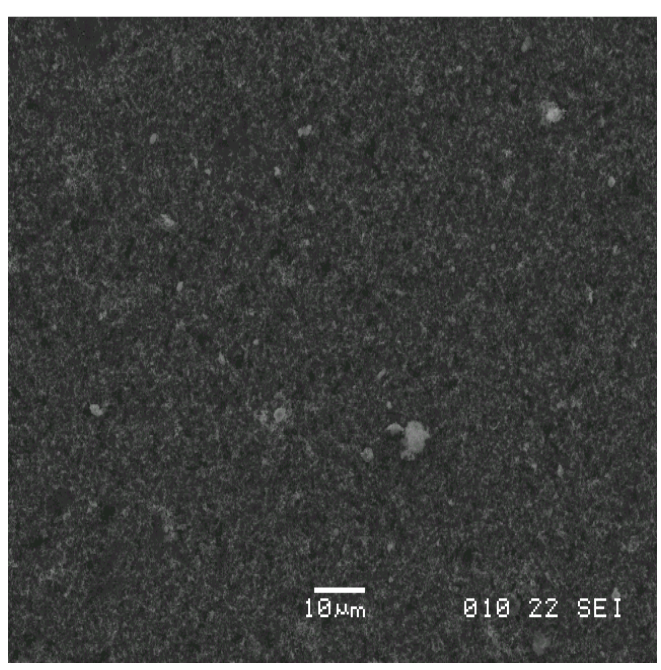

Figura 5.1: Imagem obtida com microscópio eletrônico de varredura em modo elétrons secundários - particulado fino.

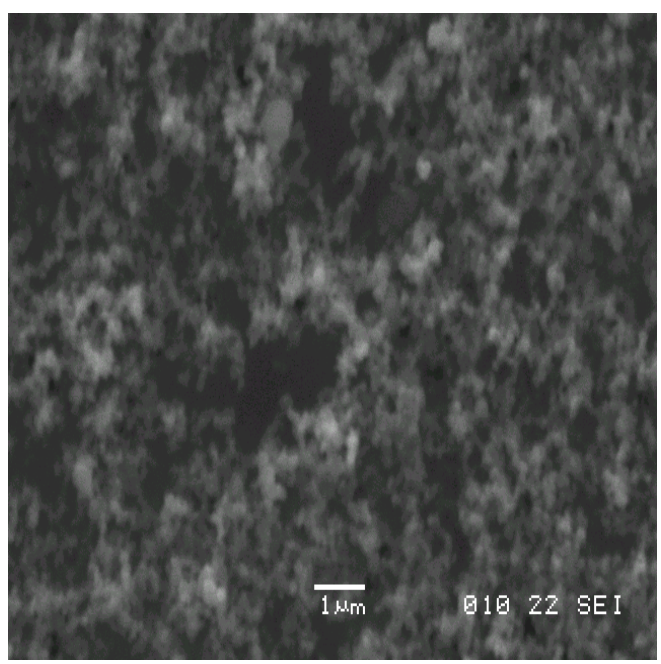

Figura 5.2: Imagem obtida com microscópio eletrônico de varredura em modo elétrons secundários - particulado fino.

A Figura 5.3 (escala de $10 \mu \mathrm{m}$ ) destaca na parte inferior alguns precipitados finos, indicando formas aleatórias esferoidais, aciculares e 
placosas numa clara evidência de heterogeneidade na formação dessas partículas. A figura 5.4 apresenta um fragmento depositado sobre a superfície do filtro recoberta por particulado fino. Embora o comprimento do fragmento seja maior do que $10 \mu \mathrm{m}$, uma melhor observação indica a sobreposição de partículas finas na forma de placas demonstrando a forma prismática das partículas sobrepostas.

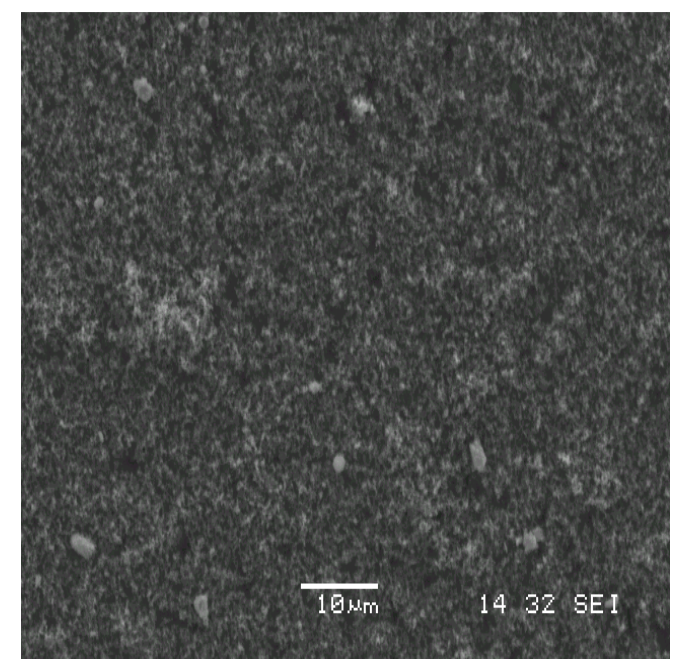

Figura 5.3: Imagem obtida com microscópio eletrônico de varredura em modo elétrons secundários - particulado fino. 


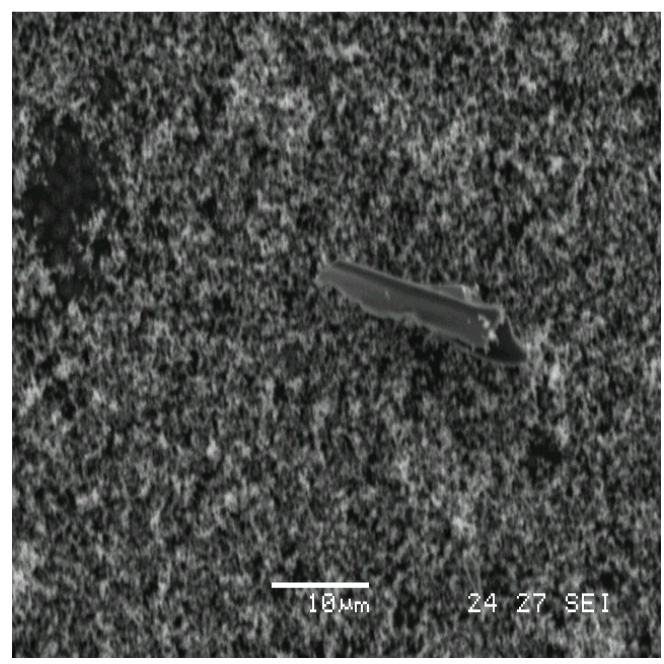

Figura 5.4: Imagem obtida com microscópio eletrônico de varredura em modo elétrons secundários - particulado fino.

\subsection{2- Particulado grosso}

A Figura 5.5 (escala $10 \mu \mathrm{m}$ ) foi obtida a partir do impactador, utilizado para captação de particulado grosso, onde se observa a distribuição heterogênea quanto à forma dos precipitados. São evidentes as formas equiaxiais, aciculares e pseudo-esféricas resultando em distribuição multiforme. A Figura 5.6 (escala $2 \mu \mathrm{m}$ ) apresenta em maior aumento uma partícula observada no centro da figura anterior. Observa-se a partícula com uma das dimensões lineares de aproximadamente $2 \mu \mathrm{m}$, indicando sua forma prismática. As demais partículas na figura corroboram a observação das diferentes formas nas quais se apresentam. 


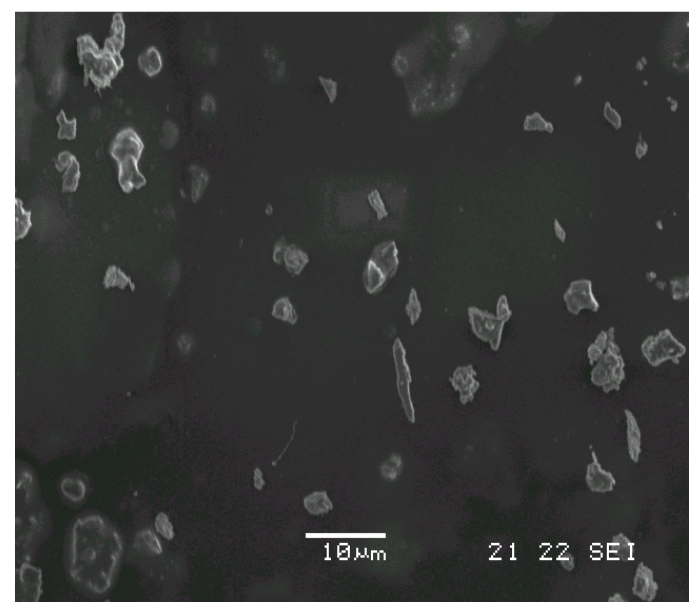

Figura 5.5: Imagem obtida com microscópio eletrônico de varredura em modo elétrons secundários - particulado grosso.

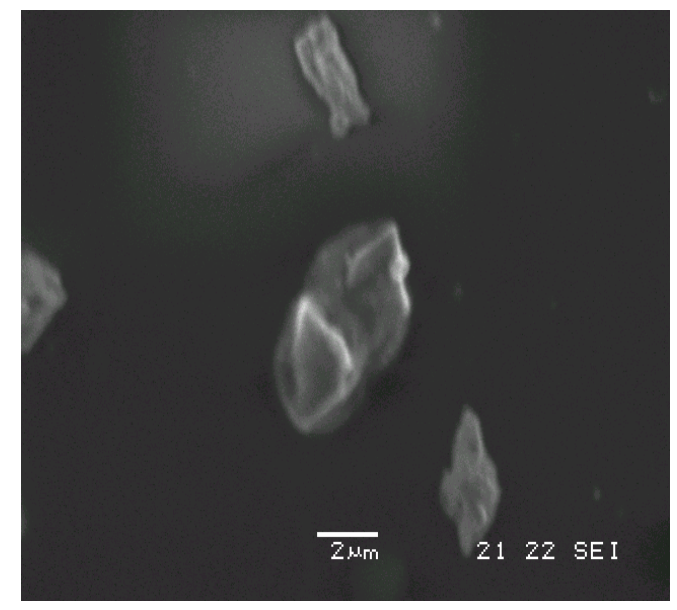

Figura 5.6: Imagem obtida com microscópio eletrônico de varredura em modo elétrons secundários - particulado grosso.

A Figura 5.7 apresenta uma das partículas em maior aumento (escala $1 \mu \mathrm{m}$ ) onde pode ser observado o caráter planar e placoso com incrustração de partículas menores na superfície. A partícula na Figura 5.8 (escala $1 \mu \mathrm{m}$ ) é um evidente exemplo de partícula na forma de agregados bem comum constatado nas análises. 


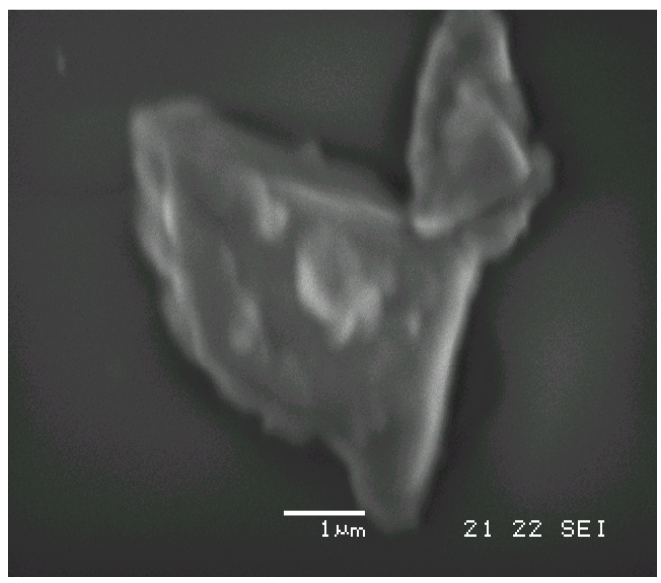

Figura 5.7: Imagem obtida com microscópio eletrônico de varredura em modo elétrons secundários - particulado grosso.

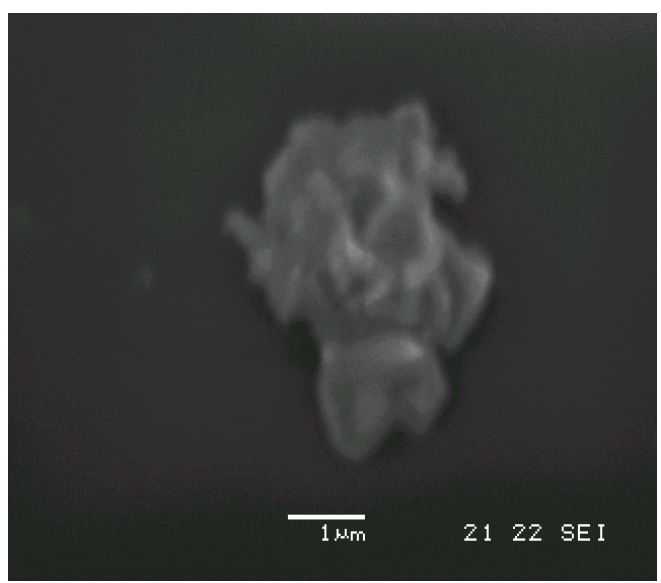

Figura 5.8: Imagem obtida com microscópio eletrônico de varredura em modo elétrons secundários - particulado grosso.

\section{2- Sensibilidade analítica elementar e limite de detecção}

Para avaliar a confiabilidade do sistema excitação-detecção a qual viabiliza a análise das amostras, levantou-se a curva da sensibilidade analítica elementar do espectrômetro para a geometria excitação-detecção utilizada na análise das amostras coletadas durante a fundição de bronze (Figura 5.9), de ferro (figura 5.10) e de alumínio (figura 5.11) utilizando os 
padrões (filmes de $\mathrm{Cl}, \mathrm{K}, \mathrm{Ca}, \mathrm{Sc}, \mathrm{Ti}, \mathrm{Mn}, \mathrm{Fe}, \mathrm{Cu}$ e $\mathrm{Zn}$ ) certificados, produzidos pela MicroMatter. Desta forma foi possível estimar a sensibilidade do espectrômetro para os outros elementos os quais não se possui padrão, como o $\mathrm{Cr}$ e Ni. Esse procedimento foi realizado para a amostragem de cada fundição, pois o equipamento precisou ser utilizado para outros fins durante as coletas/análises das amostras de particulado referentes a este trabalho. Decorrente a isso, ocorreu alteração da geometria excitação-detecção e, conseqüentemente, a sensibilidade elementar e o limite de detecção do equipamento também são alterados.

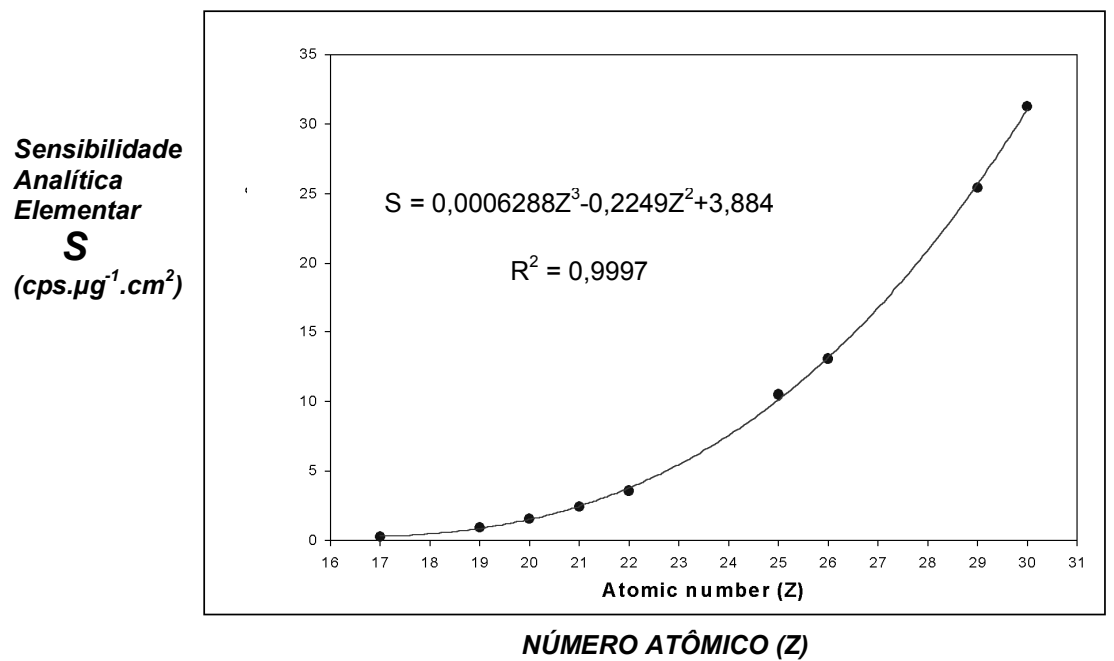

Figura 5.9: Sensibilidade elementar "S" vs. $n^{\circ}$ atômico "Z" para os raios X-Ka obtidos com os padrões mono-elementares da MicroMatter/USA fundição de bronze. 


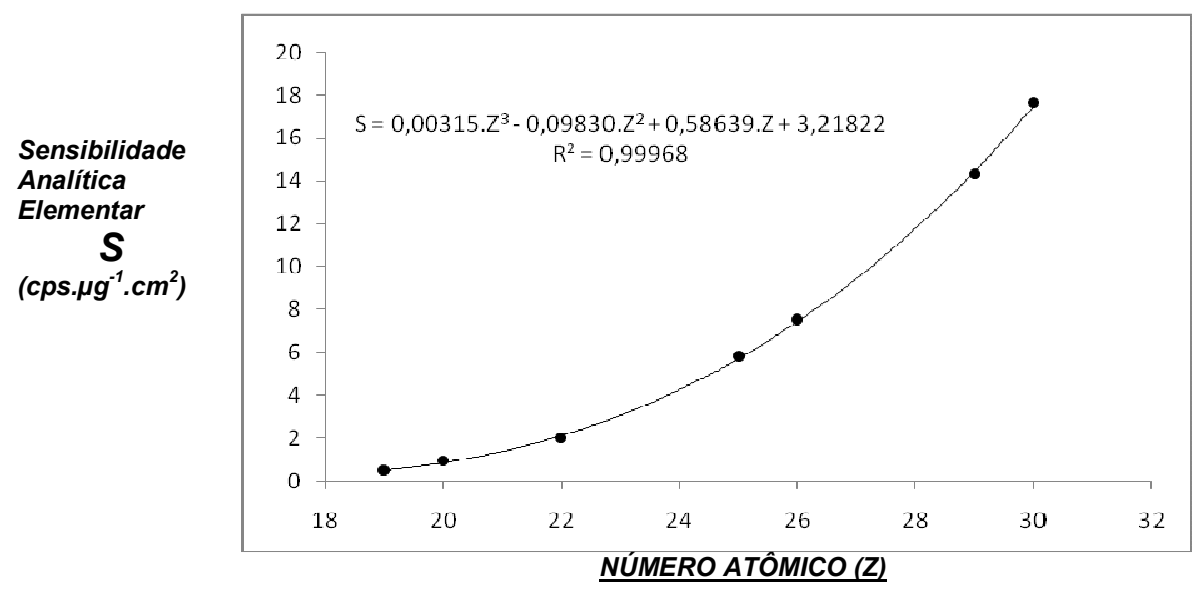

Figura 5.10: Sensibilidade elementar "S" vs. $\mathrm{n}^{\circ}$ atômico "Z" para os raios X-Ka obtidos com os padrões mono-elementares da MicroMatter/USA fundição de ferro.

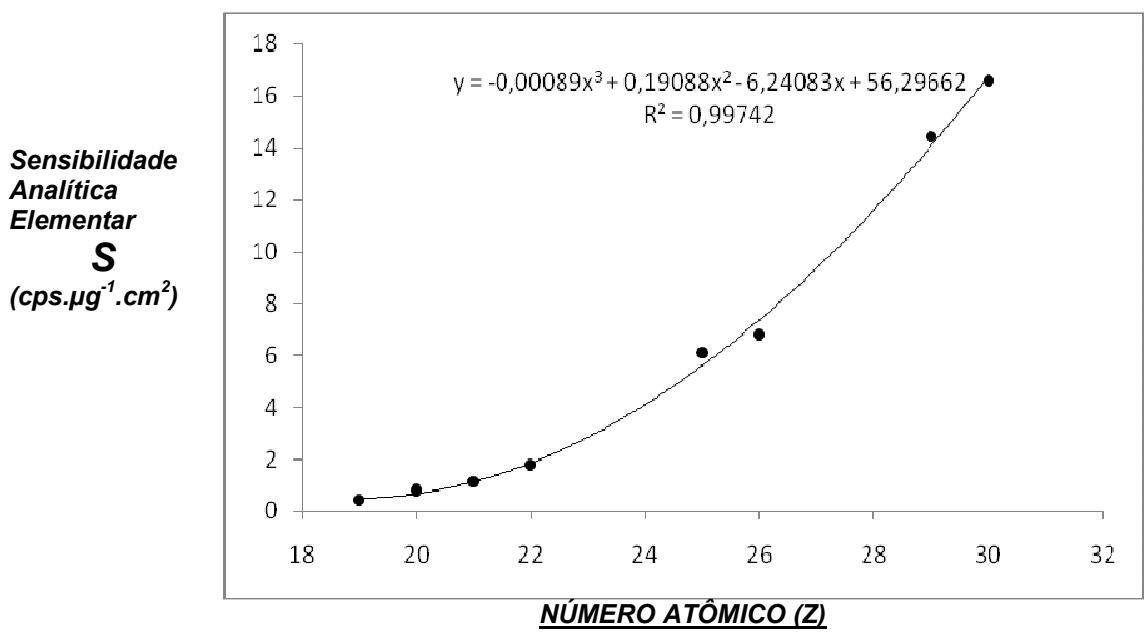

Figura 5.11: Sensibilidade elementar "S" vs. $n^{\circ}$ atômico " $Z$ " para os raios X-Ka obtidos com os padrões mono-elementares da MicroMatter/USA fundição de alumínio.

Com os valores estimados para a sensibilidade analítica dos elementos, foi feito um levantamento do limite de detecção do sistema para cada elemento de interesse contido nas amostras de particulados fino e grosso coletadas durante as fundições, utilizando a equação 6. As Tabelas 5.1, 5.2 e 5.3 mostram esses elementos de interesse e seus respectivos limites de 
detecção (em $\mathrm{ng} / \mathrm{m}^{3}$ ) para as fundições de bronze, ferro e alumínio, respectivamente. Para cada caso, são apresentados valores de limite de detecção para os elementos encontrados nas amostras de aerossóis da respectiva fundição, ou seja, não se encontrou o mesmo número de elementos de interesse no particulado atmosférico nos diferentes processos de fundição.

Tabela 5.1: Limites de detecção para os elementos de interesse presentes nas amostras de particulado fino $\left(\mathrm{MP}_{2,5}\right)$ e grosso $\left(\mathrm{MP}_{10-2,5}\right)$ - fundição de bronze.

\begin{tabular}{|c|c|c|}
\hline & \multicolumn{2}{|c|}{ LIMITE DE DETECÇÃO - LD (ng/ $\mathbf{m}^{\mathbf{3}}$ ) } \\
\hline ELEMENTO & MP $_{\mathbf{2 , 5}}$ & $\mathbf{M P}_{\mathbf{1 0 - 2 , 5}}$ \\
\hline $\mathrm{K}$ & 692,0 & 57,5 \\
\hline $\mathrm{Ca}$ & 382,3 & 32,0 \\
\hline $\mathrm{Ti}$ & 158,0 & 14,0 \\
\hline $\mathrm{V}$ & 115,0 & 9,5 \\
\hline $\mathrm{Cr}$ & 83,5 & 8,2 \\
\hline $\mathrm{Mn}$ & 62,5 & 6,4 \\
\hline $\mathrm{Fe}$ & 44,0 & 3,6 \\
\hline $\mathrm{Ni}$ & 32,0 & 3,4 \\
\hline $\mathrm{Cu}$ & 28,1 & 2,9 \\
\hline $\mathrm{Zn}$ & 23,7 & 2,5 \\
\hline $\mathrm{Pb}$ & 54,1 & 5,8 \\
\hline
\end{tabular}


Tabela 5.2: Limites de detecção para os elementos de interesse presentes nas amostras de particulado fino $\left(\mathrm{MP}_{2,5}\right)$ e grosso $\left(\mathrm{MP}_{10-2,5}\right)$ - fundição de ferro.

\begin{tabular}{|c|c|c|}
\hline & \multicolumn{2}{|c|}{ LIMITE DE DETECÇÃO - LD $\left(\mathbf{n g} / \mathbf{m}^{\mathbf{3}}\right)$} \\
\hline ELEMENTO & MP $_{\mathbf{2 , 5}}$ & $\mathbf{M P}_{\mathbf{1 0}-\mathbf{2}, \mathbf{5}}$ \\
\hline $\mathrm{Ca}$ & 739,0 & 87,0 \\
\hline $\mathrm{Ti}$ & 331,8 & 28,5 \\
\hline $\mathrm{V}$ & 222,6 & 26,3 \\
\hline $\mathrm{Cr}$ & 158,2 & 18,7 \\
\hline $\mathrm{Mn}$ & 120,2 & 13,9 \\
\hline $\mathrm{Fe}$ & 88,4 & 11,1 \\
\hline $\mathrm{Ni}$ & 50,5 & 6,7 \\
\hline $\mathrm{Cu}$ & 44,0 & 5,7 \\
\hline $\mathrm{Zn}$ & 39,1 & 4,9 \\
\hline $\mathrm{Br}$ & 40,2 & 5,2 \\
\hline $\mathrm{Pb}$ & 91,9 & 11,7 \\
\hline
\end{tabular}

Tabela 5.3: Limites de detecção para os elementos de interesse presentes nas amostras de particulado fino $\left(\mathrm{MP}_{2,5}\right)$ e grosso $\left(\mathrm{MP}_{10-2,5}\right)$ - fundição de alumínio.

\begin{tabular}{|c|c|c|}
\hline & \multicolumn{2}{|c|}{ LIMITE DE DETECÇ̃̃O - LD $\left(\mathbf{n g} / \mathbf{m}^{\mathbf{3}}\right)$} \\
\hline ELEMENTO & $\mathbf{M P}_{\mathbf{2}, \mathbf{5}}$ & $\mathbf{M P}_{\mathbf{1 0}-\mathbf{2}, \mathbf{5}}$ \\
\hline $\mathrm{Fe}$ & 143,6 & 15,4 \\
\hline $\mathrm{Cu}$ & 80,5 & 7,3 \\
\hline $\mathrm{Zn}$ & 70,1 & 6,4 \\
\hline
\end{tabular}




\section{3- Amostras-padrão Certificadas}

Para apresentar a validação da metodologia e do equipamento utilizado para a realização deste presente trabalho, irradiou-se e mediu a concentração de elementos presentes em amostras certificadas. Estas amostras certificadas foram produzidas pelo National Institute of Standard and Technology (NIST-USA), cujo código de certificação é SRM 1832 - número de série 227 e SRM 1833 - número de série 1062.

A Tabela 5.4 confronta os valores certificados pelo fabricante da amostra com seus respectivos intervalos de confiança e os valores medidos com a utilização da metodologia descrita.

Tabela 5.4: Concentração dos elementos das amostras certificadas comparadas com os valores medidos com o equipamento utilizado nos experimentos.

\begin{tabular}{|c|c|c|c|c|c|c|c|c|c|}
\hline \multicolumn{5}{|c|}{ SRM 1832 } & \multicolumn{5}{c|}{ SRM 1833 } \\
\hline El. & $\mathbf{Z}$ & $\begin{array}{c}\text { Certif. } \\
\mu \mathrm{g} / \mathrm{cm}^{2}\end{array}$ & $\begin{array}{c}\text { Incert. } \\
\mu \mathrm{g} / \mathrm{cm}^{2}\end{array}$ & $\begin{array}{c}\text { Medido } \\
\mu \mathrm{g} / \mathrm{cm}^{2}\end{array}$ & El. & $\mathbf{Z}$ & $\begin{array}{c}\text { Certif. } \\
\mu \mathrm{g} / \mathrm{cm}^{2}\end{array}$ & $\begin{array}{c}\text { Incert. } \\
\mu \mathrm{g} / \mathrm{cm}^{2}\end{array}$ & $\begin{array}{c}\text { Medido } \\
\mu \mathrm{g} / \mathrm{cm}^{2}\end{array}$ \\
\hline $\mathrm{Ca}$ & 20 & 19,98 & 1,343 & 20,697 & $\mathrm{~K}$ & 19 & 17,4 & 1,18 & 17,07 \\
\hline $\mathrm{V}$ & 23 & 4,53 & 0,504 & 4,268 & $\mathrm{Ti}$ & 22 & 12,9 & 0,78 & 13,19 \\
\hline $\mathrm{Mn}$ & 25 & 4,53 & 0,504 & 4,552 & $\mathrm{Fe}$ & 26 & 14,3 & 1,98 & 15,16 \\
\hline $\mathrm{Co}$ & 27 & 0,99 & 0,067 & 1,010 & $\mathrm{Zn}$ & 30 & 3,8 & 0,79 & 4,18 \\
\hline $\mathrm{Cu}$ & 29 & 2,52 & 0,168 & 2,437 & $\mathrm{~Pb}$ & 82 & 15,9 & 1,97 & 16,79 \\
\hline
\end{tabular}




\section{4- Concentração dos elementos no MPS e momento crítico da fundição}

Durante a análise das amostras referentes aos processos de fundição de bronze, ferro e alumínio, constatou-se que o momento mais crítico dessas atividades foi durante a moldagem, isto é, durante o momento em que o metal fundido é retirado do forno e em seguida é levado até os moldes os quais são preenchidos com esse material.

Como ilustração, a Figura 5.12 mostra picos de concentração de elementos presentes nos aerossóis num determinado momento do processo de fundição - a moldagem (15h:50min - bronze; 17h:00min - ferro; 17h:20min - alumínio). Pode-se observar picos elevados de $\mathrm{Pb}$ durante a fundição de ferro e bronze e de $\mathrm{Zn}$ durante as três fundições (bronze, ferro e alumínio) tanto no $\mathrm{MP}_{2,5}$ como no $\mathrm{MP}_{10-2,5}$. 


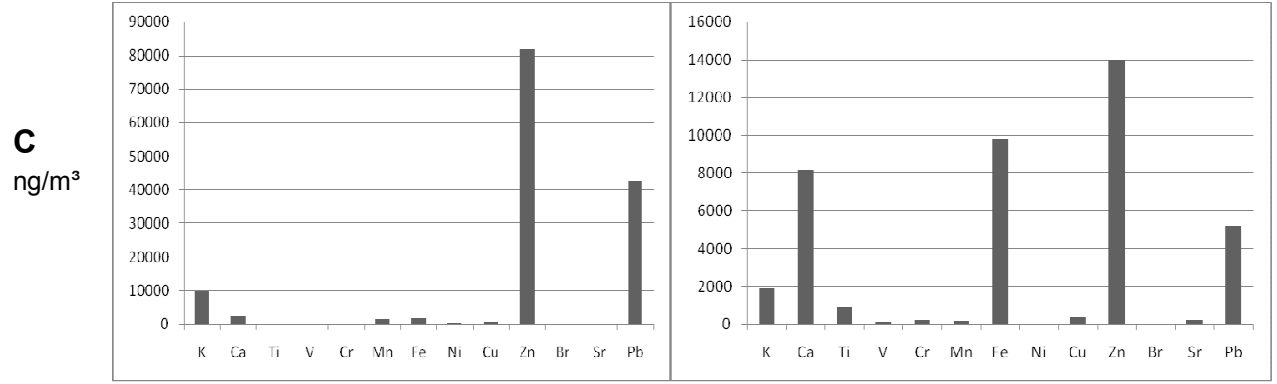

Bronze: Particulado Fino $-\mathrm{MP}_{2,5} \quad$ Particulado Grosso $-\mathrm{MP}_{10-2,5}$

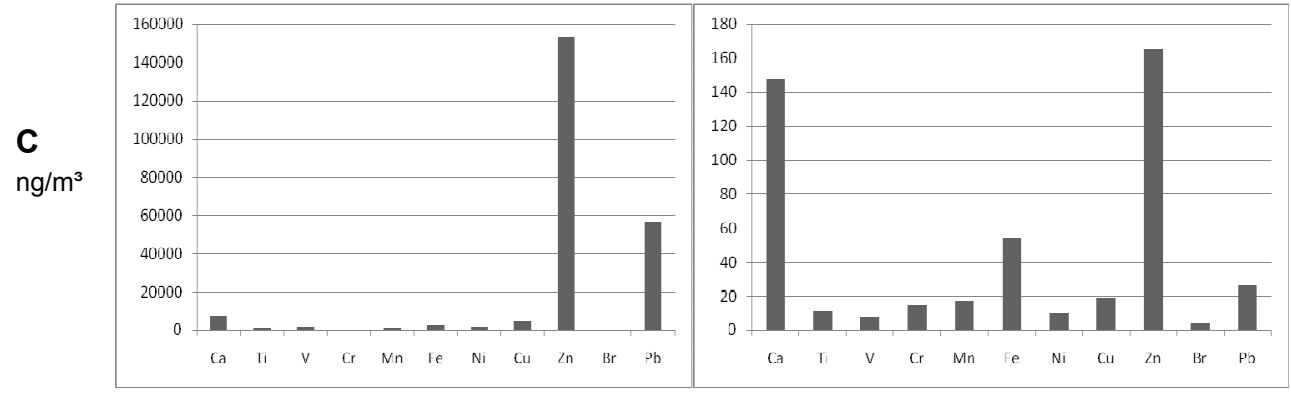

Ferro: $\quad$ Particulado Fino $-\mathrm{MP}_{2,5} \quad$ Particulado Grosso $-\mathrm{MP}_{10-2,5}$

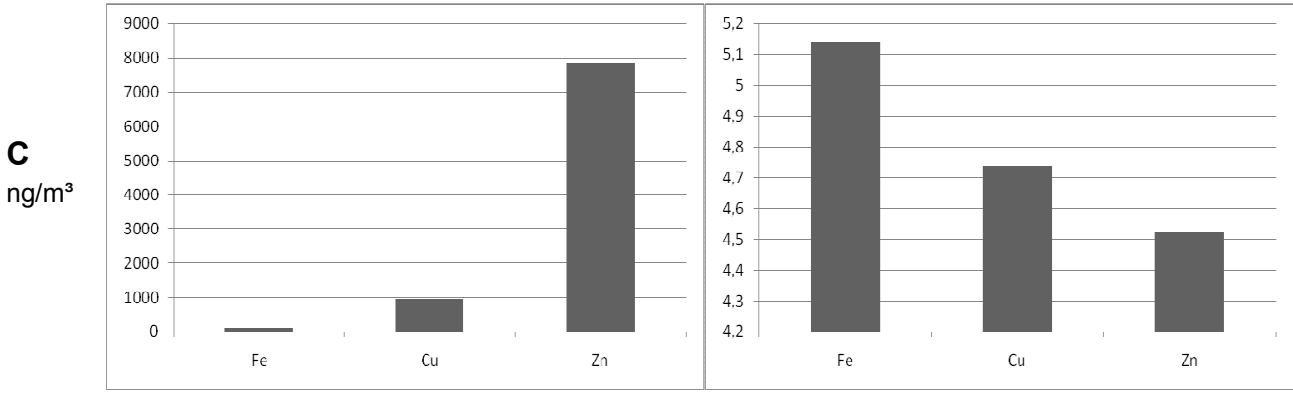

Alumínio: $\quad$ Particulado Fino $-\mathrm{MP}_{2,5} \quad$ Particulado Grosso $-\mathrm{MP}_{10-2,5}$

Figura 5.12: Picos de concentração " $\mathrm{C}$ " em ng/m³ dos elementos presentes no particulado atmosférico fino $\left(\mathrm{MP}_{2,5}\right)$ e grosso $\left(\mathrm{MP}_{10-2,5}\right)$ na rotação do filtro na qual ocorreu a moldagem do bronze, ferro e alumínio. 
As Figuras 5.135 .16 mostram a variação das concentrações dos elementos de interesse em função do tempo em horas, durante o processo de fundição de bronze. Graças ao amostrador rotativo temporal que coletou automaticamente os aerossóis em intervalos de tempo de 20 min durante 8 horas. O processo de fundição do bronze se iniciou às $8 \mathrm{~h}: 30 \mathrm{~min}$ e finalizou às 16h:30min. 

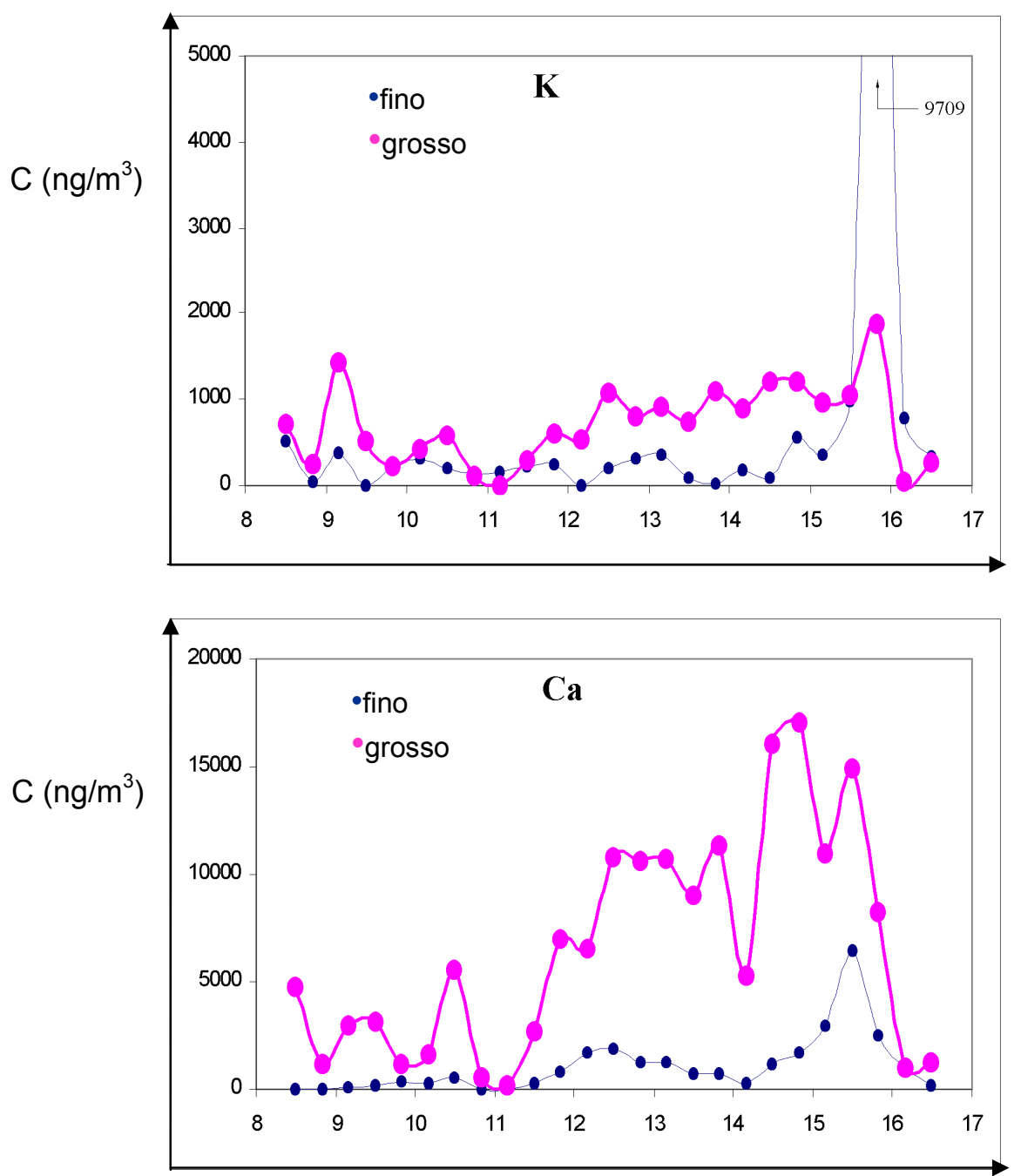

$t(h)$

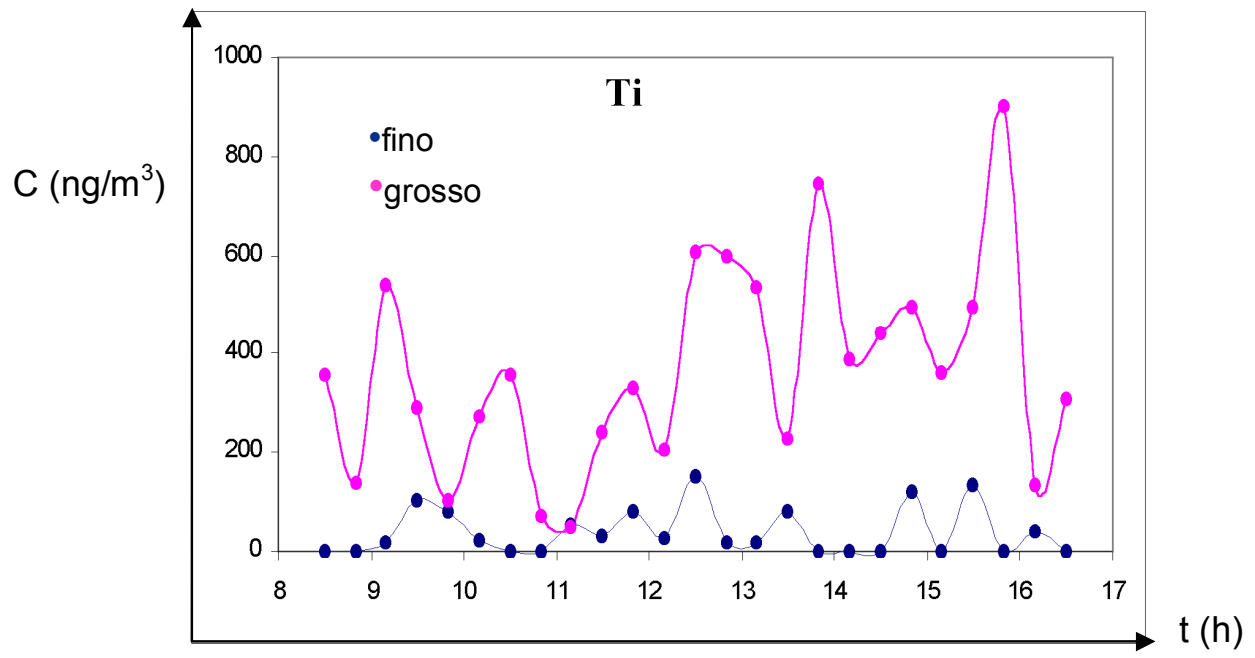

Figura 5.13: Concentração temporal dos elementos $\mathrm{K}, \mathrm{Ca}$ e Ti durante a fundição de bronze. 

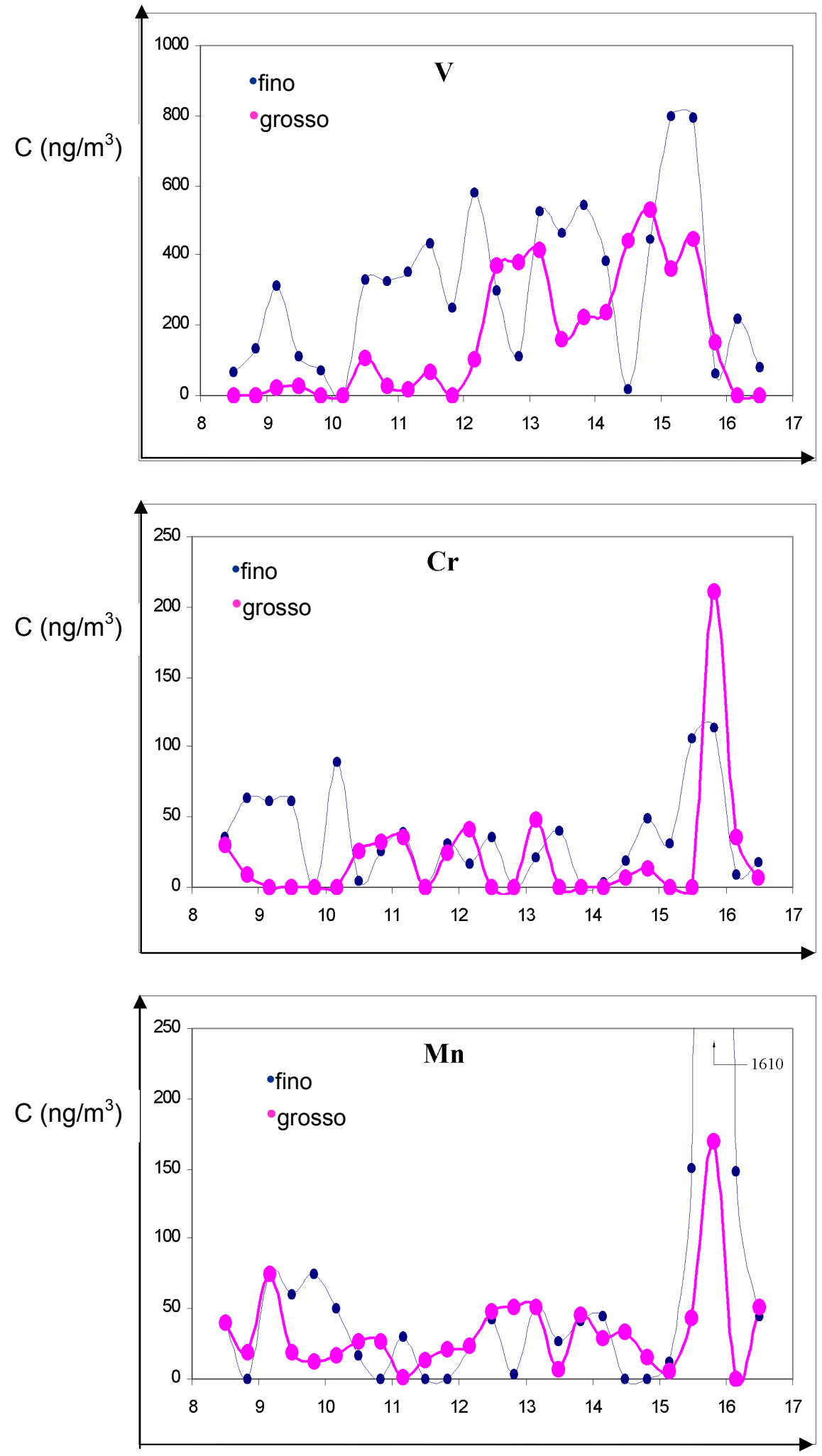

(c)

Figura 5.14: Concentração temporal dos elementos $\mathrm{V}, \mathrm{Cr}$ e $\mathrm{Mn}$ durante a fundição de bronze. 

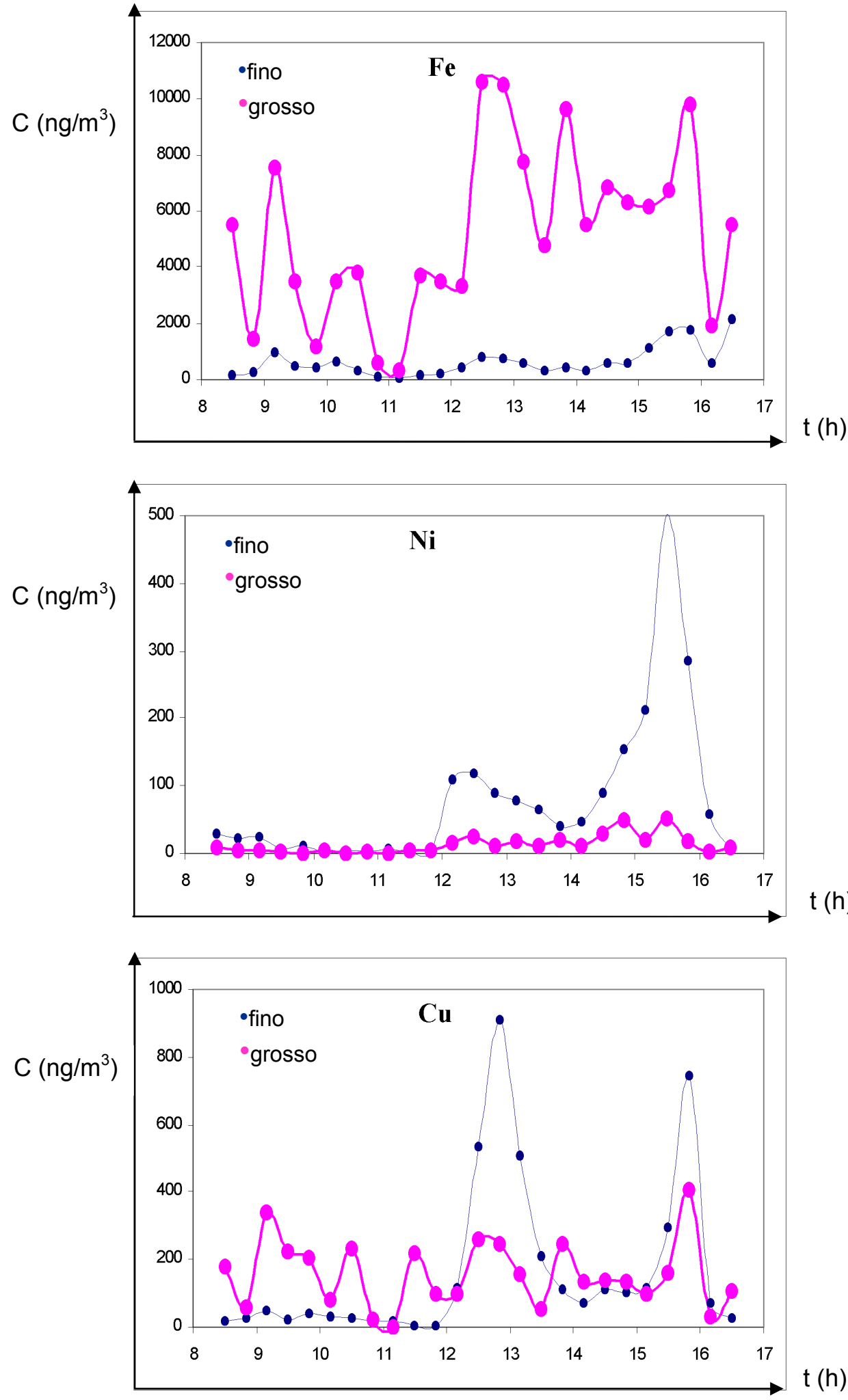

Figura 5.15: Concentração temporal dos elementos $\mathrm{Fe}, \mathrm{Ni}$ e $\mathrm{Cu}$ durante a fundição de bronze. 

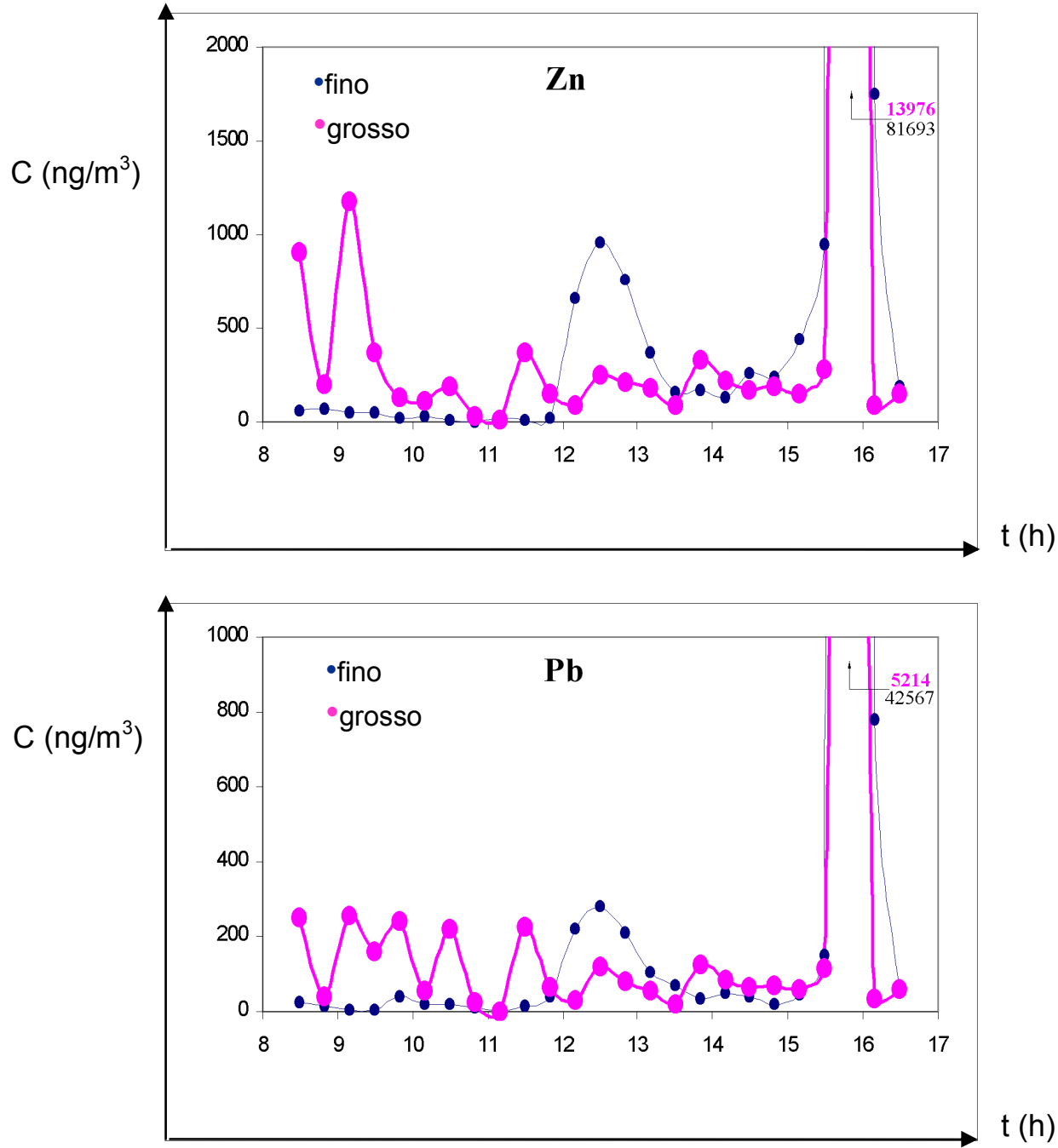

Figura 5.16: Concentração temporal dos elementos $\mathrm{Zn}$ e $\mathrm{Pb}$ durante a fundição de bronze.

A variação temporal das concentrações dos elementos de interesse durante o processo de fundição de ferro é apresentada nas Figuras 5.17 a 5.20. Neste caso o amostrador rotativo coletou material particulado em intervalos de tempo de $20 \mathrm{~min}$ por um período de 5 horas. O processo de fundição do ferro se iniciou às 12h:40min e finalizou às 17h:40min. 


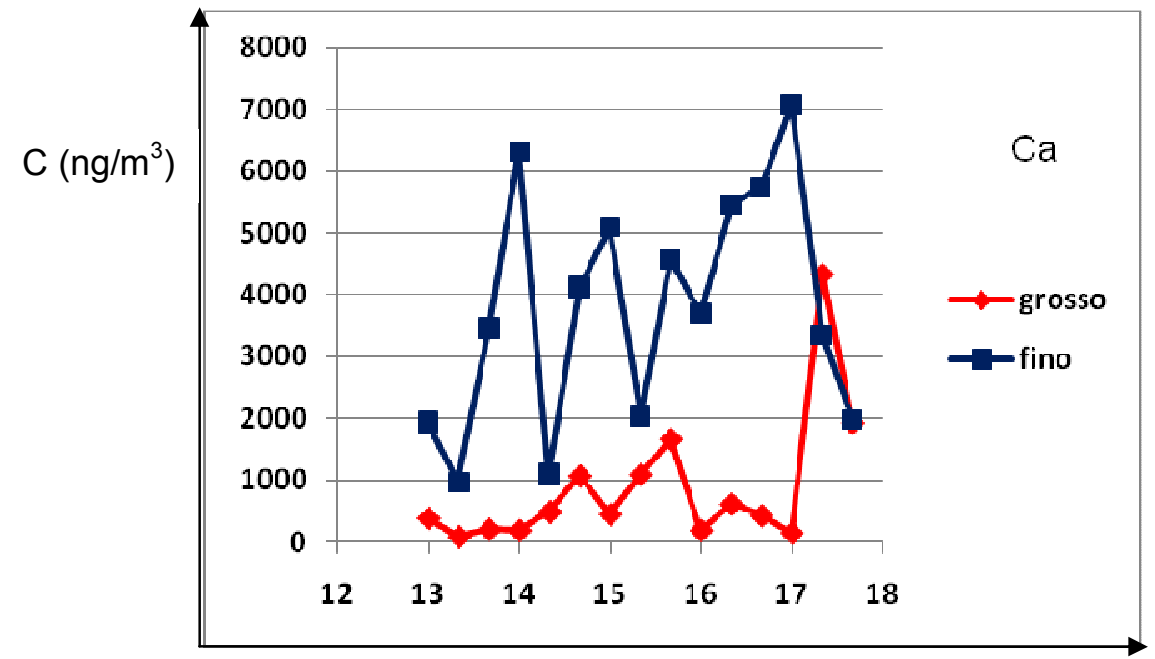

$t(h)$
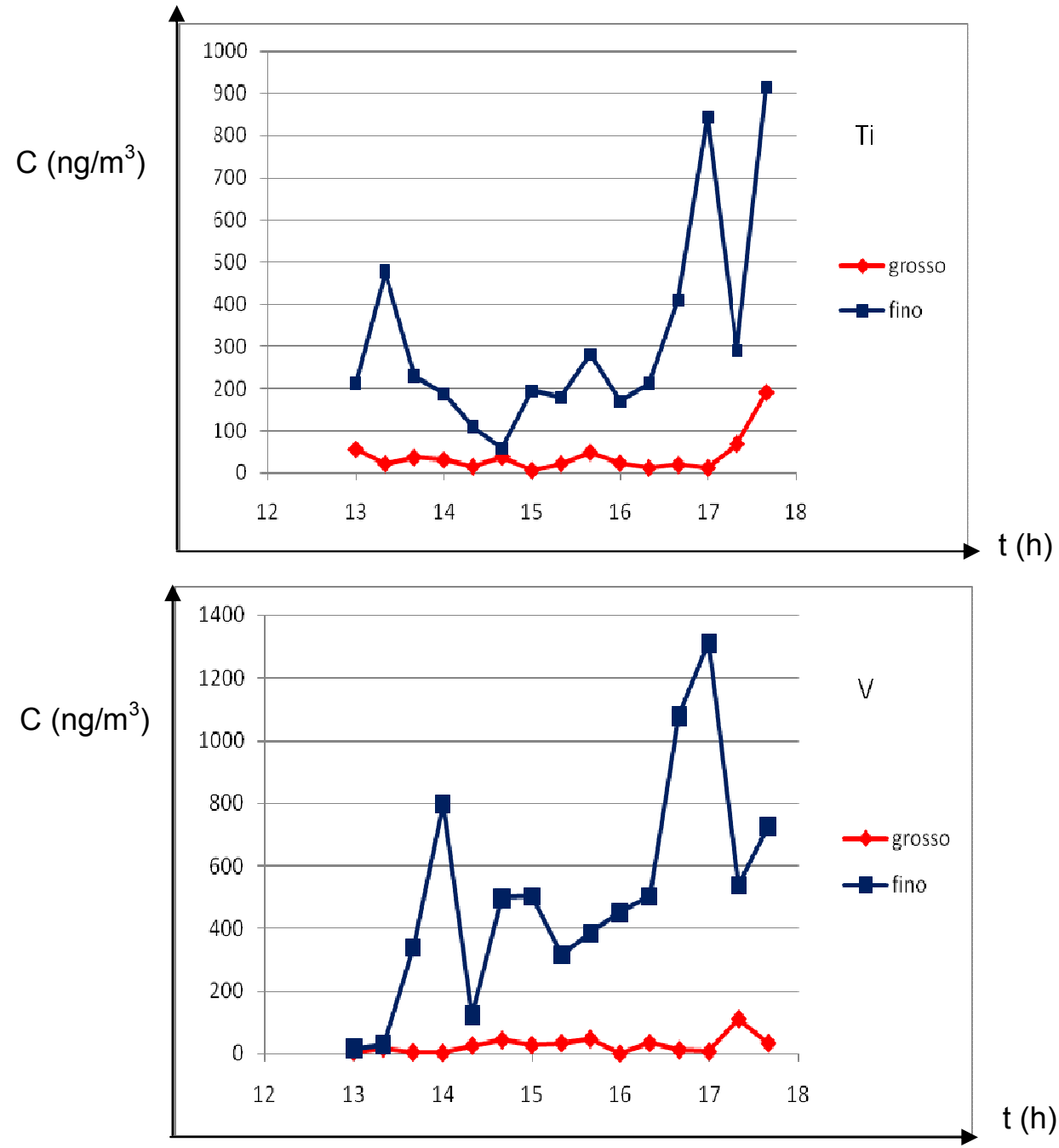

Figura 5.17: Concentração temporal dos elementos Ca, Ti e V durante a fundição de ferro. 


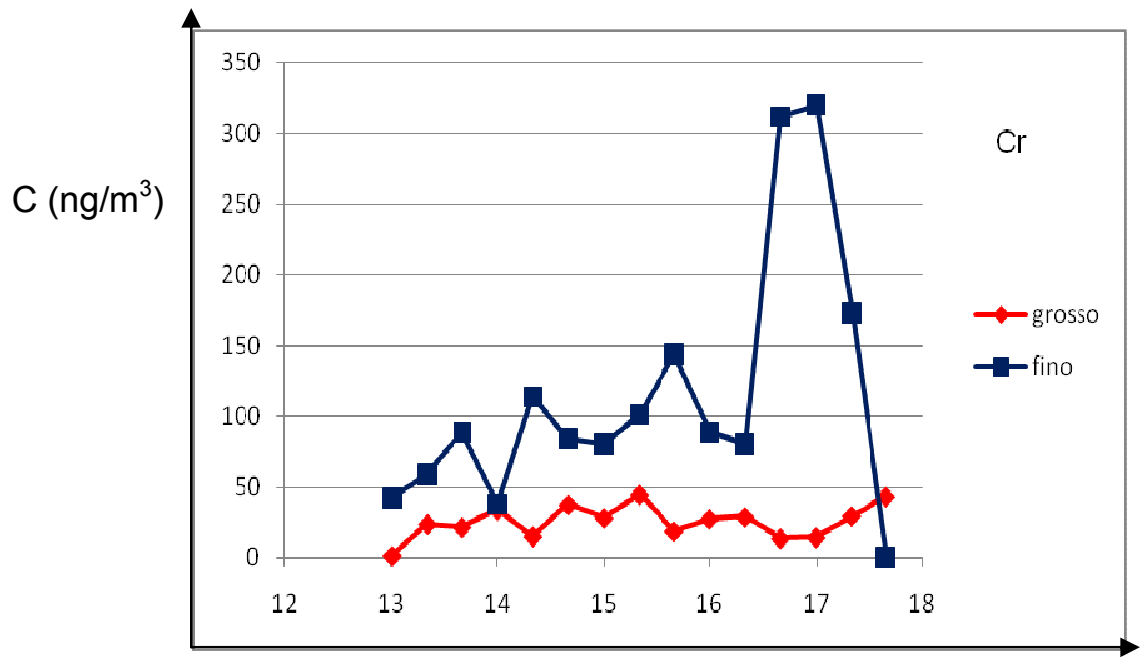

$t(h)$
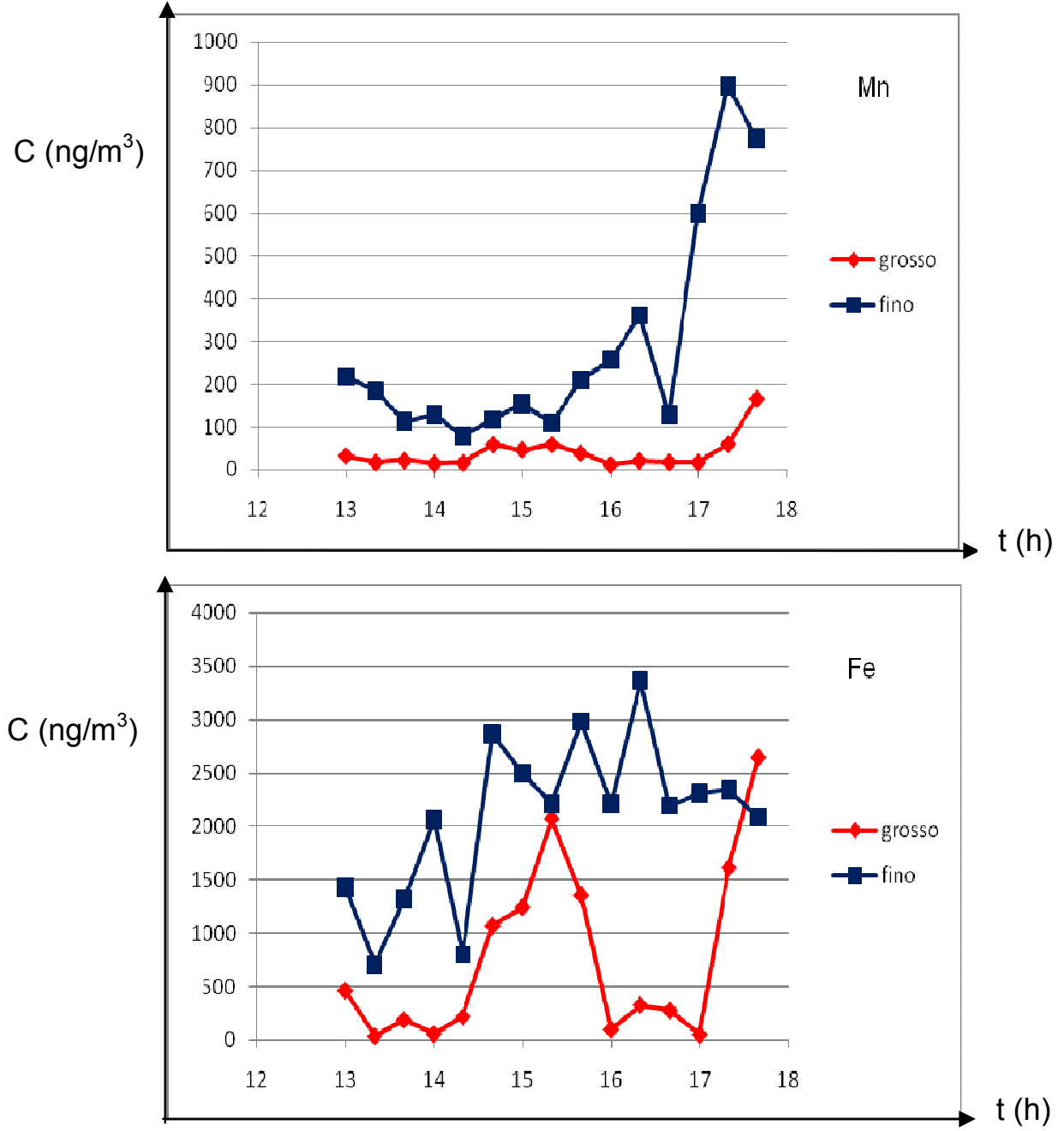

Figura 5.18: Concentração temporal dos elementos $\mathrm{Cr}$, Mn e Fe durante a fundição de ferro. 

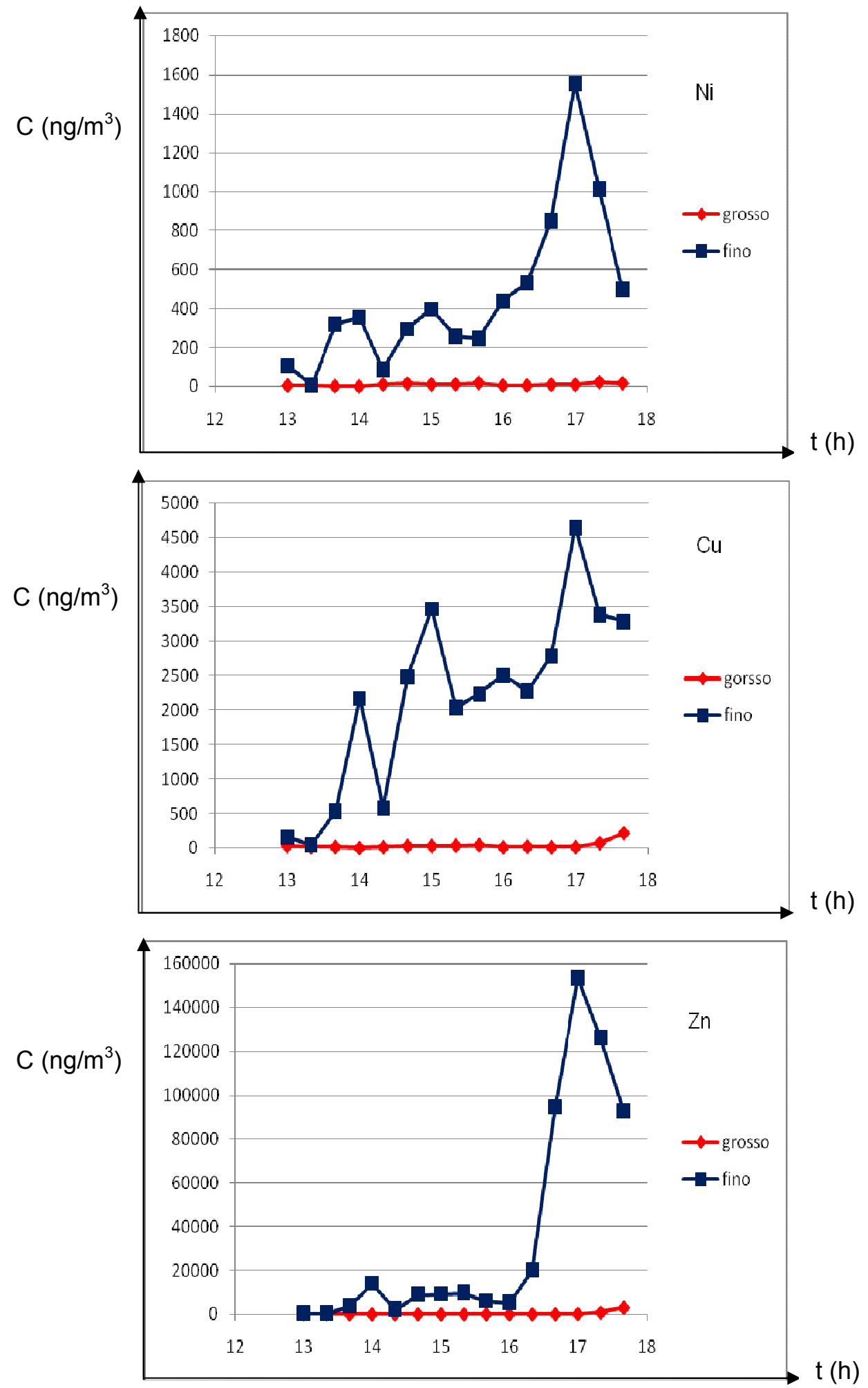

Figura 5.19: Concentração temporal dos elementos $\mathrm{Ni}, \mathrm{Cu}$ e $\mathrm{Zn}$ durante a fundição de ferro. 

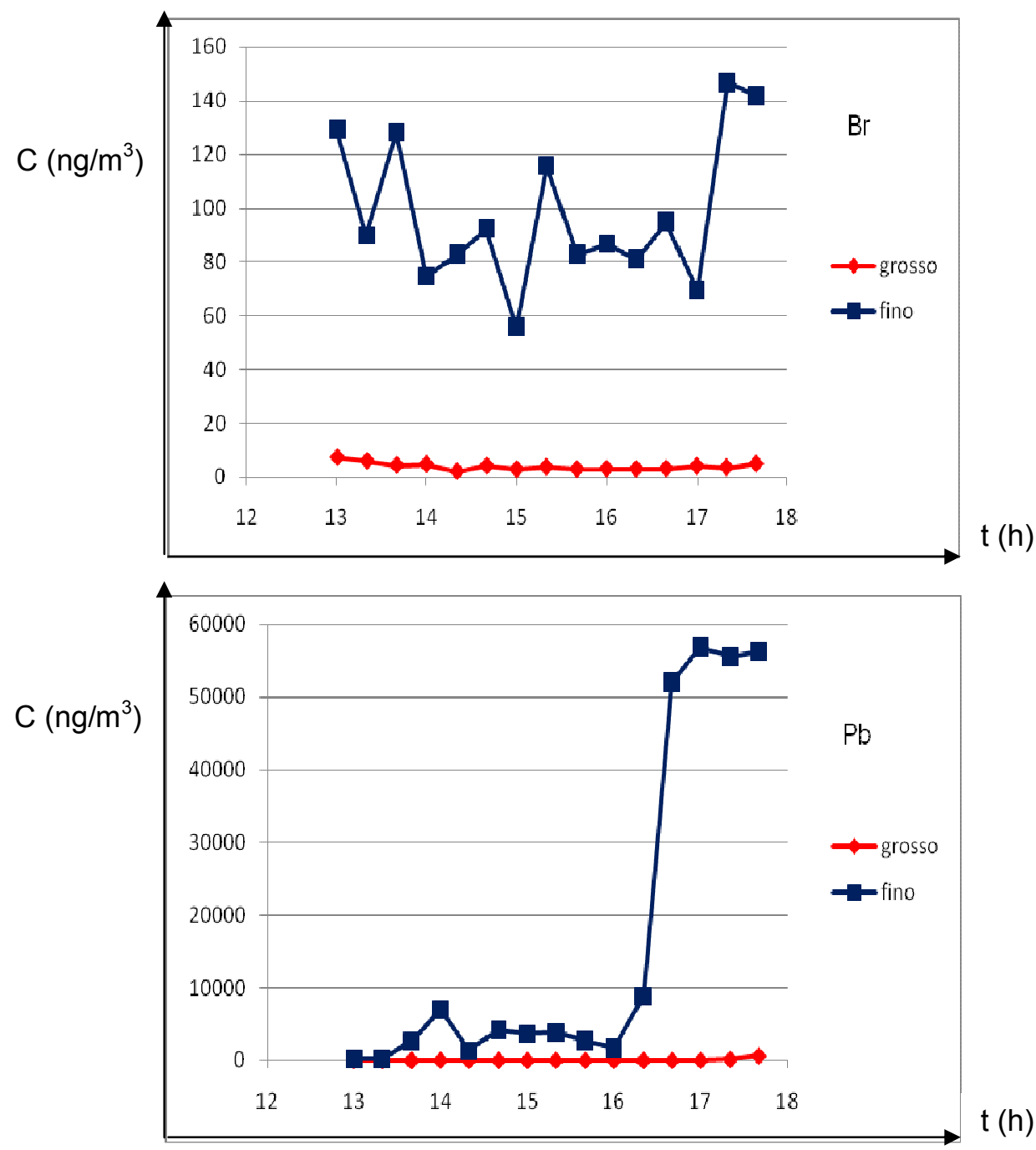

Figura 5.20: Concentração temporal dos elementos $\mathrm{Br}$ e $\mathrm{Pb}$ durante a fundição de ferro.

Na Figura 5.21 vê-se a variação da concentração de apenas três elementos (Fe, Cu e Zn) que apresentaram alguma notável concentração durante o processo de fundição de alumínio, na qual a coleta que se iniciou às 13h:55min e finalizou às $17 \mathrm{~h}: 55 \mathrm{~min}$, totalizando um período de 4 horas de coleta dividido em intervalos iguais de $20 \mathrm{~min}$. 


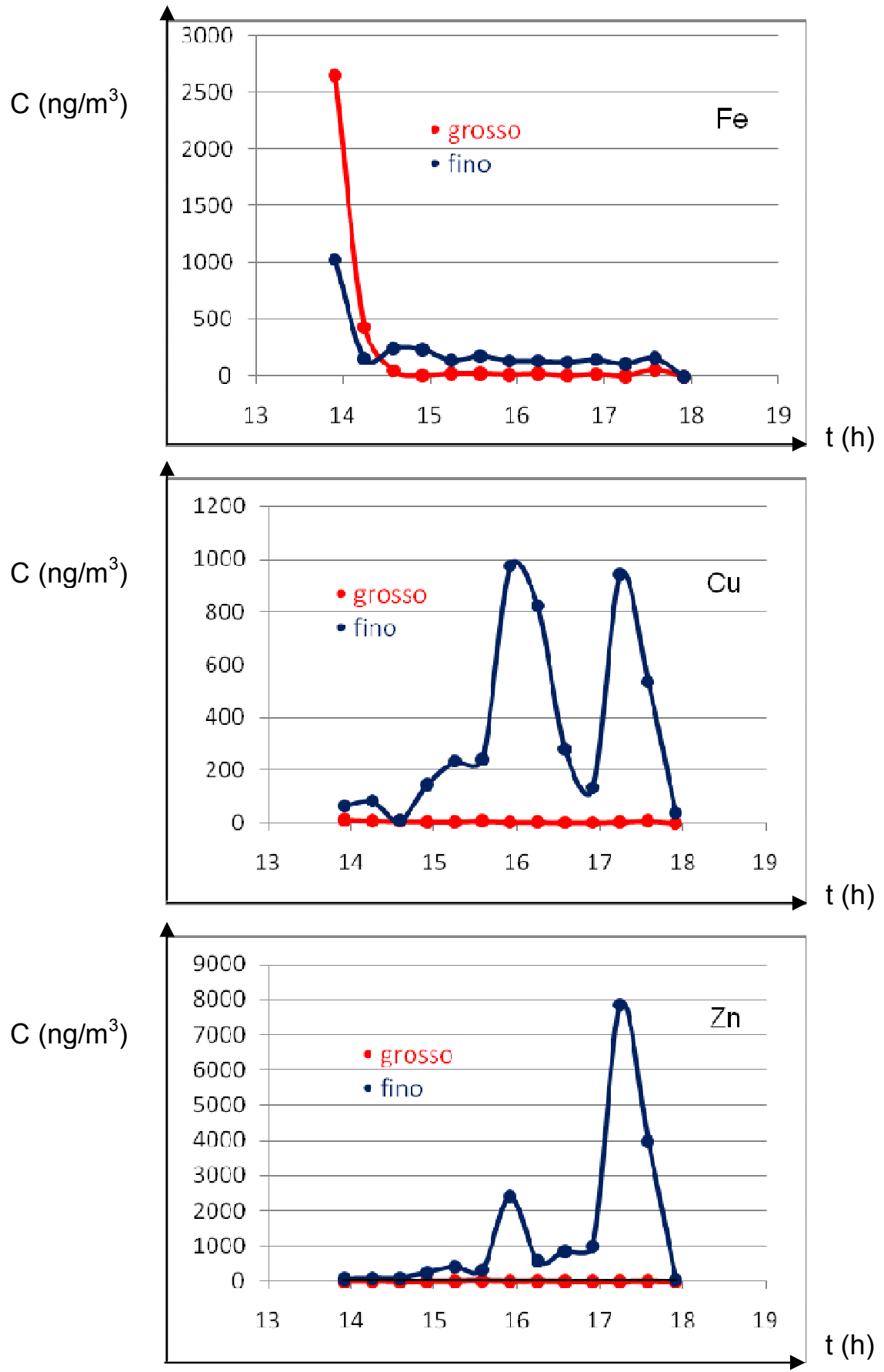

Figura 5.21: Concentração temporal dos elementos $\mathrm{Fe}, \mathrm{Cu}$ e $\mathrm{Zn}$ durante a fundição de alumínio. 
Por meio desses gráficos apresentados da concentração temporal, nota-se que o momento mais crítico foi durante a moldagem, quando concentrações de elementos potencialmente tóxicos, como o $\mathrm{Cr}, \mathrm{Mn}, \mathrm{Ni}, \mathrm{Cu}, \mathrm{Zn}$ e $\mathrm{Pb}$, tanto na fundição de bronze quanto na de ferro, são bastante elevadas, principalmente na fração fina. No caso da fundição de alumínio, foram detectados nas amostras de aerossóis poucos elementos, mesmo no momento da moldagem, que também se mostrou o mais crítico desse processo.

Feitas as amostragens de particulado atmosférico nas fundições de bronze, ferro e alumínio, bem como suas análises quantitativas, fez-se novamente novas coletas amostrais (nos mesmos locais) e análises do particulado atmosférico em de fundição dos mesmos metais, e constatou-se uma mesma média dos resultados obtidos nas análises anteriores referentes a concentração de elementos potencialmente tóxicos na atmosfera local.

Analisando os gráficos das figuras, vê-se claramente que os picos mais altos de concentração dos elementos ocorrem no final do processo de fundição o qual compreende o momento da moldagem, que é a deposição do metal fundido dentro dos moldes por meio de um canal no qual, em seguida, é colocado o pó isotérmico de modo que o mesmo seja fechado para que o resfriamento do metal seja mais lento, evitando possíveis fissuras após sua solidificação (caso das fundições de bronze e ferro).

O momento da moldagem durante o processo de fundição de bronze ocorreu às 15h:30min, durante a fundição de ferro foi às $17 \mathrm{~h}: 00 \mathrm{~min}$ e na fundição de alumínio, ocorreram duas moldagens, a primeira às 16h:00min e a segunda às $17 \mathrm{~h}: 15 \mathrm{~min}$. 


\section{5- Concentração dos elementos durante a fundição comparados aos níveis de concentração estabelecidos por agências ambientais}

Inicialmente fez-se a análise do $\mathrm{Pb}$ por ser um dos principais elementos potencialmente tóxicos para a saúde humana, mesmo em baixas concentração. A Organização Mundial de Saúde (WHO - World Health Organization, 1999) estabelece que o valor limite para o PTS no ar é $500 \mathrm{ng} / \mathrm{m}^{3}$ (média trimestral - não deve exceder mais que 1 vez ao ano).

No processo de fundição de bronze, durante a moldagem, houve pico de concentração de $\mathrm{Pb}$ no particulado fino $\left(\mathrm{MP}_{2,5}\right)$ de $43.000 \mathrm{ng} / \mathrm{m}^{3}$, com valor médio obtido nesse particulado de $1.870 \mathrm{ng} / \mathrm{m}^{3}$ e no total de fino e grosso $\left(\mathrm{MP}_{2,5}+\mathrm{MP}_{10-2,5}=\mathrm{MP}_{10}\right)$ foi $2.190 \mathrm{ng} / \mathrm{m}^{3}$ (média de 8 horas). Mesmo se considerar média em 24 horas, o valor encontrado de $730 \mathrm{ng} / \mathrm{m}^{3}$ se mostra acima do limite.

Já durante o processo de fundição de ferro, apareceu pico de concentração de $\mathrm{Pb}$ (média de 5 horas) de $57.000 \mathrm{ng} / \mathrm{m}^{3}$ e o valor médio obtido no particulado fino foi de $17.150 \mathrm{ng} / \mathrm{m}^{3}$, sendo no total $\left(\mathrm{MP}_{10}\right) 17.230 \mu \mathrm{g} / \mathrm{m}^{3} \mathrm{e}$ ainda considerando média de 24 horas, o valor chega a $3.600 \mathrm{ng} / \mathrm{m}^{3}$. Ambos os valores de concentração apresentam-se bastante superiores ao padrão limite de concentração. No caso da fundição de alumínio, não foi detectada presença de $\mathrm{Pb}$ durante o processo.

Os valores médios obtidos de concentração de outros elementos nas frações grossa, fina e total $\left(\mathrm{MP}_{10}\right.$, para cada elemento) apresentaram-se maiores que os valores padrões de poluentes atmosféricos inorgânicos carcinogênicos e não carcinogênicos, adotados pela Fundação Nacional de Saúde (FUNASA; BRASIL, 2002), dos quais se pode citar os 
elementos $\mathrm{Cr}, \mathrm{Mn}$ e $\mathrm{Ni}$ (Tabelas 5.5 e 5.6), que apresentaram picos de concentração durante as fundições de bronze e de ferro apenas.

A CETESB (2008) classifica o particulado atmosférico como

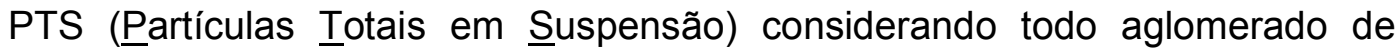
partículas que variam de tamanho até menores que $100 \mu \mathrm{m}$ compostas por material sólido ou líquido em forma de poeira, neblina, aerossol, fumaça, fuligem, etc.

Tabela 5.5. Valores padrões limites de concentração de alguns poluentes atmosféricos no PTS adotados pela FUNASA e valores de concentração encontrados para o $\mathrm{MP}_{2,5}, \mathrm{MP}_{10-2,5}$ e $\mathrm{MP}_{10}$ durante $\mathrm{O}$ processo de fundição de bronze.

\begin{tabular}{|c|c|c|c|c|}
\hline Elemento & $\begin{array}{c}\text { Concentração } \\
\text { de } \mathrm{MP}_{2,5} \\
\left(\mathrm{ng} / \mathrm{m}^{3}\right)\end{array}$ & $\begin{array}{c}\text { Concentração } \\
\text { de } \mathrm{MP}_{10-2,5} \\
\left(\mathrm{ng} / \mathrm{m}^{3}\right)\end{array}$ & $\begin{array}{c}\text { Concentração } \\
\text { de } \\
\mathrm{MP}_{10}\left(\mathrm{ng} / \mathrm{m}^{3}\right)\end{array}$ & $\begin{array}{c}\text { PadrãoFUNASA } \\
\begin{array}{c}\text { PTS } \\
\left(\mathrm{ng} / \mathrm{m}^{3}\right)\end{array}\end{array}$ \\
\hline $\mathrm{Cr}$ & $<L D$ & 22 & 59 & 1 \\
\hline $\mathrm{Mn}$ & 106 & 35 & 141 & 50 \\
\hline $\mathrm{Ni}$ & 82 & 13 & 95 & 40 \\
\hline
\end{tabular}

Tabela 5.6. Valores padrões limites de concentração de alguns poluentes atmosféricos (PTS) adotados pela FUNASA e valores de concentração encontrados para o $\mathrm{MP}_{2,5}, \mathrm{MP}_{10-2,5}$ e $\mathrm{MP}_{10}$ durante $\mathrm{o}$ processo de fundição de ferro.

\begin{tabular}{|c|c|c|c|c|}
\hline Elemento & $\begin{array}{c}\text { Concentração } \\
\text { de } \mathrm{MP}_{2,5} \\
\left(\mathrm{ng} / \mathrm{m}^{3}\right)\end{array}$ & $\begin{array}{c}\text { Concentração } \\
\text { de } \mathrm{MP}_{10-2,5} \\
\left(\mathrm{ng} / \mathrm{m}^{3}\right)\end{array}$ & $\begin{array}{c}\text { Concentração } \\
\text { de } \\
\operatorname{MP}_{10}\left(\mathrm{ng} / \mathrm{m}^{3}\right) \\
\end{array}$ & $\begin{array}{c}\text { PadrãoFUNASA } \\
\begin{array}{c}\text { PTS } \\
\left(\mathrm{ng} / \mathrm{m}^{3}\right)\end{array} \\
\end{array}$ \\
\hline $\mathrm{Cr}$ & $<\mathrm{LD}$ & 26 & 140 & 1 \\
\hline $\mathrm{Mn}$ & 289 & 40 & 329 & 50 \\
\hline $\mathrm{Ni}$ & 463 & 10 & 473 & 40 \\
\hline
\end{tabular}

As concentrações de $\mathrm{MP}_{2,5}$ e no $\mathrm{MP}_{10-2,5}$ no interior da indústria, durante os processos de fundição de bronze e ferro (Tabelas 5.7 e 
5.8), também apresentaram valores bastante preocupantes se comparados aos limites de concentração na atmosfera, determinados pela United States Environmental Protection Agency (USEPA, 1999), que define $\mathrm{MP}_{2,5}$ e no $\mathrm{MP}_{10}$ como partículas que variam de tamanho menores que 2,5 e $10 \mu \mathrm{m}$, respectivamente, compostas por material sólido ou líquido em forma de poeira, neblina, aerossol, fumaça, fuligem, etc., enquanto que no presente trabalho, é apresentado apenas a concentração total dos elementos detectados no $\mathrm{MP}_{2,5} \mathrm{e}$ no $\mathrm{MP}_{10-2,5}$.

Os valores totais da concentração dos particulados $\mathrm{MP}_{2,5}$ e $\mathrm{MP}_{10}$, encontrados durante o prcesso de fundição de alumínio, não apresentaram valores alarmantes para a saúde humana, segundo os parâmetros estabelecidos pela USEPA. Esses dados estão apresentados na Tabela 5.9.

Tabela 5.7. Valores padrões limites de concentração de particulados atmosféricos determinados pela USEPA e valores de concentração de $\mathrm{MP}_{2,5}$ e $\mathrm{MP}_{10}$ encontrados nas amostras coletadas na fundição de bronze.

\begin{tabular}{|c|c|c|}
\hline $\begin{array}{c}\text { Particulado } \\
\text { (todos os } \\
\text { elementos) }\end{array}$ & $\begin{array}{c}\text { Padrão de } \\
\text { Concentração } \\
\text { USEPA }\left(\mathbf{n g} / \mathbf{m}^{3}\right)\end{array}$ & $\begin{array}{c}\text { Concentração } \\
\text { Elementos } \\
\text { estudados } \\
\left(\mathbf{n g} / \mathbf{m}^{3}\right)\end{array}$ \\
\hline $\mathrm{MP}_{10}$ & 50.000 & $24.000(48 \%)^{*}$ \\
\hline $\mathrm{MP}_{2,5}$ & 15.000 & $9.000(60 \%)^{*}$ \\
\hline
\end{tabular}

${ }^{*}$ Porcentagem de concentração em relação ao padrão USEPA. 
Tabela 5.8. Valores padrões limites de concentração de particulados atmosféricos determinados pela USEPA e valores de concentração encontrados nas amostras de $\mathrm{MP}_{2,5}$ e $\mathrm{MP}_{10}$ na fundição de ferro.

\begin{tabular}{|c|c|c|}
\hline $\begin{array}{c}\text { Particulado } \\
\text { (todos elementos) }\end{array}$ & $\begin{array}{c}\text { Padrão de } \\
\text { Concentração } \\
\text { USEPA (ng/m }\end{array}$ & $\begin{array}{c}\text { Concentração na } \\
\text { fundição de ferro } \\
\text { (ng/m }^{3} \text { ) }\end{array}$ \\
\hline $\mathrm{MP}_{10}$ & 50.000 & $67.000(134 \%)^{*}$ \\
\hline $\mathrm{MP}_{2,5}$ & 15.000 & $64.000(427 \%)^{\star}$ \\
\hline
\end{tabular}

${ }^{*}$ Porcentagem de concentração em relação ao padrão USEPA.

Tabela 5.9. Valores padrões limites de concentração de particulados atmosféricos determinados pela USEPA e valores de concentração encontrados nas amostras de $\mathrm{MP}_{2,5}$ e $\mathrm{MP}_{10}$ na fundição de alumínio.

\begin{tabular}{|c|c|c|}
\hline $\begin{array}{c}\text { Particulado } \\
\text { (todos elementos) }\end{array}$ & $\begin{array}{c}\text { Padrão de } \\
\text { Concentração } \\
\text { USEPA (ng/m }\end{array}$ & $\begin{array}{c}\text { Concentração na } \\
\text { fundição de ferro } \\
\text { (ng/m } \mathbf{m}^{3} \text { ) }\end{array}$ \\
\hline $\mathrm{MP}_{10}$ & 50.000 & $2.300(4,6 \%)^{*}$ \\
\hline $\mathrm{MP}_{2,5}$ & 15.000 & $2.000(13,3 \%)^{*}$ \\
\hline
\end{tabular}

${ }^{*}$ Porcentagem de concentração em relação ao padrão USEPA.

O Conselho Nacional do Meio Ambiente (CONAMA) estabelece uma concentração limite para o PTS de $60.000 \mathrm{ng} / \mathrm{m}^{3}$. A concentração determinada na fundição de bronze, apenas no particulado $\mathrm{PM}_{10}$ para os elementos detectados, foi de $24.000 \mathrm{ng} / \mathrm{m}^{3}$, isto é, $40 \%$ do PTS limite, e na fundição de ferro foi de $67.000 \mathrm{ng} / \mathrm{m}^{3}$, o que representa mais de $10 \%$ acima do valor limite do PTS. Esses resultados são bastante preocupantes, já que a comparação foi feita entre PTS e a soma da concentração dos elementos detectados presentes nos particulados de fino e grosso $\left(\mathrm{MP}_{10}\right)$.

Já no caso do resultado da soma dos particulados $\mathrm{MP}_{2,5} \mathrm{e}$ $\mathrm{MP}_{10-2,5}$ que se apresentaram durante a fundição de alumínio, foi de 
$2.300 \mathrm{ng} / \mathrm{m}^{3}$ ar, que representa menos de $4 \%$ do limite estabelecido para PTS pelo CONAMA.

Apesar de serem encontrados nas fundições picos de concentração para os elementos K (apenas fundição de bronze), Ti (fundição de ferro e bronze), V (fundição de ferro e bronze), Cu, Zn (vide Tabela 5.10 para concentração de particulado fino que apresentou valores bastante superiores ao do grosso) e $\mathrm{Br}$ ( apenas na fundição de ferro: $\mathrm{MP}_{2,5}=100 \mathrm{ng} / \mathrm{m}^{3}$ e $\mathrm{MP}_{10-2,5}=4 \mathrm{ng} / \mathrm{m}^{3}<\mathrm{LD}$ ), não há registros riscos de inalação associados a esses elementos, mas a inalação de vapor de óxido de zinco pode resultar em febre. Alguns dos sintomas são: gosto metálico na boca, acompanhado de secura e irritação da garganta com tosse e, às vezes com dificuldade para respirar, sensação de fraqueza e fadiga. A recuperação nesses casos é de no máximo dois dias (NOVAMET ZINC FLAKE, 2006).

Tabela 5.10. Valores de concentração do elemento $\mathrm{Zn}$ encontrada nos processos de fundição de bronze, ferro e alumínio para o $\mathrm{MP}_{2,5}$.

\begin{tabular}{|c|c|c|}
\hline Fundição & $\begin{array}{l}\text { Pico de } \mathrm{Zn:} \\
\mathrm{MP}_{2,5}\left(\mathrm{ng} / \mathrm{m}^{3}\right)\end{array}$ & $\begin{array}{l}\text { Concentração } \\
\text { média de } Z n: \\
M_{2,5}\left(n g / m^{3}\right)\end{array}$ \\
\hline Bronze & 81.700 & 3.700 \\
\hline Ferro & 153.340 & 36.400 \\
\hline Alumínio & 8.000 & 1420 \\
\hline
\end{tabular}

Para comparar os valores de concentração, encontrados no MPS durante os processos de fundição (tanto para bronze quanto para ferro e alumínio) aos limites estabelecidos por instituições de proteção e fiscalização relacionadas ao meio ambiente e saúde, foi calculada a concentração média para os elementos e de particulados totais durante o processo de fundição. 
Mesmo assim, foram encontrados nas amostras níveis de concentração muito superiores a esses limites, indicando um risco à saúde dos trabalhadores das indústrias de fundição e, deste modo, alertando para um monitoramento da qualidade da atmosfera (concentração de elementos potencialmente tóxicos) e das condições dos funcionários neste tipo de ambiente de trabalho.

Quanto à concentração média do elemento Fe encontrada no particulado atmosférico presente no local durante os três processos de fundição, cujos resultados estão apresentados na Tabela 5.11, mesmo apresentando valores de concentrações relativamente elevadas, não se encontrou na literatura limites para a sua concentração no MPS ou que sua presença nele oferecesse risco à saúde. O mesmo aconteceu com o elemento $\mathrm{Ca}$ (fundição de bronze: $\mathrm{MP}_{2,5}=684 \mathrm{ng} / \mathrm{m}^{3}$ e $\mathrm{MP}_{10-2,5}=6.847 \mathrm{ng} / \mathrm{m}^{3}$; fundição de ferro: $\mathrm{MP}_{2,5}=3.800 \mathrm{ng} / \mathrm{m}^{3}$ e $\mathrm{MP}_{10-2,5}=900 \mathrm{ng} / \mathrm{m}^{3}$; não encontrado na fundição de alumínio), o qual não se tem níveis máximos na atmosfera relatados como padrão ideal por agências ambientais.

Tabela 5.11. Valores de concentração do elemento Fe encontrada nos processos de fundição de bronze, ferro e alumínio para o $\mathrm{PM}_{2,5}$, $\mathrm{MP}_{10-2,5}$ e MP 10 .

\begin{tabular}{|c|c|c|c|}
\hline Fundição & $\begin{array}{c}\text { Concentração } \\
\text { de Fe: } \mathbf{M P}_{\mathbf{2 , 5}} \\
\left(\mathbf{n g} / \mathbf{m}^{\mathbf{3}}\right)\end{array}$ & $\begin{array}{c}\text { Concentração } \\
\text { de Fe: } \mathbf{M P}_{\text {10-2,5 }} \\
\left(\mathbf{n g}_{\mathbf{m}} \mathbf{m}^{\mathbf{3}}\right)\end{array}$ & $\begin{array}{c}\text { Concentração } \\
\text { de Fe: } \\
\mathbf{M P}_{\mathbf{1 0}}\left(\mathbf{n g} / \mathbf{m}^{\mathbf{3}}\right)\end{array}$ \\
\hline Bronze & 665 & 5.421 & 6.086 \\
\hline Ferro & 2.100 & 800 & 2.900 \\
\hline Alumínio & 251 & 255 & 506 \\
\hline
\end{tabular}

Observa-se no gráfico da Figura 5.21-Fe, que representa a variação temporal da concentração de Fe presente no particulado pelo tempo 
do processo de fundição de alumínio, um pico de Fe que ocorreu no início da fundição (primeiros $20 \mathrm{~min}$ ). Esse pico isolado se deu apenas devido ao fato de a indústria ter realizado um processo de fundição de ferro no primeiro período do dia (manhã) e, em seguida, logo no início do período da tarde, foi que se iniciou o processo de fundição de alumínio (informação obtida junto ao funcionário da indústria). A Figura também mostra que durante o processo de fundição de alumínio, inclusive no momento mais crítico, não se apresentou picos consideráveis de concentração do elemento Fe.

No caso da fundição de ferro, observa-se que foram encontrados picos de concentração de $\mathrm{Pb}$, porém o produtor da matéria prima não especifica a sua presença. Sendo assim, foi feita uma investigação de todos os materiais participantes da fundição de ferro (que servem para a fundição de bronze também), inclusive da própria matéria-prima. Isso se fez necessário devido ao fato de terem sido detectados picos elevadíssimos de concentração de $\mathrm{Pb}\left(57.000 \mathrm{ng} / \mathrm{m}^{3}\right)$ no particulado durante a fundição de ferro.

A análise qualitativa destes materiais foi feito por fluorescência de raios $\mathrm{X}$ por dispersão de energia (EDXRF), porém sem a utilização do colimador de bronze. Os materiais analisados foram:

- Ferro (cinzento e nodular) - matéria-prima;

- Pó isotérmico - impede o resfriamento rápido do material fundido no molde e é colocado sobre o canal do molde, após ser preenchido com o material;

- Inoculante - colocado sobre o material fundido assim que ele sai do forno para a "panela" (recipiente utilizado para receber o material fundido do forno, que em seguida é levado para preencher o molde) 
- Tinta para acabamento - reveste o interior do molde de areia para melhor resultado no acabamento da peça.

- Liga Fe-Si-Mg - material sólido em forma de granulado grosso, colocado na panela vazia, antes de despejar o material fundido, com a intenção de melhor resultado pós-fundição ("dá a liga”).

Destas amostras a que apresentou presença de $\mathrm{Pb}$ foi o pó isotérmico, que é responsável por uma lenta solidificação do metal em estado líquido, de modo a obter melhor qualidade no produto final, como evitar grandes fissuras nas peças. Como ele é colocado no canal do molde logo após ser totalmente preenchido com metal fundido, o pó isotérmico sofre queima que possibilita a volatilização de vários elementos químicos nele presente, inclusive o chumbo.

Após o fornecimento dos dados da pesquisa deste trabalho à indústria de fundição, ela solicitou a composição química do pó isotérmico à empresa fornecedora, que não se manifestou até o momento. 


\section{CONCLUSÕES}

Em ambos os casos, o momento mais crítico durante todo o processo de fundição foi o da moldagem, no qual é retirado material fundido da caldeira e colocado num pequeno recipiente onde se encontra a liga Fe-Si-Mg em forma de pequeninas esferas e posteriormente misturado ao inoculante. Em seguida, essa mistura é levada aos moldes, os quais são totalmente preenchidos e encerrados com o pó isotérmico, fechando o canal do molde. Esse processo se repete até o completo esvaziamento da caldeira.

Após a realização das análises das amostras, identificação e determinação da concentração dos elementos químicos contidos no particulado atmosférico e comparação dos resultados obtidos com os limites de concentração estabelecidos por agências ambientais nacionais e internacionais, pode-se concluir que, tanto numa fundição de bronze como numa de ferro, os trabalhadores ficam expostos por um longo período da jornada de trabalho diária, não somente aos gases tóxicos emanados nesses processos de fundição, mas também ao material particulado em suspensão atmosférica, o qual pode conter elementos químicos com propriedades 
carcinogênicas e causadoras de doenças pulmonares, imunológicas, neurológicas entre outras, quando se apresentam em concentrações críticas.

Pode-se também concluir que em fundição de bronze e ferro, o MPS tem alta concentração de elementos químicos potencialmente tóxicos como o $\mathrm{Cr}$, $\mathrm{Ni}$ e $\mathrm{Pb}$, não somente pelos elementos presentes na matéria-prima, mas também dos elementos presentes nos materiais que possibilitam um bom rendimento da fundição, como o pó isotérmico.

Apesar de durante o processo de fundição de alumínio não apresentar alta concentração de elementos químicos potencialmente tóxicos, apresenta uma considerável concentração de particulado atmosférico que pode causar também doenças pulmonares nos trabalhadores que todos os dias recebem esta carga durante horas.

Com isso, faz-se necessário um monitoramento eficaz quanto à concentração de material particulado presente no ambiente de trabalho durante o processo de fundição de metais, bem como a fiscalização do uso de equipamento de proteção e segurança pelos trabalhadores nestes ambientes de trabalho.

A análise morfológica do particulado atmosférico tanto para o fino $\left(\mathrm{MP}_{2.5}\right)$ quanto para o grosso $\left(\mathrm{MP}_{10-2.5}\right)$, feita com microscopia eletrônica de varredura acoplada ao sistema de análises por micro-fluorescência de raios X, foi de grande importância para o melhor entendimento deste trabalho, pois com isso foi mostrado não somente a dimensão do particulado, mas também os diversos formatos que as partículas se apresentam, possibilitando uma 
interpretação mais refinada a respeito da deposição do MPS tanto no filtro como no impactador.

$$
\text { Quanto ao amostrador rotativo (streaker air-particulate }
$$
sampler), mostrou-se bastante eficaz não somente na coleta do material particulado, mas também na simplicidade de montagem para coleta, na periodicidade da amostragem (a qual pode ser previamente programada), na utilização de apenas um filtro e impactador para coleta das frações grossa e fina do particulado atmosférico (inalável e respirável, respectivamente), e não precisando de manuseio do aparelho durante a coleta. Devido a essas vantagens do amostrador rotativo, pôde-se identificar os momentos críticos deste tipo de atividade industrial, isto é, os momentos nos quais os picos de concentração dos elementos químicos potencialmente tóxicos apresentam-se mais altos. 


\section{REFERÊNCIAS}

AIGINGER, H.; WOBRAUSCHEK, P. A method for quantitative X-ray fluorescence analysis in the nanogram region. Nuclear Instruments and Methods, Amsterdam, v. 114, p. 157-158, 1974.

APPOLONI, C. R.; LOPES, F.; NASCIMENTO FILHO, V. F.; SUGUIHIRO, N. M.; JESUS, L. S.; ARAGÃO, P. H. A. Chemical and morphological characterization of $\mathrm{PM}_{10}$ and $\mathrm{PM}_{2.5}$ employng EDXRF and SEM techniques. Brazilian Journal of Morphological Sciences, São Paulo, v. 205, p. 335-336, 2005.

ALI, E. A.; BASCÓ, J. Investigation of different types of filters for atmospheric trace elements analysis by three analytical techniques. Journal of Radioanalytical and Nuclear Chemistry, Budapest, v. 209, n. 1, p. 147-155, 1996.

ARTAXO, P. The chemistry of atmospheric aerosol particles in the Amazon Basin. In: SEIDL, P. R.; GOTTLIEB, O. R.; KAPLAN, M. A. C. (Ed.). Chemistry of the Amazon: biodiversity natural products and environmental issues. Washington: American Chemical Society, 1995. p. 265-280. (ACS Symposium Series, 588).

AZEVEDO, A. A.; CHASIN, A. A. M. (Coord.) As bases toxicológicas da ecotoxicologia. São Carlos: Rima, 2003. 340 p. 
BERNASCONI, G.; HASELBERGER, N.; MARKOWICZ, A.; VALKOVIC, V. Application of a capillary based X-ray microfluorescence system. Nuclear Instruments and Methods in Physics Research Series B, Amsterdam, v. 86, p. 333-338, 1994.

BRASIL. Ministério da Saúde. Fundação Nacional de Saúde. Vigilância ambiental em saúde. Brasília, 2002.

BRUNO, R. L.; ALMEIDA, A. F.; NASCIMENTO FILHO, V. F.; AGUIAR, M. L.; GONÇALVES, J. A. S.; COURY, J. R. Atmospheric particulate matter in the city of São Carlos/SP, Brazil. International Journal of Environment and Pollution, Geneva, v. 22, p. 476-489, 2004.

CARNEIRO, A. E. V.; NASCIMENTO FILHO, V. F. Análise quantitativa de amostras geológicas utilizando a técnica de fluorescência de raios $X$ por dispersão de energia. Scientia Agricola, Piracicaba, v. 53, p. 95-105, 1996.

CENTRO DE INFORMÁTICA NA AGRICULTURA. Informações econômicas. Piracicaba, 2003. Disponível em: http://www.ciagri.usp.br/piracica/econ p.htm. Acesso em: 03 dez. 2008.

COCHRAN, J. K.; FRIGNAMI, M.; SALAMANCA, M.; BELLUCCI, L G.; GUERZONI, S. Lead-210 as a tracer of atmospheric input of heavy metals in the northern Venice Lagoon. Marine Chemistry, Amsterdam, v. 62, p. 15-29, 1998.

COMPANHIA DE TECNOLOGIA DE SANEAMENTO AMBIENTAL. Relatório de qualidade do ar do Estado de São Paulo - 2007. São Paulo: CETESB, 2008. 284 p.

CUNHA e SILVA, R. M.; NASCIMENTO FILHO, V. F.; APPOLONI, C. R.; PEREZ, C. A. Caracterização química de fragmentos cerâmicos arqueológicos por micro-fluorescência de raios $X(\mu-X R F)$. In: INTERNATIONAL ATLANTIC NUCLEAR CONFERENCE, 1.; CONGRESSO GERAL DE ENERGIA NUCLEAR, 9.; ENCONTRO NACIONAL DE APLICAÇÕES NUCLEARES, $6 .$, 2002, Rio de Janeiro. Anais... Rio de Janeiro: ABEN, 2002. 1 CD-ROM. 
D'ALESSANDRO, A.; LUCARELLI, F.; MARCAZZAN, G.; NAVA, S.; PRATI, P.; VALLI, G.; VECCHI, R.; ZUCCHIATTI, A. A summertime investigation on urban PM fine and coarse fractions using hourly elemental concentration data series. IL Nuovo Cimento C, Bologna, v. 27, n. 1, p. 17-28, 2004.

DERÍSIO, J. C. Introdução ao controle ambiental. São Paulo: CETESB, 1992. 201 p.

ELLIS, A. T.; POTTS, P. J.; HOMES, M.; OLIVER, G. J.; STRELI, C.; WOBRAUSCHEK, P. Atomic spectrometry update: X-ray fluorescence spectrometry. Journal of Analytical Atomic Spectrometry, London, v. 12, n. 11, p. 461-490, 1997.

ESPEN, P. van; ADAMS, F. Tube-excited energy dispersive X-ray fluorescence analysis. Part II. Energy-dispersive X-ray fluorescence analysis of air particulate material. Analytica Chimica Acta, Amsterdam, v. 75, p. 61-85, 1974.

ESPEN, P. van; NULLENS, H.; ADAMS, F. A computer analysis of X-ray fluorescence spectra. Nuclear Instruments and Methods, Amsterdam, v. 142, p. 243-250, 1977.

FIORI, C. E.; MYKLEBUST, R. L.; HEINRICH, K. F. J. Prediction of continuum intensity in energy-dispersive X-ray microanalysis. Analytical Chemistry, Washington, v. 48, p. 172-176, 1976.

GATEBE, C. K.; KINYUA, A. M.; MANGALA, M. J.; KWACH, R.; NJAU, L. N.; MUKOLWE, E. A.; MAINA, D. M. Determination of suspended particulates matter of major significance to human health using nuclear techniques in Kenya. Journal of Radioanalytical and Nuclear Chemistry, Budapest, v. 203, n. 1, p.125-134, 1996.

GERAB, F. Técnicas analíticas nucleares aplicadas a medidas em larga escala de aerossóis atmosféricos na região amazônica. 2003. 203 f. Tese (Doutorado em Física) - Instituto de Física, Universidade de São Paulo, São Paulo, 1996. 
GRIEKEN, R. E. van. XRS and atmospheric aerosols: new "hot" applications. In: LATIN AMERICAN SEMINAR OF ANALYSIS BY X-RAY TECHNIQUESSARX, 11., 2008, Cabo Frio. Book of abstracts... Rio de Janeiro: UFRJ, 2008. $213 p$.

GRIEKEN, R. E. van; MARKOWICS A. A. (Ed.). Handbook of X-ray spectrometry. 2. ed. New York: Marcel Dekker, 2002. 1016 p. (Practical Spectroscopy Series, 29).

HE, F.; ESPEN, P. J. van. General approach for quantitative energy dispersive $\mathrm{X}$-ray fluorescence analysis based on fundamental parameters. Analytical Chemistry, Washington, v. 63, p. 2237-2244, 1991.

HINDS, W. C. Aerosol technology: properties, behavior and measurements of airbone particles. 2. ed. New York: John Wiley \& Sons, 1999. 482 p.

HO, K. F.; LEE, S. D.; CHOW, J. C.; WATSON, J. G. Characterization of PM10 and $\mathrm{PM}_{2.5}$ source profiles for fugitive dust in Hong Kong. Atmospheric Environment, Oxford, v. 37, p. 1023-1032, 2003.

HOLYNSKA, B.; OSTACHOWICZ, B.; OSTACHOWICZ, J.; OSTROWSKI, A.; PTASINSKI, J.; WEGRZYNEK, D. Multifunctional system for energy dispersive X-ray fluorescence analysis. Journal of Trace and Microprobe Techniques, New York, v. 13, p. 163-175, 1995.

HOLYNSKA, B.; PTASINSKI, J.; MAENHAUT, W.; ANNEGARN, H. J. Energydispersive X-ray fluorescence spectrometer with capillary optics for the chemical analysis of atmospheric with high time resolution. Journal of Aerosol Science, Oxford, v. 28, p. 1455-1463, 1997.

INNOCENTINI, M. D. M. Estudo do desempenho de três monitores de aerossóis na faixa respirável. 1993. 128 f. Dissertação (Mestrado em Engenharia Química) - Departamento de Engenharia Química, Universidade Federal de São Carlos, São Carlos, 1993. 
INTERNATIONAL ATOMIC ENERGY AGENCY. Microanalysis data acquisition and control program: user's manual. Vienna: IAEA, 1996. 54 p. (Computer Manual Series).

KEBIN, H.; FUMO, Y.; YONGLIANG, M.; QIANG, Z.; XIAOHONG, Y.; CHAN, K. C.; STEVEN, C.; TAI, C.; PATRICIA, M. The characteristics of $\mathrm{PM}_{2.5}$ in Beijing, China. Atmospheric Environment, Oxford, v. 35, p. 4959-4970, 2001.

KUCZUMOW, A.; LARSSON, S.; RINDBY, A. Analysis of the distribution of inorganic components of wood by X-ray capillary microprobe. X-Ray Spectrometry, London, v. 25, p. 147-155, 1996.

LOPES, F. Caracterização química do material particulado suspenso na atmosfera empregando a fluorescência de raios $X$ dispersiva em energia (EDXRF). 2003. 89 f. Dissertação (Mestrado em Ciências) - Centro de Energia Nuclear na Agricultura, Universidade de São Paulo, Piracicaba, 2003.

MANAHAN, S. E. Environmental chemistry. 6. ed. Boca Raton: CRC Press, 1994. 843 p.

MARQUES, A. M. Caracterização do material particulado suspenso na atmosfera da cidade de São Carlos (SP). 2000. 189 f. Dissertação (Mestrado em Engenharia Química) - Departamento de Engenharia Química, Universidade Federal de São Carlos, São Carlos, 2000.

MARTINS, L. C.; PEREIRA, L. A. A.; LIN, C. A.; SANTOS, U. P.; PRIOLI, G.; LUIZ, O. C.; SALDIVA, P. H. N.; BRAGA, A. L. F. The effects of air pollution on cardiovascular diseases: lag structures. Revista de Saúde Pública, São Paulo, v. 40, n. 4, p. 677-683, 2006.

MASSONI, P. R.; SILVA, R. M. C.; ALMEIDA, E.; NASCIMENTO FILHO, V. F. Air pollution inside a small bronze foundry plant, measured by the energy dispersive X-ray fluorescence technique. In: INTERNATIONAL SYMPOSIUM ON NUCLEAR AND RELATED TECHNIQUES, 5., 2006, Havana, Cuba. Proceedings... Havana: Centro de Aplicaciones Tecnológicas y Desarrollo Nuclear, 2006. 1 CD-ROM. 
MATSUMOTO, E. Estudo da contaminação ambiental atmosférica e de águas superficiais, empregando a fluorescência de raios $X$ dispersiva em energia (EDXRF) e reflexão total. 2001. 150 f. Tese (Doutorado em Engenharia Civil) - Faculdade de Engenharia Civil, Universidade de Campinas, Campinas, 2001.

MIYAMARU, M. Aplicação do método de análise por ativação à determinação de poluentes atmosféricos. 1972. 56 f. Dissertação (Mestrado em Química) - Instituto de Química, Universidade de São Paulo, São Paulo, 1972.

NASCIMENTO FILHO, V. F. Técnicas analíticas nucleares na pesquisa agropecuária: fluorescência de raios $X$ e ativação neutrônica. Piracicaba, Departamento de Física e Meteorologia - ESALQ/USP, 1993. 93 p.

NASCIMENTO FILHO, V. F. Técnicas analíticas nucleares de fluorescência de raios $X$ por dispersão de energia (EDXRF) e por reflexão total (TXRF), Piracicaba: Departamento de Ciências Exatas - ESALQ/USP; Laboratório de Instrumentação Nuclear - CENA/USP, 1999. 33 p.

NASCIMENTO FILHO, V. F.; PARREIRA, P. S.; SILVA, R. M. C.; PEREZ, C. A.; MORAES, L. M. B.; APPOLONI, C. R. A low cost multi-purpose experimental arrangement for variants in energy dispersive X-ray fluorescence analysis. In: ASIA-PACIFIC SYMPOSIUM ON RADIOCHEMISTRY, 3., 2005, Beijing, China. Proceedings... Research Triangle Park: IUPAC, 2005. p. 52.

NOVAMET ZINC FLAKE. Ficha de dados de segurança dos materiais. Atualização março/2006. Disponível em: http://www.inco.com/products/msds/pdf/NOVAMETZincFlake-PortugeseMSDS.pdf. Acesso em: 14 maio 2007.

OCHSENKÜHN, K. M.; LYBEROPOULOU, T.; KOUMARIANOU, G.; PETROPOULOU, M. O. Ion chromatographic and spectrometric determination of water soluble compounds in airborne particulates and their correlations in an 
industrial area in Attica, Greece. Microchymica Acta, Wien, v. 160, n. 4, p. 485-492, 2008.

PÉREZ, C. A.; SÁNCHEZ, H. J. Cálculo de parámetros para la caracterización de microhaces de rayos $X$ generados por capilares concentradores. In: SEMINÁRIO LATINO-AMERICANO DE ANÁLISIS POR TÉCNICAS DE RAYOS X, 5., 1996, Cosquin, Argentina. Avances en analisis por técnicas em rayos X... 1996. Cosquin, 1996. v. 9, p. 14-19.

PIÓREK, S. Solving of some environmental pollution problems by X-ray fluorescence analysis. Journal of Radioanalytical Chemistry, Amsterdam, v. 58, p. 373-380, 1980.

PIXE INTERNATIONAL CORPORATION. The Streaker $^{\text {TM }}$ Air-Particulate Sampler: Instruction Manual. Disponível em: www.pixeintl.com.

PRATI, P.; ZUCCHIATTI, A.; TONUS, S.; LUCARELLI, F.; MANDÓ, P. A.; ARIOLA, V. A. Testing technique of streaker aerosol samplers via PIXE analysis. Nuclear Instruments and Methods, Amsterdam, v. 986, p. 136-138, 1998.

PUSHKIN, S. G.; MIZGINA, T. I.; FEDOROV, V. K. Elemental composition study of atmospheric aerosols by the X-ray fluorescence method, using synchrotron radiation. Nuclear Instruments and Methods in Physics Research Series A, Amsterdam, v. 26, n. 1, p. 290-291, 1987.

RAOOF, S. A.; AL-SAHHAF, M. Study of particulate pollutants in the air of Riyadh by energy dispersive X-ray fluorescence spectrometry. Atmospheric Environment, Oxford, v. 26, n. 3, p. 42-423, 1992.

SAIKI, M.; LIMA, F. W. Aplicação do Método de Análise Por Ativação a Determinação de Poluentes Atmosféricos. Revista Brasileira de Tecnologia, Brasília, v. 4, p. 133-138, 1973.

SIMABUCO, S. M.; NASCIMENTO FILHO, V. F. Quantitative analysis by energy dispersive $\mathrm{X}$-ray fluorescence by transmission method applied 
geological samples. Scientia Agricola, Piracicaba, v. 51, p. 197-206, 1994.

STERN, A. C. Air pollution: engineering control of air pollution. London: Academic Press, 1977. 968 p.

TAVARES, F. A. Caracterização de diatomitos calcinados por microscopia eletrônica de varredura. In: SIMPÓSIO BRASILEIRO DE MICROSCOPIA ELETRÔNICA E TÉCNICAS ASSOCIADAS NA PESQUISA DE MATERIAIS, 2., 1990, São Paulo. Anais... São Paulo: SBMM, 1990. p. 73-76.

USEPA. United States Environmental Protection Agency. Risk-based concentration table: technical background document. Washington, DC: EPA/Office of Solid Waste and Emergency Response, 1999.

VANZ, A.; MIRLEAN, N.; BAISCH, P. Avaliação de poluição do ar por chumbo particulado: uma abordagem geoquímica. Química Nova, São Paulo, v. 26, n. 1, p. 25-29, 2003.

VECCHI, R.; BERNARDONI, V.; FERMO, P.; LUCARELLI, F.; MAZZEI, F.; NAVA, S.; PRATI, P.; PIAZZALUNGA, A.; VALLI, G. 4-hours resolution data to study $\mathrm{PM}_{10}$ in a "hot spot" area in Europe. Environmental Monitoring and Assessment, Dordrecht, 2008. DOI 10.1007/s10661-008-0396-1. Disponível em: http://www.ncbi.nlm.nih.gov/pubmed/1856360.

WHO. World Health Organization. Environmental health indicators: framework and methodologies. Geneva, 1999.

WILLEKE, K.; BARON, P. A. Aerosol measurement: principles techniques and application. New York: Van Nostrand Reinhold, 1993. 876 p.

WINBERRY JUNIOR, W. T.; CHENEY, J. L.; DAVIS, M. F.; ELKINS JUNIOR, J. B.; LEWIS, R. G.; McCLENY, W. A.; McELROY, F. F. Determination of metals in ambient particulate matter using Proton Induced X-Ray Emission (PIXE) spectrometry. In: USEPA. Compendium of methods for the determination of inorganic compounds in ambient air. Cincinnati, 1999. 20 p. (Compendium Method, IO-3.6). 